OAK RIDGE

NATIONAL LABORATORY

MANAGED BY UT-BATTELLE

FOR THE DEPARTMENT OF ENERGY

\title{
Evaluation of Air Barriers for Residential Buildings
}

\section{May 2014}

Prepared by

Diana E. Hun

Peter Spafford

Andre O. Desjarlais

Approved for public release;

distribution is unlimited.

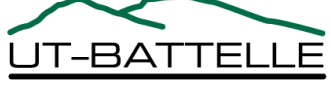




\section{DOCUMENT AVAILABILITY}

Reports produced after January 1, 1996, are generally available free via the U.S. Department of Energy (DOE) Information Bridge.

Web site http://www.osti.gov/bridge

Reports produced before January 1, 1996, may be purchased by members of the public from the following source.

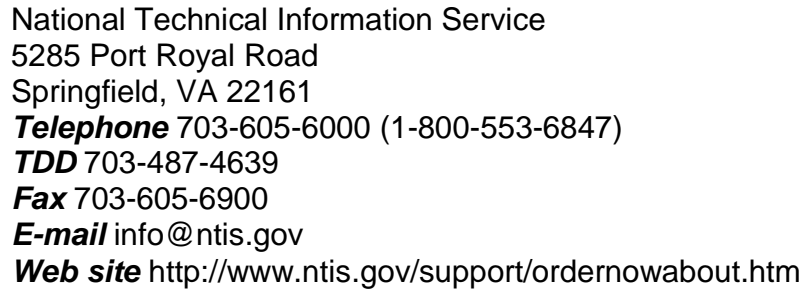

Reports are available to DOE employees, DOE contractors, Energy Technology Data Exchange (ETDE) representatives, and International Nuclear Information System (INIS) representatives from the following source.

Office of Scientific and Technical Information

P.O. Box 62

Oak Ridge, TN 37831

Telephone 865-576-8401

Fax 865-576-5728

E-mail reports@osti.gov

Web site http://www.osti.gov/contact.html

This report was prepared as an account of work sponsored by an agency of the United States Government. Neither the United States Government nor any agency thereof, nor any of their employees, makes any warranty, express or implied, or assumes any legal liability or responsibility for the accuracy, completeness, or usefulness of any information, apparatus, product, or process disclosed, or represents that its use would not infringe privately owned rights. Reference herein to any specific commercial product, process, or service by trade name, trademark, manufacturer, or otherwise, does not necessarily constitute or imply its endorsement, recommendation, or favoring by the United States Government or any agency thereof. The views and opinions of authors expressed herein do not necessarily state or reflect those of the United States Government or any agency thereof. 


\title{
Evaluation of Air Barriers for Residential Buildings
}

\author{
Diana E. Hun \\ Peter Spafford \\ Andre O. Desjarlais
}

Date Published: May 2014

Prepared by

OAK RIDGE NATIONAL LABORATORY

Oak Ridge, Tennessee 37831-6283

managed by

UT-BATTELLE, LLC

for the

U.S. DEPARTMENT OF ENERGY

under contract DE-AC05-00OR22725 


\section{Content}

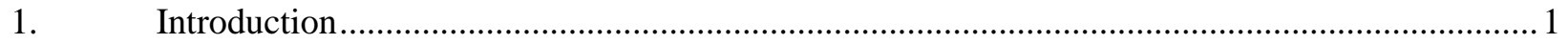

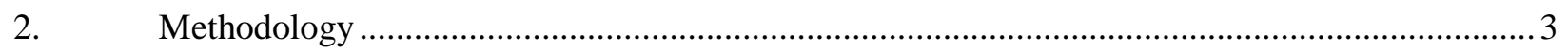

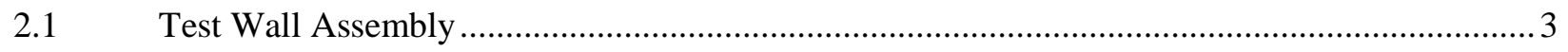

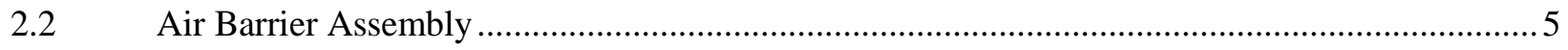

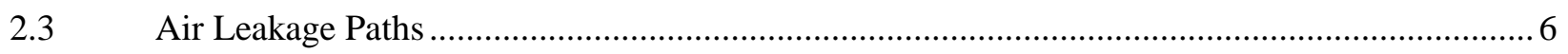

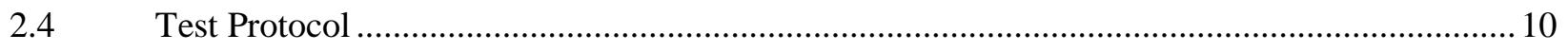

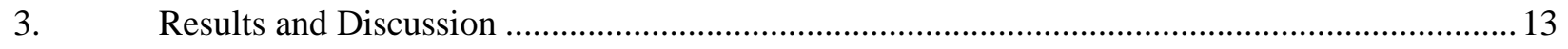

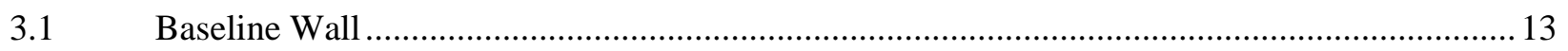

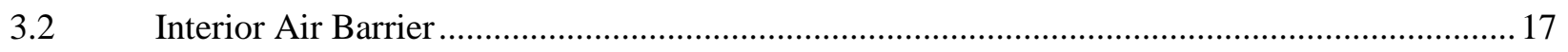

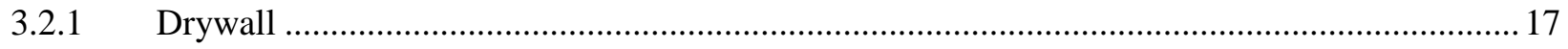

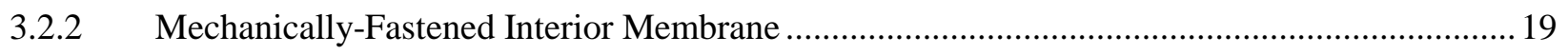

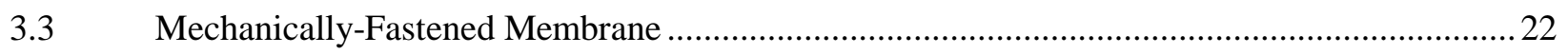

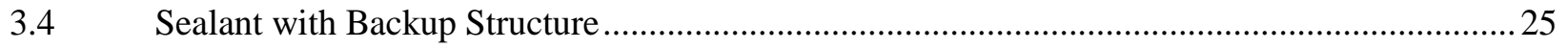

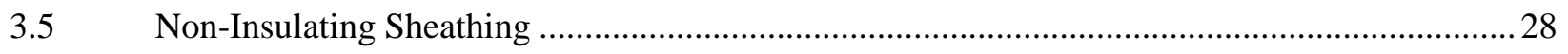

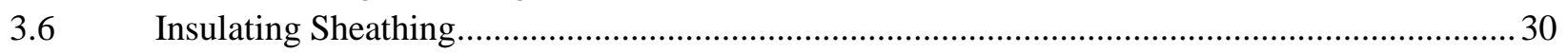

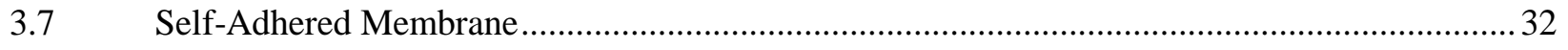

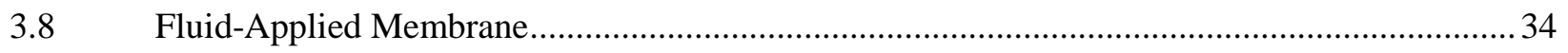

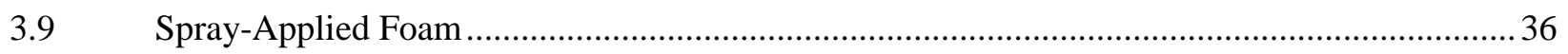

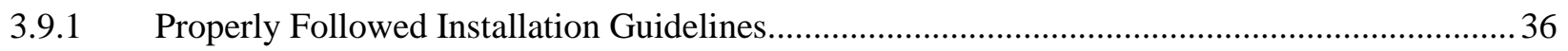

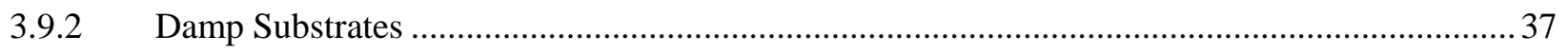

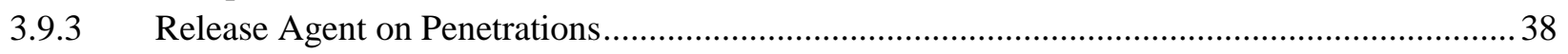

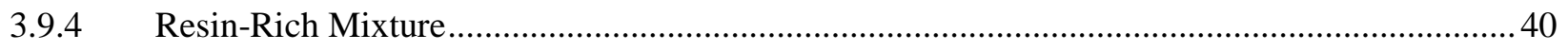

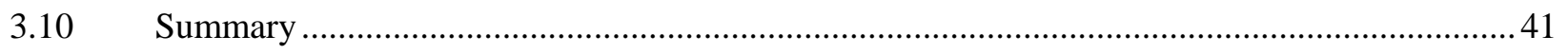

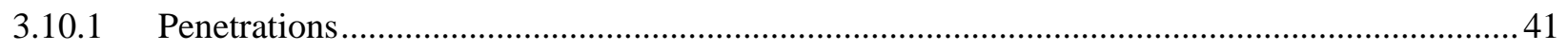

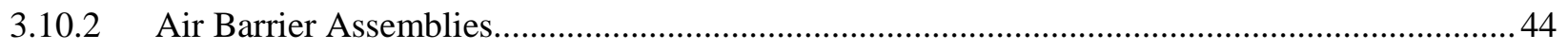

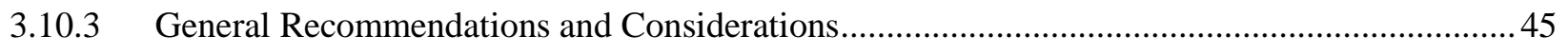

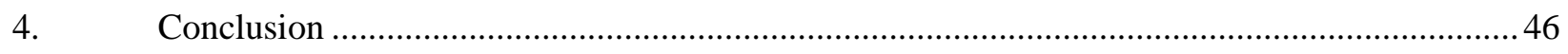

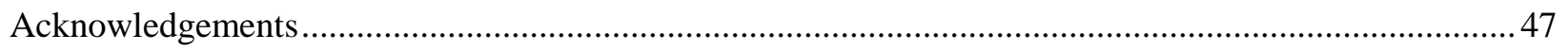

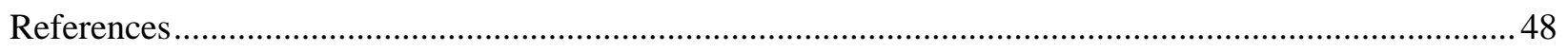




\section{List of Figures}

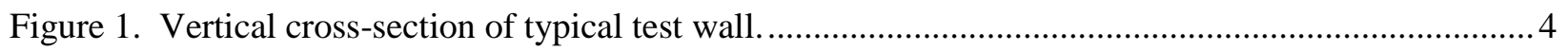

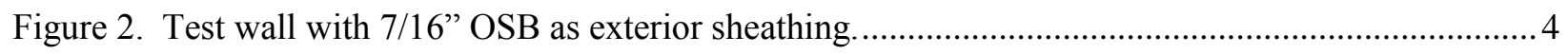

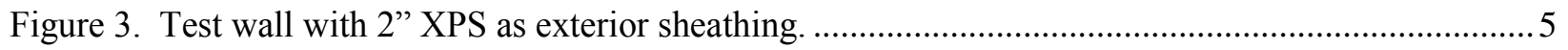

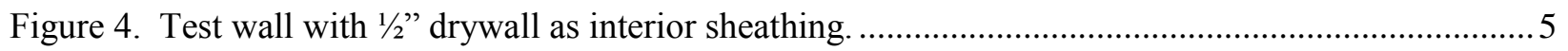

Figure 5. Location of air barrier assembly on test wall................................................................... 9

Figure 6. Setup to measure the air leakage rate through test walls..................................................... 11

Figure 7. Inner side of baseline wall (left), $\sim 1 / 8$ "-wide horizontal OSB joint (top right), and $\sim 1 / 8$ "-wide

joint between mud plate and CMU (bottom right).......................................................................... 14

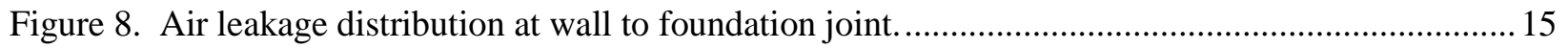

Figure 9. Air and moisture penetration test chamber ...................................................................... 15

Figure 10. Inner side of wall to foundation joint (left) and infrared picture (right) showing the effect of

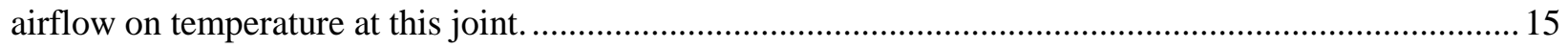

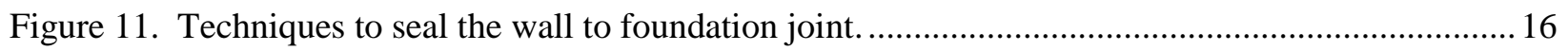

Figure 12. Air distribution at wall to roof joint in a house with an unvented attic................................ 17

Figure 13. Techniques to eliminate airflow into the exterior walls of a house with an unvented attic due to

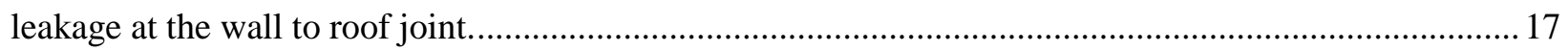

Figure 14. Test wall with interior drywall as the air barrier material. ................................................ 18

Figure 15. Test wall with polyamide membrane as the air barrier material..........................................20

Figure 16. Penetrations through membrane sealed with tape and sealant.............................................20

Figure 17. Air leakage through fasteners was avoided by replacing the typically used 1" caps (left) with

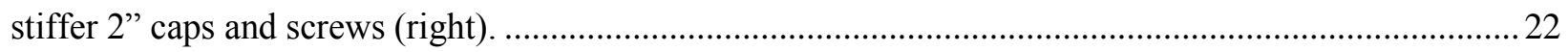

Figure 18. Flashing tape detached from the left side of the CMU during the ASTM E2357 test.............23

Figure 19. Failure of the flashing tape adhesive ...........................................................................23

Figure 20. Fixed flashing tape connecting membrane to CMU block. ................................................24

Figure 21. Test wall with OSB as the air barrier material and latex foam sealant at OSB joints. ............25

Figure 22. Penetrations through OSB sealed with latex foam sealant or canned foam. .........................26

Figure 23. Locations where the latex foam sealant detached from substrates after two months probably

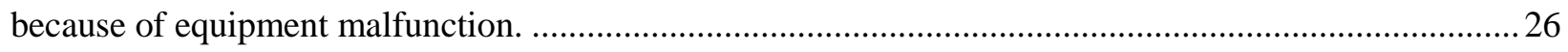

Figure 24. Test wall with OSB with an integrated water-resistive overlay as the air barrier material. .....28

Figure 25. Gasket installed between the foam board and wood at the perimeter of each XPS board. .......30

Figure 26. Air bypassed the tape at the butt joint through the score in the foam board............................ 30

Figure 27. Test wall with 2" XPS foam board as the air barrier material............................................. 31

Figure 28. Test wall with asphalt-based, self-adhered membrane as the air barrier material.................... 33

Figure 29. Sealing of steel ducts and PVC pipes was evaluated by measuring air leakage before and after

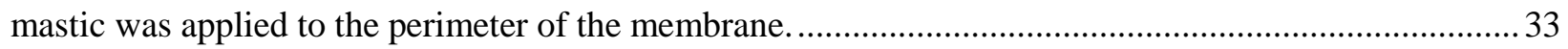

Figure 30. Test wall with fluid-applied membrane as the air barrier material....................................... 35

Figure 31. Enclosed and ventilated area built to contain emissions during spray foam installation........... 36

Figure 32. Test wall with 1" closed-cell foam as the air barrier material. ............................................ 37

Figure 33. Leakage site between OSB and steel duct where gap was too narrow for the foam to penetrate.

Figure 34. Test wall where 1" closed-cell foam was applied over damp surfaces. ................................. 38

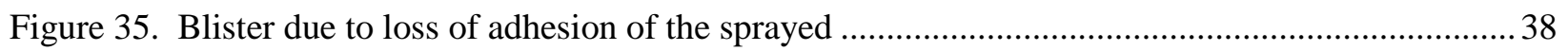


Figure 36. Penetrations sprayed with silicone to simulate on oil film that would compromise the adhesion

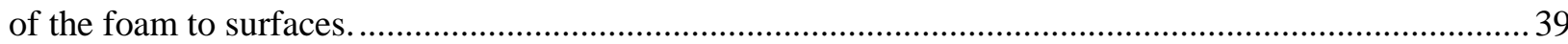

Figure 37. Foam easily detached from ducts that were sprayed with silicone...........................................3 39

Figure 38. Test wall where a resin-rich foam mixture was utilized.................................................... 40

Figure 39. Steps to seal the perimeter of a pipe with a self-adhered membrane or tape.......................... 42

Figure 40. Steps to seal the perimeter of a duct with a self-adhered membrane or tape.........................43

Figure 41. Cumulative contribution of unsealed joints and penetrations to total air leakage in a 2,000 $\mathrm{ft}^{2}$

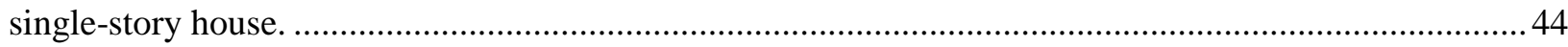




\section{List of Tables}

Table 1. Air barrier types and materials evaluated in this study....................................................... 3

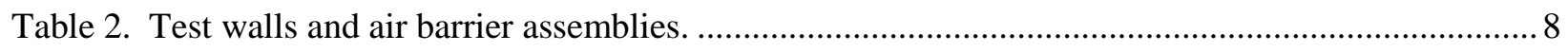

Table 3. Typical sequence in which air leakage paths were sealed or added to the test walls.................. 12

Table 4. Sequence in which air leakage paths in the baseline wall were sealed..................................... 12

Table 5. Sealing sequence in test wall where spray foam was adequately installed............................... 13

Table 6. Air leakage rates at wall joints........................................................................................ 14

Table 7. Air leakage rates through penetrations in a test wall with interior drywall as the air barrier

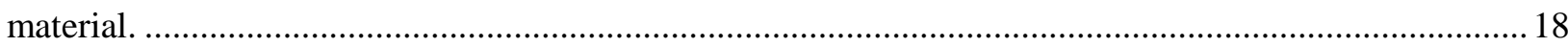

Table 8. Air leakage rates through penetrations in a test wall with polyamide membrane as the air barrier

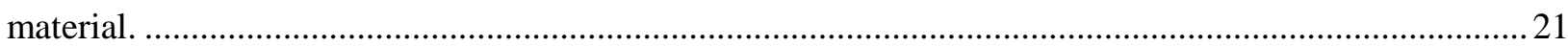

Table 9. Air leakage rates through penetrations in a test wall with non-woven, spun bonded polyolefin

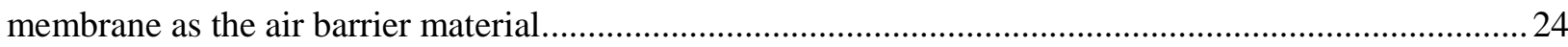

Table 10. Air leakage rates through penetrations in a test wall OSB as the air barrier material and a latex

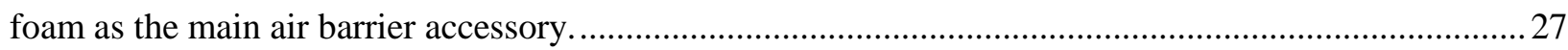

Table 11. Air leakage rates through penetrations in a test wall with OSB with an integrated waterresistive overlay as the air barrier material.

Table 12. Air leakage rates through penetrations in a test wall with 2" XPS foam board as the air barrier material.

Table 13. Air leakage rates through penetrations in a test wall with asphalt-based, self-adhered membrane as the air barrier material.

Table 14. Air leakage rates through penetrations in a test wall with fluid-applied membrane as the air

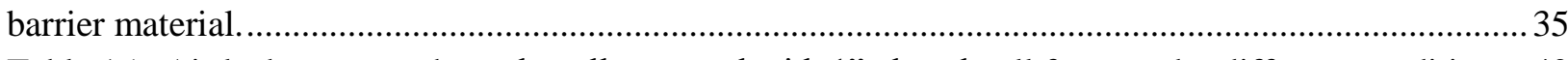

Table 15. Air leakage rates through walls sprayed with 1" closed-cell foam under different conditions.. 40 Table 16. Summary of air leakage rates through unsealed and sealed penetrations................................42

Table 17. Air leakage rates used in airtightness example................................................................4

Table 18. Summary of air leakage rates before and after wind conditioning loads per ASTM E2357. .... 45 


\section{Abstract}

In this project we aimed to increase the knowledgebase on air barriers for residential buildings. To this end, we evaluated nine air barrier assemblies following a modified version of the ASTM E2357 Standard Test Method from the American Society for Testing and Materials. The assemblies included the eight air barrier types that are readily available in the US, even if some of these are currently mostly used in commercial construction. This decision was made because technologies that are utilized in the commercial sector may be adopted by residential builders in the future. We also followed ASTM Standard E283 to estimate the air leakage rates through flow paths that are typically found in walls before and after these were sealed following typical techniques. Assessed leakage paths included wall to foundation joints, as well as penetrations through air barrier systems due to PVC pipes, steel ducts, electrical outlets and brick ties. In addition to the gathered measurements, this report also includes recommendations and considerations on each of the air barrier types. Findings from this research will contribute to the improvement of construction practices that will help meet airtightness requirements set by building codes and programs that seek to reduce energy consumption in homes. 


\section{Introduction}

Air leakage through the building enclosure is a significant contributor to the energy consumption in homes. Estimates for 2010 indicate that infiltration in residential buildings was responsible for 2.85 quads of energy (EERE 2011). Air barriers can be installed as part of the building enclosure to reduce this energy penalty. Although several air barrier types are readily available, only a subset has targeted residential construction. Consequently, information on the performance of air barriers on wood construction needs to be expanded to include the broader range of current technologies.

The objective of this project was to increase the knowledgebase on air barriers for residential buildings. Previous research primarily focused on documenting air leakage rates in homes. Dickerhoff et al. (1982) and Colliver et al. (1994) give insight on air leakage rates from various building components. Murray and Burmaster (1995), Sherman and Matson (2002), and Chan et al. (2013) provide extensive information on the airtightness of US homes. We supplement this work with information on how to reduce air leakage with current technologies. More specifically, we conducted laboratory tests to:

1. Evaluate the performance of the air barrier types commonly installed in the US.

2. Examine the effectiveness of techniques that are usually specified by air barrier manufacturers or used by builders to seal common airflow paths in walls.

3. Provide designers and contractors general information about the eight air barrier types that could help them select the appropriate technology for their building.

We utilize in this report definitions set by the American Society for Testing and Materials (ASTM) International on air barriers. More specifically, we employ terminology from ASTM E2357-11, Standard Test Method for Determining Air Leakage of Air Barrier Assemblies:

- Air barrier: a designated "plane" of reduced airflow between different environments.

- Air barrier material: a primary element that provides a continuous barrier to the movement of air. Common materials include sheathings and membranes.

- Air barrier accessory: a transitional component of the air barrier that provides continuity. Examples include sealants, tapes and canned foam.

- Air barrier assembly: the air barrier materials and accessories that provide a continuous designated plane to the movement of air through portions of building enclosure assemblies.

- Air barrier system: a combination of air barrier assemblies installed to provide a continuous barrier to the movement of air through building enclosures.

- Building enclosure: a system of building components and materials designed and installed in such a manner as to provide a barrier between different environments, including dissimilar interior environments. 
In this report we reference the air leakage requirements set by the 2012 International Energy Conservation Code (IECC). The requirements for residential construction are based on air changes per hour at a pressure differential of $50 \mathrm{~Pa}\left(\mathrm{ACH}_{50}\right)$ :

- DOE Zones 1 and 2: $\mathrm{ACH}_{50} \leq 5$

- DOE Zones 3 through 8: $\mathrm{ACH}_{50} \leq 3$

The air leakage requisite for commercial construction uses units of flow rate per surface area at a pressure differential of $75 \mathrm{~Pa}\left(\mathrm{CFM} 75 / \mathrm{ft}^{2}\right.$ or $\left.\mathrm{L} /\left(\mathrm{s} \cdot \mathrm{m}^{2}\right)\right)$. The IECC 2012 allows for the compliance of one of the following options:

- Leakage thru air barrier material $\leq 0.004 \mathrm{cfm} / \mathrm{ft}^{2}$ at $1.57 \mathrm{psf}\left(0.02 \mathrm{~L} /\left(\mathrm{s} \cdot \mathrm{m}^{2}\right)\right.$ at $\left.75 \mathrm{~Pa}\right)$

- Leakage thru air barrier assembly $\leq 0.04 \mathrm{cfm} / \mathrm{ft}^{2}$ at $1.57 \mathrm{psf}\left(0.2 \mathrm{~L} /\left(\mathrm{s} \cdot \mathrm{m}^{2}\right)\right.$ at $\left.75 \mathrm{~Pa}\right)$

- Leakage thru air barrier system $\leq 0.4 \mathrm{cfm} / \mathrm{ft}^{2}$ at $1.57 \mathrm{psf}\left(2 \mathrm{~L} /\left(\mathrm{s} \cdot \mathrm{m}^{2}\right)\right.$ at $\left.75 \mathrm{~Pa}\right)$

The aforementioned leakage rates through air barrier materials and assemblies are standard industry requirements as they do not distinguish between residential and commercial construction. Conformance to the material and assembly requirements is based on laboratory tests per ASTM Standards E2178 and E2357, respectively.

Given that the present work focuses on residential construction, we report most of the data with respect to a pressure differential of $50 \mathrm{~Pa}$. However, we use the $75 \mathrm{~Pa}$ reference when determining if the completed test wall complies with the air barrier assembly requisite.

A simple comparison of the IECC residential and commercial requirements reveals that they are somewhat similar. In this example we have a single-story house with eight-foot tall walls, and a $2,000 \mathrm{ft}^{2}$ square footprint that sits on a slab-on-grade. This house has a volume of $16,000 \mathrm{ft}^{3}$ and combined exterior wall and ceiling area of $3,430 \mathrm{ft}^{2}$. To estimate the air leakage thru the air barrier system we use the following equation:

$$
Q=C \cdot \Delta P^{n}
$$

where $Q$ is the air leakage rate, $C$ is the leakage coefficient, $\Delta P$ is the pressure differential across the building enclosure, and $n$ is the flow exponent. If the leakage requirement is $3 \mathrm{ACH}_{50}$ and we assume that $n$ is 0.65 , then we can estimate $C$ and back calculate the airflow through the building enclosure to be $0.3 \mathrm{cfm} / \mathrm{ft}^{2}$ at $75 \mathrm{~Pa}$. This indicates that the residential requisite of 3 $\mathrm{ACH}_{50}$ can be stricter than the commercial requirement of $0.4 \mathrm{cfm} / \mathrm{ft}^{2}$ at $75 \mathrm{~Pa}$ primarily because of the smaller volume in homes.

As previously mentioned, air barriers have been classified into eight types based on their location within the wall assembly, installation method, and thermal resistance. These types are: interior air barrier, mechanically-fastened membrane, sealant with backup structure, non-insulating sheathing, insulating sheathing, self-adhered membrane, fluid-applied membrane, and sprayapplied foam. Table 1 provides general information on these air barrier types, gives examples of materials that fall within each of these types, and indicates which materials were evaluated in this project. The air barrier materials we tested were selected primarily because they were easily 
accessible. Evaluations were conducted at Tremco's Sustainable Building Solutions Test Facility in Cleveland, $\mathrm{OH}$. The research team performed tests at this facility from spring 2012 to fall 2013.

Table 1. Air barrier types and materials evaluated in this study.

\begin{tabular}{|c|c|c|}
\hline Air Barrier Type & Description & $\begin{array}{c}\text { Examples of Air Barrier Materials } \\
\text { (underlined materials were evaluated in } \\
\text { this project) }\end{array}$ \\
\hline Interior air barrier & $\begin{array}{l}\text { Membranes and sheathings installed on the inner } \\
\text { side of the stud cavity }\end{array}$ & $\begin{array}{l}\text { - Polyamide membrane } \\
\text { - Poly membrane } \\
\text { - Drywall }\end{array}$ \\
\hline $\begin{array}{l}\text { Mechanically-fastened } \\
\text { membrane }\end{array}$ & $\begin{array}{l}\text { Membranes that are attached to the exterior } \\
\text { sheathing with nails, screws or staples }\end{array}$ & - - Non-woven, spun bonded polyolefin \\
\hline Sealant w/ backup structure & $\begin{array}{l}\text { Exterior sheathings where joints are sealed from the } \\
\text { inner side of the wall }\end{array}$ & $\begin{array}{l}\text { OSB perimeter sealed with caulk or } \\
\text { foam }\end{array}$ \\
\hline Non-insulating sheathing & $\begin{array}{l}\text { Exterior sheathings where joints are sealed from the } \\
\text { exterior side of the building }\end{array}$ & $\begin{array}{l}\text { - } \underline{\text { OSB }} \\
\text { - Plywood } \\
\text { - Exterior grade gypsum board }\end{array}$ \\
\hline Insulating sheathing & $\begin{array}{l}\text { Rigid foam boards that increase the thermal } \\
\text { performance of a wall }\end{array}$ & - XPS rigid foam \\
\hline Self-adhered membrane & $\begin{array}{l}\text { Membranes that are adhered to the exterior } \\
\text { sheathing }\end{array}$ & - - Asphalt-based membrane \\
\hline Fluid-applied membrane & $\begin{array}{l}\text { Membranes that are brushed, rolled or sprayed to } \\
\text { the exterior sheathing }\end{array}$ & - $\frac{\text { Water-based }}{\text { Solvent-based }}$ \\
\hline Spray-applied foam & $\begin{array}{l}\text { Foams that are sprayed on to the inner or outer side } \\
\text { of exterior sheathings and increase the thermal } \\
\text { performance of a wall }\end{array}$ & $\begin{array}{l}\text { - Open-cell polyurethane foam } \\
\text { - Closed-cell polyurethane foam }\end{array}$ \\
\hline
\end{tabular}

Abbreviations: EPS; expanded polystyrene; OSB, oriented strand board; XPS, extruded polystyrene.

\section{Methodology}

\subsection{Test Wall Assembly}

Test walls were 8'-0" wide and 8'-0" tall. As shown in Figure 1, the wall frame consisted of $2 \times 4$ studs at 16 " on center on top of 7/16" oriented strand board (OSB), $2 \times 8$ floor joists and 8 " concrete masonry unit (CMU) blocks. The latter were introduced to simulate a wall to crawlspace or wall to basement joint. The sheathings on the walls varied with the air barrier type. These included 7/16" OSB, 2" extruded polystyrene (XPS) rigid foam, and 1/2" drywall. The layout of these sheathings is illustrated in Figures 2 through 4. 


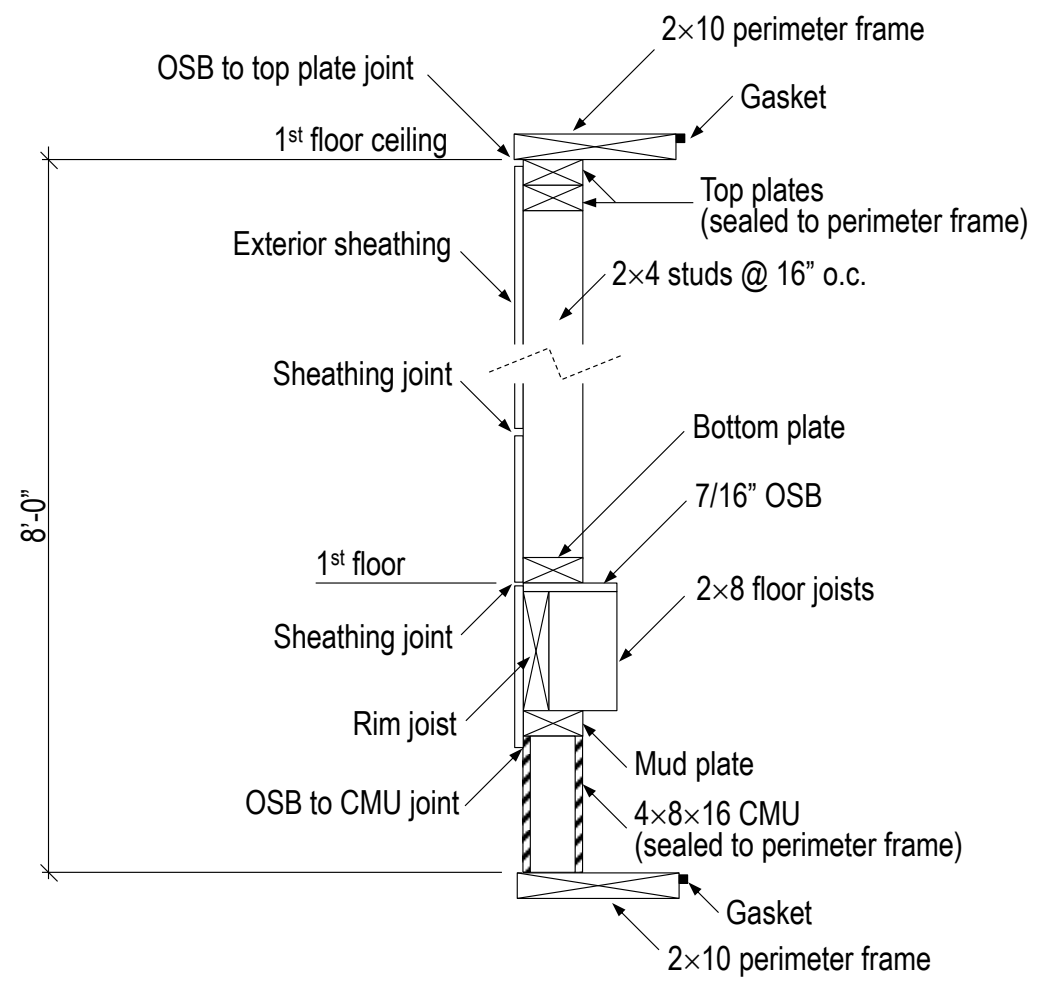

Figure 1. Vertical cross-section of typical test wall.

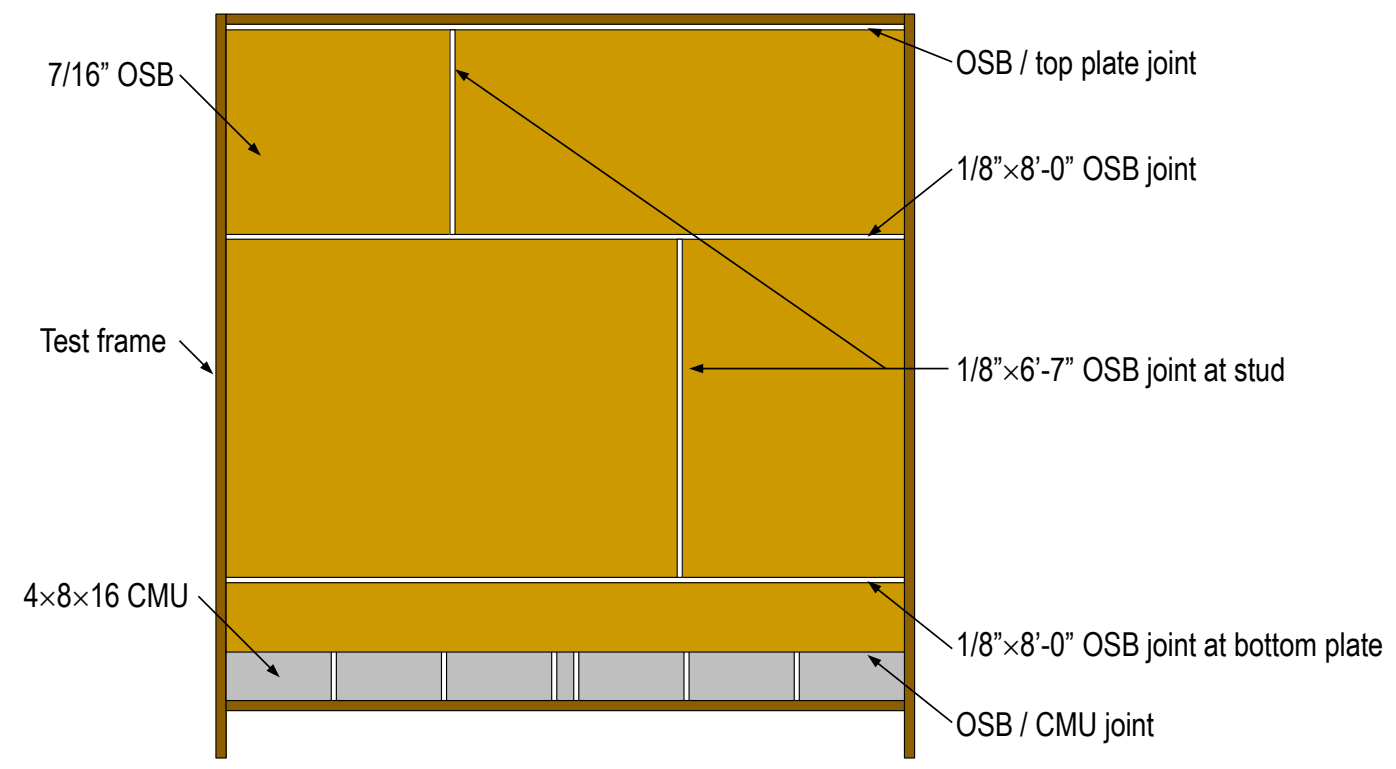

Figure 2. Test wall with $7 / 16$ " OSB as exterior sheathing. 


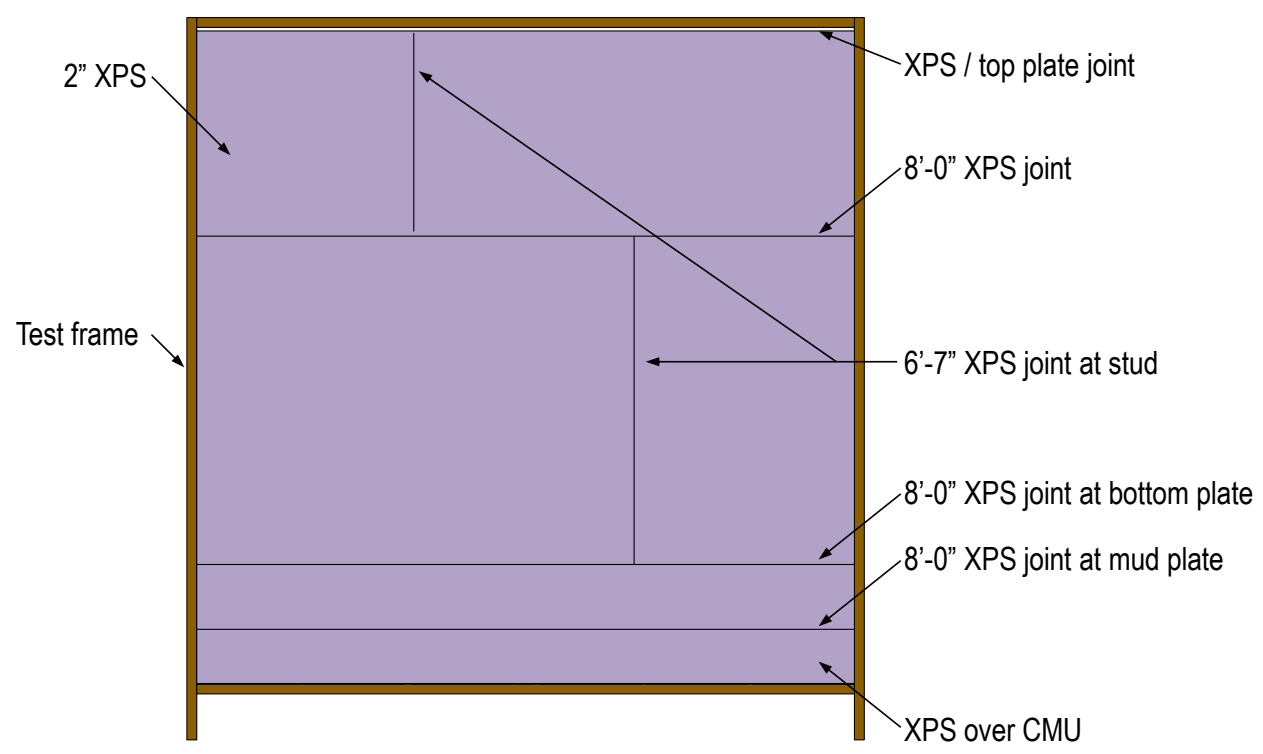

Figure 3. Test wall with 2" XPS as exterior sheathing.

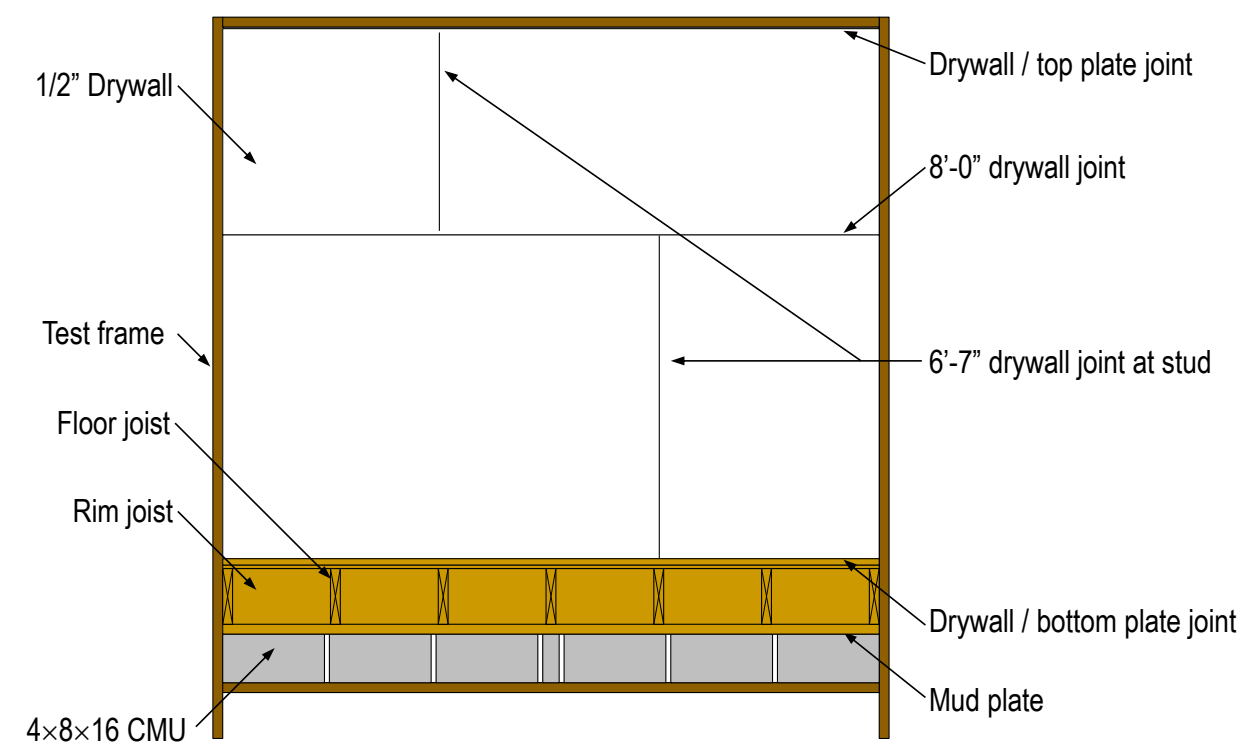

Figure 4. Test wall with $1 / 2$ " drywall as interior sheathing.

\subsection{Air Barrier Assembly}

Table 2 describes the 13 air barrier assemblies assessed in this project, and Figure 5 illustrates the location of the air barrier materials and accessories in the test walls. We had one test wall for each air barrier type, except for the interior air barrier and the spray-applied foam. We tested two materials that served as the interior air barrier, a polyamide membrane and drywall, given that their installations are quite different. In order for the polyamide membrane to act as an air barrier, it had to be tested with the interior drywall in place so the wallboard provides resistance against the infiltration loads. However, the penetrations that were installed through the wall (e.g. pipes or ducts) were only sealed to the polyamide membrane and not to the drywall because only 
the former is supposed to resist the airflow movement. We also included a test wall where the interior drywall acted as the air barrier material given that drywall has been commonly used for this purpose, and we wanted to compare its performance with respect to that of other air barrier materials.

In most of the test walls, we installed penetrations in a sequential manner in order to study various sealing techniques; the followed steps will be described in more detail later in the report. However, we could not follow this sequential approach with the spray-applied foam as it has to be applied in a single pass where the foam handles all the gaps around penetrations at once. Therefore, we modified our evaluation approach with this air barrier type. We utilized 1"-thick closed-cell, medium-density, spray-applied foam in four walls to examine the effect of three common installation problems on air leakage, and how these compare to the leakage rates from a wall with properly installed foam. These walls were representative of the following conditions:

1. Installation guidelines were properly followed

2. Damp wood and CMU surfaces

3. Release agent applied to PVC pipes, steel ducts and electrical boxes

4. Resin-rich foam mixture

The air barrier assemblies were installed on the test walls by a certified installer who verified his procedure with instructions provided by manufacturers on their websites with regard to:

- Minimum required thickness for the product to act as an air barrier material

- Accessories needed by the air barrier material to properly perform in an air barrier assembly, such as tapes, sealants, transition membranes, and fasteners

- Installation procedures

When information was not available online, we either contacted manufacturers for guidance or used our judgment.

\subsection{Air Leakage Paths}

As shown in Table 2, a baseline wall that lacked an air barrier assembly was included in this project in order to estimate airflows through the following joints:
a. 1/8"-wide OSB horizontal joints
b. 1/8"-wide OSB vertical joint over studs
c. OSB to top plate interface
d. OSB to bottom plate interface
e. OSB to CMU interface
f. Stud to top plate joint
g. Stud to bottom plate joint
h. Bottom plate to subfloor interface
i. Subfloor to rim joist interface 
In the walls with an air barrier assembly, we added penetrations through these assemblies in order to characterize their effects on air leakage and to examine several sealing methods. The penetrations we evaluated are specified in ASTM E2357:

a. Six 1-1/2" capped PVC pipes

b. Six 4"x4" capped steel ducts

c. Six rectangular electrical outlets: we utilized boxes that did not have perimeter flanges because these are more difficult to seal to air barrier materials, and these are what most electricians currently install. Airflow through unsealed wire holes was measured in some of the test walls. A set of wires was installed in each box to simulate actual conditions.

d. Six circular electrical outlets with 4" diameter: we utilized boxes that did not have perimeter flanges because these are more difficult to seal to air barrier materials, and these are what most electricians currently install. Airflow through unsealed wire holes was measured in some of the test walls. A set of wires was installed in each box to simulate actual conditions.

e. Twenty-five corrugated brick ties

We installed multiple pieces for each of these items, although only one is required per ASTM E2357 for all penetrations but the brick ties. The larger sample size allowed us to better estimate the effectiveness of various sealing techniques. Gaps between the sheathing and the pipes, ducts and outlets were about $1 / 4$ " wide. We did not use the $3 / 8$ " gap width specified in ASTM E2357 because it appeared to represent extreme cases. 
Table 2. Test walls and air barrier assemblies.

\begin{tabular}{|c|c|c|c|c|c|c|c|}
\hline \multirow{3}{*}{ Wall } & \multirow{3}{*}{ Air Barrier Type } & \multicolumn{6}{|c|}{ Test Wall Components } \\
\hline & & \multicolumn{5}{|c|}{ Wood Frame } & \multirow{2}{*}{$\begin{array}{c}\text { CMU } \\
\begin{array}{c}\text { Air Barrier } \\
\text { Material }\end{array}\end{array}$} \\
\hline & & Air Barrier Material & $\begin{array}{l}\text { Air Barrier } \\
\text { Thickness }^{a}\end{array}$ & $\begin{array}{c}\text { Location of } \\
\text { Air Barrier Material }\end{array}$ & Substrate & Air Barrier Accessories ${ }^{b}$ & \\
\hline 1 & Baseline (no air barrier) & ( & - & 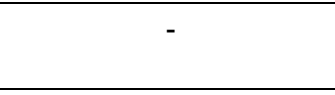 & - & - & $\begin{array}{c}\text { Fluid-applied } \\
\text { membrane }\end{array}$ \\
\hline $2 a$ & Interior air barrier & Drywall sheathing & $1 / 2 "$ & Inner side of stud cavity & - & Sealant & $\begin{array}{c}\text { Fluid-applied } \\
\text { membrane }\end{array}$ \\
\hline $2 b$ & Interior air barrier & $\begin{array}{l}\text { Polyamide } \\
\text { membrane }\end{array}$ & - & Inner side of stud cavity & - & $\begin{array}{l}\text { Tape, sealant, interior } \\
\text { drywall }\end{array}$ & $\begin{array}{l}\text { Polyolefin } \\
\text { membrane }\end{array}$ \\
\hline 3 & $\begin{array}{l}\text { Mechanically-fastened } \\
\text { membrane }\end{array}$ & $\begin{array}{l}\text { Non-woven, spun } \\
\text { bonded polyolefin } \\
\text { membrane }\end{array}$ & - & $\begin{array}{l}\text { Outer side of exterior } \\
\text { sheathing }\end{array}$ & $7 / 16^{\prime \prime}$ OSB & $\begin{array}{l}\text { Screws with 2" caps, tape, } \\
\text { sealant }\end{array}$ & $\begin{array}{l}\text { Fluid-applied } \\
\text { membrane }\end{array}$ \\
\hline 4 & Sealant w/ backup structure & OSB sheathing & $7 / 16 "$ & Outer side of stud cavity & - & Latex sealant & $\begin{array}{l}\text { Fluid-applied } \\
\text { membrane }\end{array}$ \\
\hline 5 & Non-insulating sheathing & OSB sheathing & $7 / 16 "$ & Outer side of stud cavity & - & Tape, canned foam & $\begin{array}{l}\text { Fluid-applied } \\
\text { membrane }\end{array}$ \\
\hline 6 & Insulating sheathing & $\begin{array}{c}\text { XPS rigid foam } \\
\text { sheathingd }\end{array}$ & $2 "$ & Outer side of stud cavity & - & $\begin{array}{l}\text { Screws with 2" caps, tape, } \\
\text { canned foam }\end{array}$ & XPS rigid foam \\
\hline 7 & Self-adhered membrane & $\begin{array}{l}\text { Asphalt-based } \\
\text { membrane }\end{array}$ & $\begin{array}{c}36 \text { mil rubber } \\
\text { asphalt on } 4 \text { mil } \\
\text { polyethylene film }\end{array}$ & $\begin{array}{l}\text { Outer side of exterior } \\
\text { sheathing }\end{array}$ & $7 / 16^{\prime \prime}$ OSB & Primer, mastic & $\begin{array}{l}\text { Self-adhered } \\
\text { membrane }\end{array}$ \\
\hline 8 & Fluid-applied membrane & $\begin{array}{c}\text { Rolled fluid-applied } \\
\text { membrane }\end{array}$ & 70 wet mils & $\begin{array}{c}\text { Outer side of exterior } \\
\text { sheathing }\end{array}$ & $7 / 16^{\prime \prime}$ OSB & $\begin{array}{l}\text { Sealant, transition } \\
\text { membrane }\end{array}$ & $\begin{array}{c}\text { Fluid-applied } \\
\text { membrane }\end{array}$ \\
\hline $9 a$ & Spray-applied foame & Closed-cell SPF & $1 "$ & Stud cavity & $7 / 16^{\prime \prime}$ OSB & Sealant & Closed-cell foam \\
\hline $9 b$ & Spray-applied foame & Closed-cell SPF & $1 "$ & Stud cavity & $7 / 16^{\prime \prime}$ OSB & Sealant & Closed-cell foam \\
\hline $9 c$ & Spray-applied foame & Closed-cell SPF & $1 "$ & Stud cavity & $7 / 16^{\prime \prime}$ OSB & Sealant & Closed-cell foam \\
\hline $9 d$ & Spray-applied foame & Closed-cell SPF & $1 "$ & Stud cavity & $7 / 16^{\prime \prime}$ OSB & Sealant & Closed-cell foam \\
\hline
\end{tabular}

Abbreviations: CMU, concrete masonry unit; OSB, oriented strand board; SPF, sprayed polyurethane foam; XPS, extruded polystyrene.

a. Used thicknesses equal or greater than required by manufacturers for their products to act as air barrier materials.

b. Used accessories recommended or sold by the manufacturer of the installed air barrier material.

c. Required the interior drywall to resist infiltration loads.

d. XPS foam board also served as the exterior sheathing.

e. Variations between spray-applied foam test walls: 9a: installation guidelines were properly followed; 9b: damp wood and CMU surfaces; 9c: release agent applied to penetrations; 9d: resin-rich foam mixture. 

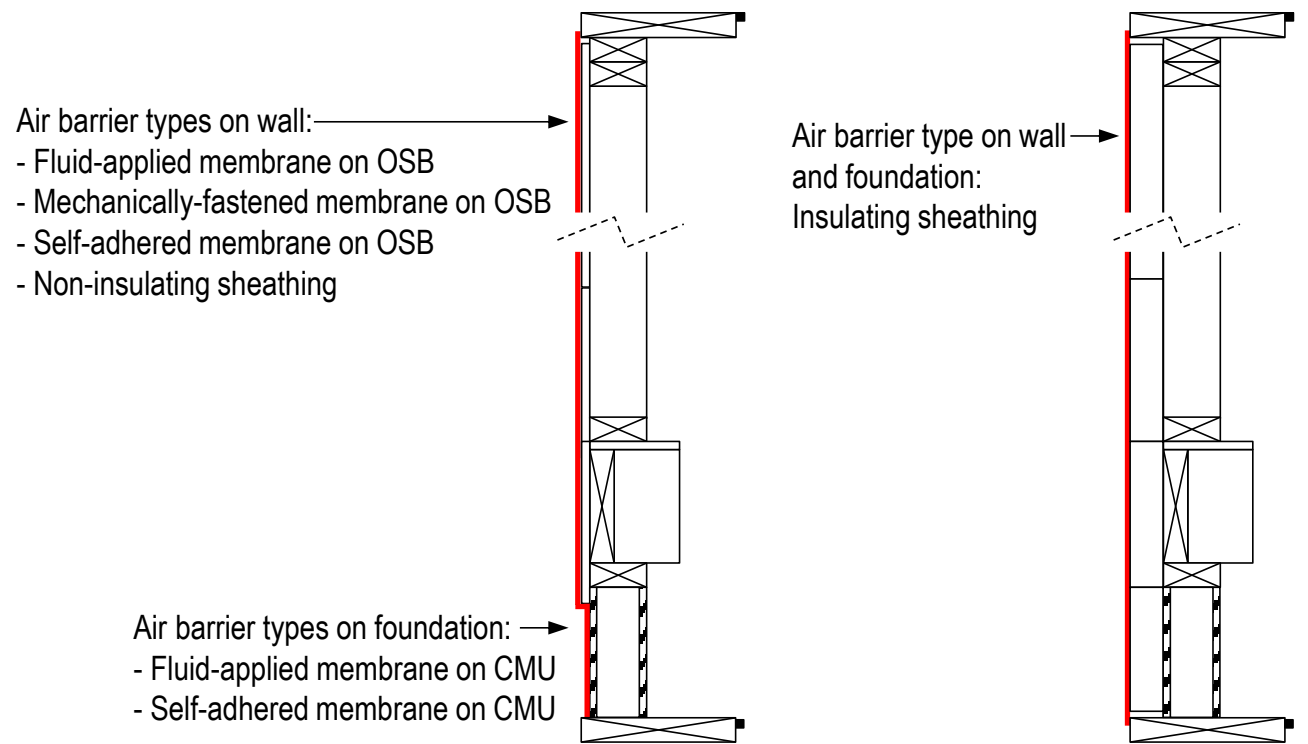

and foundation:
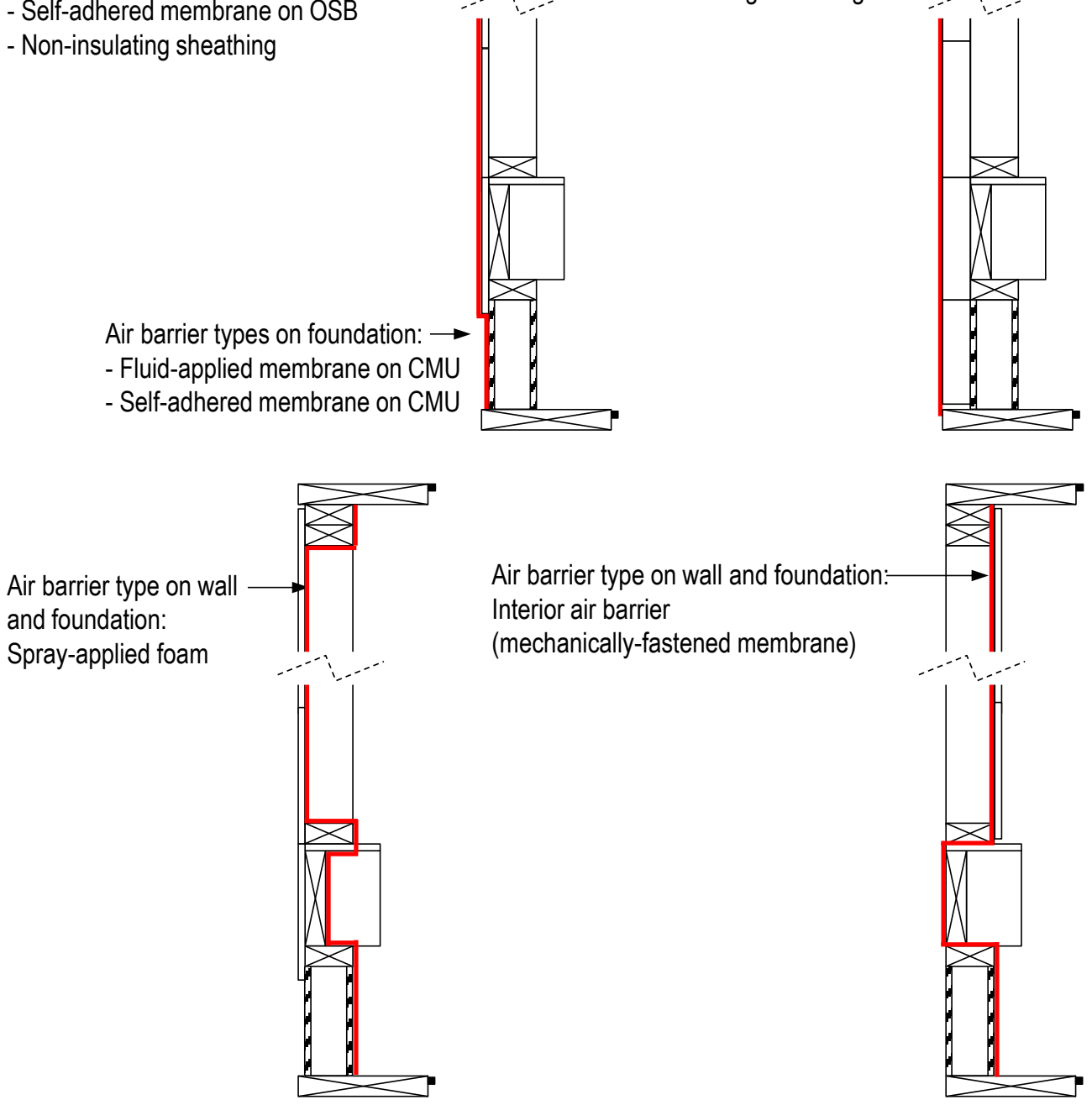
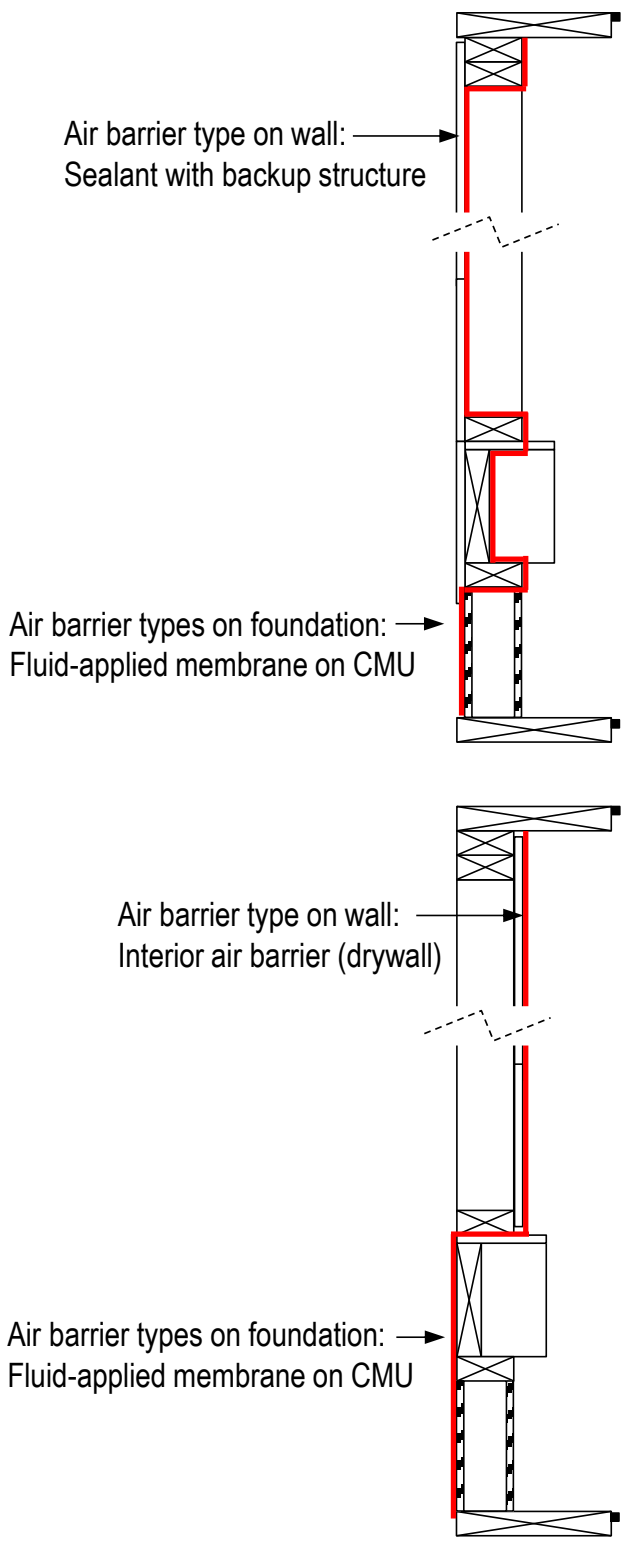

Figure 5. Location of air barrier assembly on test wall. 


\subsection{Test Protocol}

Tests were performed at Tremco's Sustainable Building Solutions Test Facility in Cleveland, $\mathrm{OH}$. The test walls were not exposed to typical outdoor conditions (e.g., UV rays, rain, high temperature differentials) in this enclosed facility. Figure 6 illustrates the experimental setup we utilized to measure the air leakage rate through test walls and specific airflow paths in these walls. In this setup the test specimen was sealed against a plexiglass wall where it was subjected to positive and negative pressure differentials $(\Delta \mathrm{P})$ with a reversible blower. Flow rates required to reach a specific $\Delta \mathrm{P}$ were measured with a Teledyne Hastings HFM-D-301 flow meter, which had a measuring range of $0.03 \mathrm{~L} / \mathrm{s}(0.06 \mathrm{cfm})$ to $14.3 \mathrm{~L} / \mathrm{s}(30 \mathrm{cfm})$ and an accuracy of $+/-0.03$ $\mathrm{L} / \mathrm{s}(0.06 \mathrm{cfm})$.

Air leakage rates were obtained by following the ASTM E283 Standard Test Method for Determining Rate of Air Leakage Through Exterior Windows, Curtain Walls, and Doors Under Specified Pressure Differences Across the Specimen. Airflows were collected at the positive and negative pressure differentials of 25, 50, 75, 100, 150, 250 and $300 \mathrm{~Pa}$. Leakage rates were normalized to the standard temperature and pressure conditions of $14.7 \mathrm{psi}(101.3 \mathrm{kPa})$ and $69.4^{\circ} \mathrm{F}\left(20.8^{\circ} \mathrm{C}\right)$, respectively.

Initial air leakage measurements consisted of a baseline test to confirm that we were starting with a very leaky specimen. This was usually followed by measurements of the extraneous air leakage, which is the contribution to the total air leakage from airflow through the perimeter frame. To this end, airflow measurements were taken after an airtight plexiglass cover was clamped to the perimeter frame of the test wall as shown in Figure 6. Afterwards, we followed one of the sequences described in Tables 3, 4 or 5. Table 3 lists the order in which we typically generated and sealed air leakage paths in the test walls with all the air barrier types, except sprayapplied foam. The difference between two consecutive steps yielded the effect from the penetration through the wall or the sealing technique. Tables 4 and 5 describe the steps that we followed with the baseline wall and the wall where spray foam was properly installed, respectively. There was not a sequence of steps in the spray foam walls that had intentional installation problems (i.e., damp surfaces, release agents on surfaces, and resin-rich foam mixture) because the foam was sprayed in a single pass. As the final step, we performed the ASTM E2357 test, Standard Test Method for Determining Air Leakage of Air Barrier Assemblies, in each of the walls after the air barrier assembly was fully in place. 


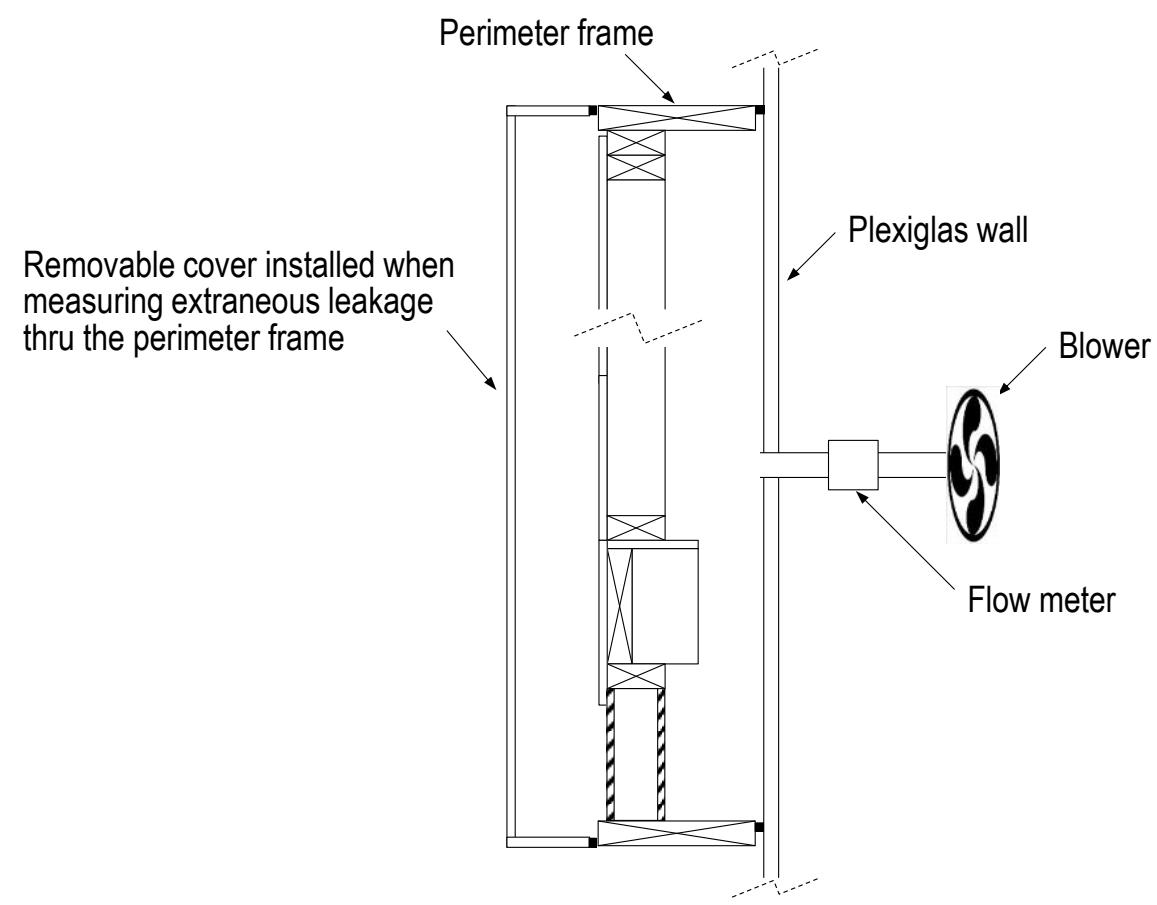

Figure 6. Setup to measure the air leakage rate through test walls. 
Table 3. Typical sequence in which air leakage paths were sealed or added to the test walls.

\begin{tabular}{cl}
\hline Step & Description \\
\hline 1 & CMU exterior surface sealed per Table 2. \\
\hline 2 & CMU sealed to OSB that covered the rim joist. \\
\hline 3 & Vertical and horizontal butt joints of sheathings (OSB, XPS or drywall) were sealed. \\
\hline 4 & Top plate was sealed to the sheathing. \\
\hline 5 & (1) $1-1 / 2$ " capped PVC pipe. Gap between pipe and air barrier was left unsealed. a, b \\
\hline 6 & (6) 1-1/2" capped PVC pipes with perimeters sealed to the air barrier material or exterior sheathing. \\
\hline 7 & $\begin{array}{l}\text { (1) Rectangular electrical outlet box. Gap between box and air barrier was left unsealed. Wire holes in box were left } \\
\text { unsealed. a, b }\end{array}$ \\
\hline 8 & (6) Rectangular electrical outlet boxes with perimeters sealed to the air barrier or exterior sheathing. \\
\hline 9 & $\begin{array}{l}\text { (6) Rectangular electrical outlet boxes with perimeters sealed to the air barrier or exterior sheathing, and wire holes } \\
\text { caulked. }\end{array}$ \\
\hline 10 & $\begin{array}{l}\text { (1) Circular electrical outlet box. Gap between box and air barrier was left unsealed. Wire holes in box were left } \\
\text { unsealed. a, b }\end{array}$ \\
\hline 11 & (6) Circular electrical outlet boxes with perimeters sealed to the air barrier or exterior sheathing. \\
\hline 12 & $\begin{array}{l}\text { (6) Circular electrical outlet boxes with perimeters sealed to the air barrier or exterior sheathing, and wire holes } \\
\text { caulked. }\end{array}$ \\
\hline 13 & (1) 4" $\times 4$ " capped steel duct. Gap between duct and air barrier was left unsealed. a, b \\
\hline 14 & (6) 4" $\times 4$ " capped steel ducts with perimeters sealed to the air barrier or exterior sheathing. \\
\hline 15 & (25) Brick ties ${ }^{c}$
\end{tabular}

a. Gap between sheathings and pipes, ducts and outlet boxes was approximately 1/4" wide.

b. This step was not performed with the exterior mechanically-fastened membrane and the interior polyamide membrane.

c. This step was not performed with the interior polyamide membrane and the interior drywall.

Table 4. Sequence in which air leakage paths in the baseline wall were sealed.

\begin{tabular}{cl}
\hline Step & Description \\
\hline 1 & Horizontal 1/8"-wide OSB joint \\
\hline 2 & CMU to mud plate \\
\hline 3 & Exterior surface of CMU covered with fluid-applied membrane \\
\hline 4 & Top of bottom plate to OSB \\
\hline 5 & Rim joist to mud plate and subfloor \\
\hline 6 & Bottom of bottom plate to subfloor \\
\hline 7 & Bottom of studs to bottom plate \\
\hline 8 & CMU to OSB \\
\hline 9 & Vertical $~ 1 / 8$ "-wide OSB joints \\
\hline 10 & Bottom of top plate to OSB \\
\hline 11 & Interface between two top plates \\
\hline 12 & Top of studs to top plate
\end{tabular}


Table 5. Sealing sequence in test wall where spray foam was adequately installed.

\begin{tabular}{cl}
\hline Step & Description \\
\hline 1 & Foam sprayed in stud cavity \\
\hline 2 & Foam sprayed over rim joist \\
\hline 3 & Foam sprayed over CMU \\
\hline 4 & Bottom plate sealed to subfloor \\
\hline 5 & Top plate sealed to test frame \\
\hline
\end{tabular}

\section{Results and Discussion}

Descriptions of the tests we conducted with each of the air barrier types and their respective results are covered in Section 3.1 to Section 3.9. More specifically, we focus in these sections on air leakage through various airflow paths. These paths include wood joints, and unsealed and sealed gaps around penetrations, where the latter allowed us to examine the effectiveness of different sealing techniques. In each of these cases we measured airflow rates following ASTM E283. The values we report are typically the difference in flow before and after a sealing step, or before and after a penetration was made. If the result from this subtraction is less than the average extraneous leakage of the 12 test walls (i.e., 0.2 CFM50), we report the measurement as “<0.2 CFM50."

We also describe in Sections 3.1 to 3.9 the leakage rates of the air barrier assemblies that we obtained before and after we subjected them to the wind conditioning pressures that are specified in ASTM E2357. However, a direct comparison of the obtained results to the air barrier assembly requirement of $0.04 \mathrm{CFM} 75 / \mathrm{ft}^{2}\left(0.2 \mathrm{~L} /\left(\mathrm{s} \cdot \mathrm{m}^{2}\right)\right.$ at $\left.75 \mathrm{~Pa}\right)$ may not be correct because the walls we tested had six times more penetrations than what is described in ASTM E2357. Additionally, we did not include a blank window in our walls; the contribution of a blank window to air leakage could be about half of what we obtained from the penetrations we evaluated (perimeter of 23.6" $\times$ 47.2" window per ASTM E2357 = 142", combined perimeter from all tested penetrations $=281$ '). In these Sections we also include beneficial aspects for each of the evaluated air barrier types, and provide information that could be helpful to designers and contractors when selecting an air barrier type for their building. Subsequently, Section 3.10 summarizes all the compiled data and supplies general recommendations.

\subsection{Baseline Wall}

Figure 7 shows the baseline wall and two of the airflow paths we evaluated: $\sim 1 / 8$ "-wide horizontal OSB joint and $\sim 1 / 8$ "-wide gap between the mud plate and the CMU block. Although the dimensions of the airflow paths in the baseline wall will not exactly match those encountered in buildings, the presented data allow for a relative comparison of typical leakage sites. Table 6 summarizes the measured flow rates. The $\sim 1 / 8$ " $\times 8$ ' -0 " horizontal OSB joint showed the largest leakage rate $(5.03 \mathrm{CFM} 50 / \mathrm{ft})$ because it is a direct airflow path, that is, no building materials obstructed the passage of flow. In contrast, leakages through the other sites were at least three times lower, ranging from 0.01 to $1.46 \mathrm{CFM} 50 / \mathrm{ft}$, because their paths were more tortuous. Actual sizes of the gaps around penetrations and their respective effects on air leakage will vary at each construction site based on the quality of workmanship and framing details. 

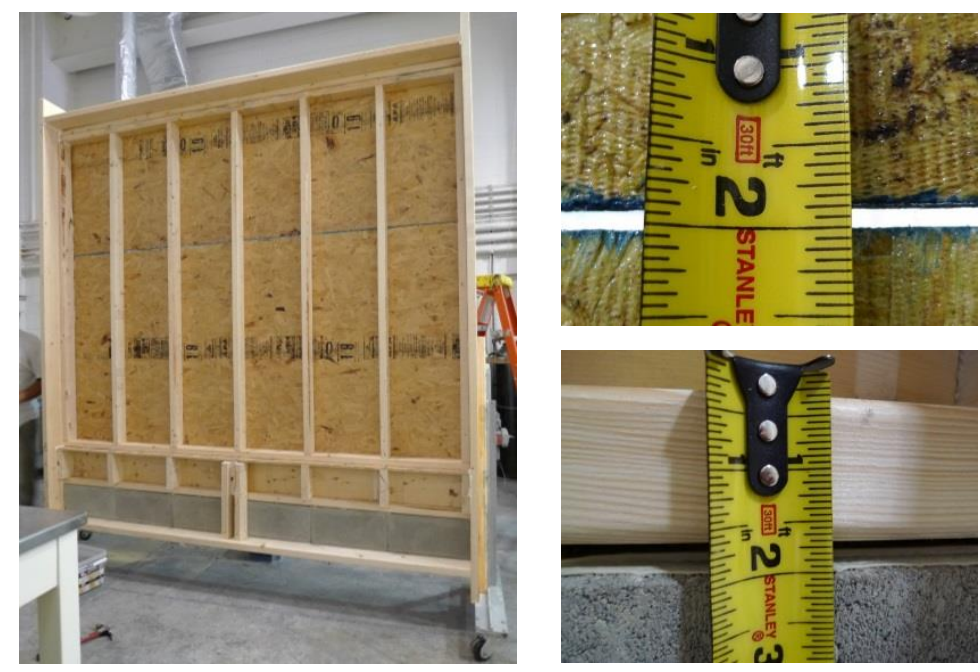

Figure 7. Inner side of baseline wall (left), $\sim 1 / 8$ "-wide horizontal OSB joint (top right), and $\sim 1 / 8$ "-wide joint between mud plate and CMU (bottom right).

Table 6. Air leakage rates at wall joints.

\begin{tabular}{lcccc}
\hline \multirow{2}{*}{ Air Leakage Site } & \multicolumn{5}{c}{ Airflow Rate } \\
\cline { 2 - 5 } & CFM50/ft & CFM50/stud & CFM75/ft & CFM75/stud \\
\hline 1/8" vertical OSB joint at stud & 0.61 & NA & 0.8 & NA \\
\hline OSB / CMU joint & 1.11 & NA & 1.46 & NA \\
\hline Wall / roof joint a & 1.11 & NA & 1.46 & NA \\
OSB / top plate joint & 1.03 & NA & 1.35 & NA \\
OSB / stud joint & 0.07 & 0.09 & 0.09 & 0.12 \\
Top plate to top plate joint & 0.01 & NA & 0.01 & NA \\
\hline Wall / foundation joint & 1.46 & NA & 1.91 & NA \\
OSB / bottom plate joint & 1.05 & NA & 1.37 & NA \\
OSB / stud joint & 0.28 & 0.37 & 0.36 & 0.48 \\
Bottom plate / subfloor joint & 0.12 & NA & 0.15 & NA \\
Subfloor / rim joist joint & 0.01 & NA & 0.02 & NA \\
\hline 1/8' horizontal OSB joint & 5.03 & NA & 6.35 & NA \\
\hline
\end{tabular}

Abbreviations: NA, not applicable.

a. Portion of the airflow at the wall to roof joint that ends up at the wall. See Figure 12.

We also examined the distribution of airflow at the wall to foundation joint and wall to roof interface. Results at the foundation joint are summarized in Figure 8, which indicates that the OSB to bottom plate interface was responsible for about $70 \%$ of the leakage we observed at the wall to foundation connection. The importance of this interface was verified with ORNL's air and moisture penetration test chamber (Figure 9). In this chamber we subjected a test wall to a temperature differential of $35^{\circ} \mathrm{F}$ (indoor room temperature $=75^{\circ} \mathrm{F}$, outdoor room temperature $=$ $40^{\circ} \mathrm{F}$ ), and a pressure differential of about $4 \mathrm{~Pa}$ where air was flowing from the outdoor room into the indoor room. The infrared picture in Figure 10 illustrates how the airflow at the OSB to bottom plate interface was dominant given that this area showed the lowest temperatures on the inner side of the stud cavity. 


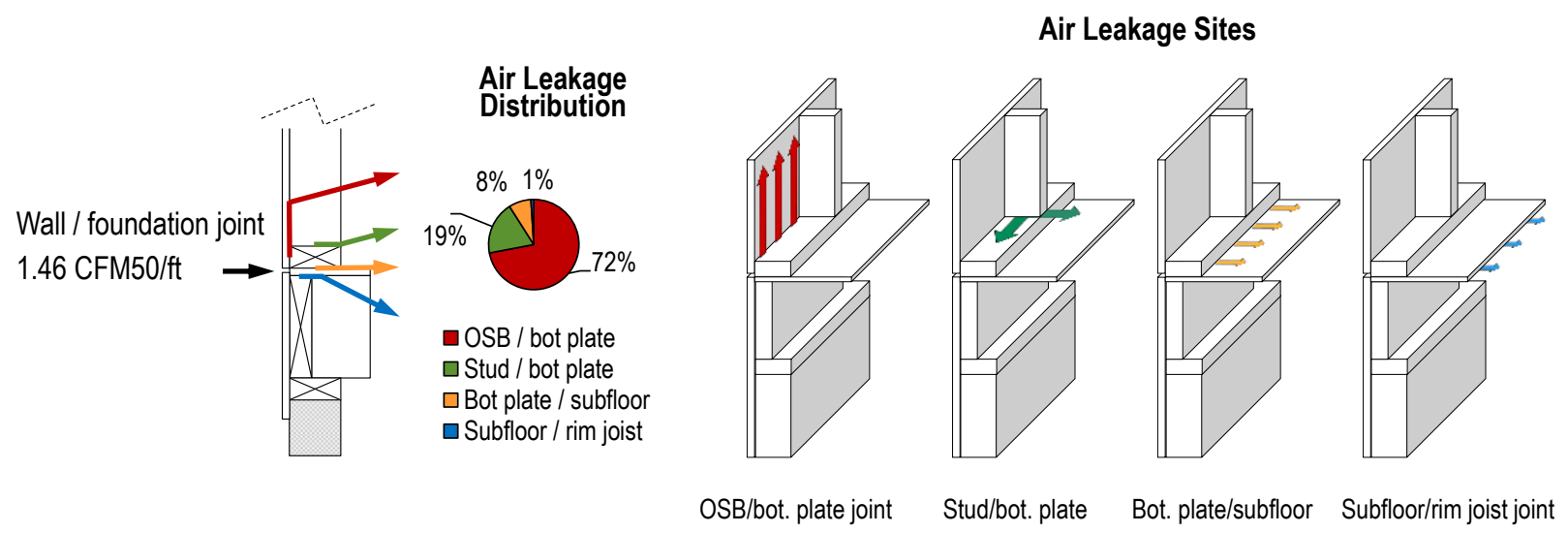

Figure 8. Air leakage distribution at wall to foundation joint.

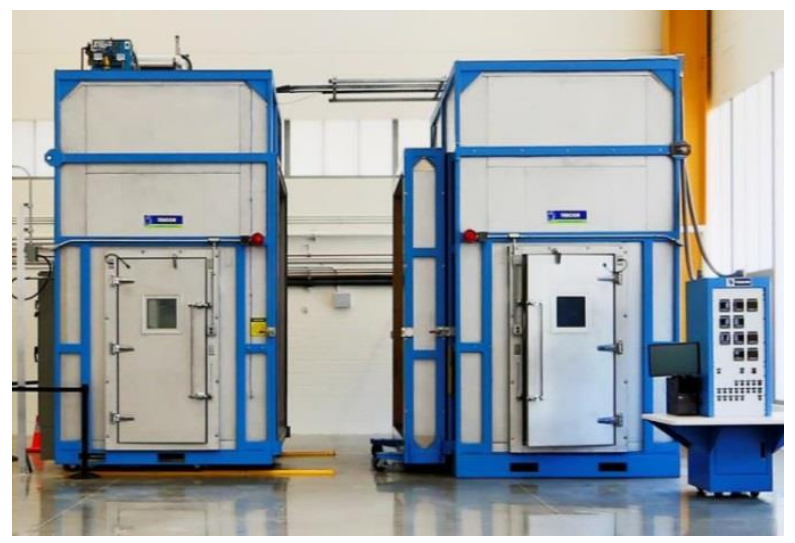

Figure 9. Air and moisture penetration test chamber
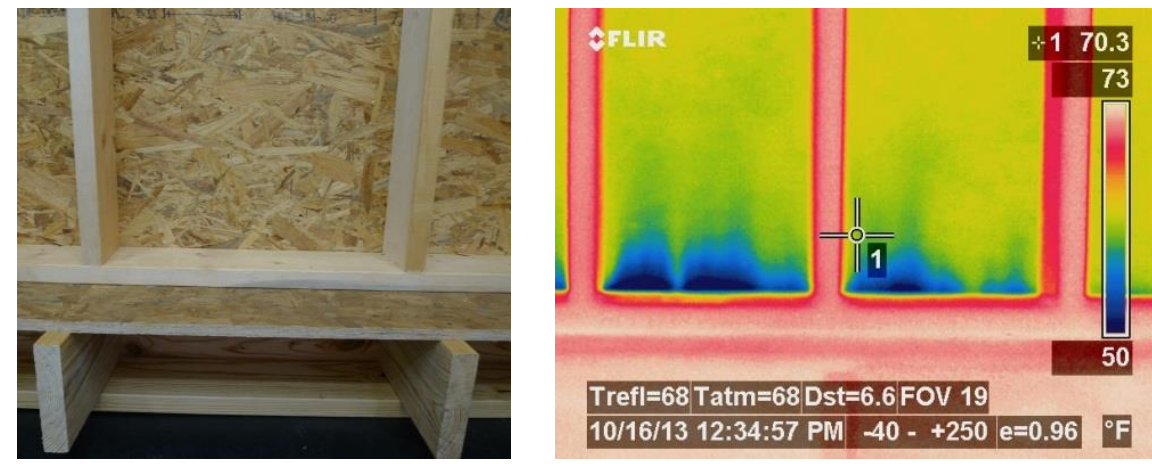

Figure 10. Inner side of wall to foundation joint (left) and infrared picture (right) showing the effect of airflow on temperature at this joint. 
A simple way to curtail leakage at the wall to foundation joint is to seal this connection with caulk or tape on the outer side of the OSB as shown in Figure 11. However, this option may not be practical in buildings with a concrete floor because not all sealants adhere well to concrete, especially if the surface is soiled. Alternatively, Figure 11 shows how a sill foam gasket that is wider than the mud plate can be folded up to also serve as a gasket between the OSB and the bottom plate. This detail requires minimal additional effort by the framing crew given that sill gaskets are commonly installed in residential construction. Note that the gasket recommendation shown in Figure 11 only applies to the following air barrier types that are located on the exterior side of the wall: fluid-applied membranes, self-adhered membranes, insulating sheathing, noninsulating sheathing, and spray-applied foam on outer side of exterior sheathing. This detail will not work well with interior air barriers because a sill gasket that has been folded up may create a gap between the OSB and the studs and increase the size of this air leakage path. For this reason, if this detail is used with a sealant with backup structure system as the air barrier, then the OSB needs to be sealed to studs wherever there is a vertical OSB joint.
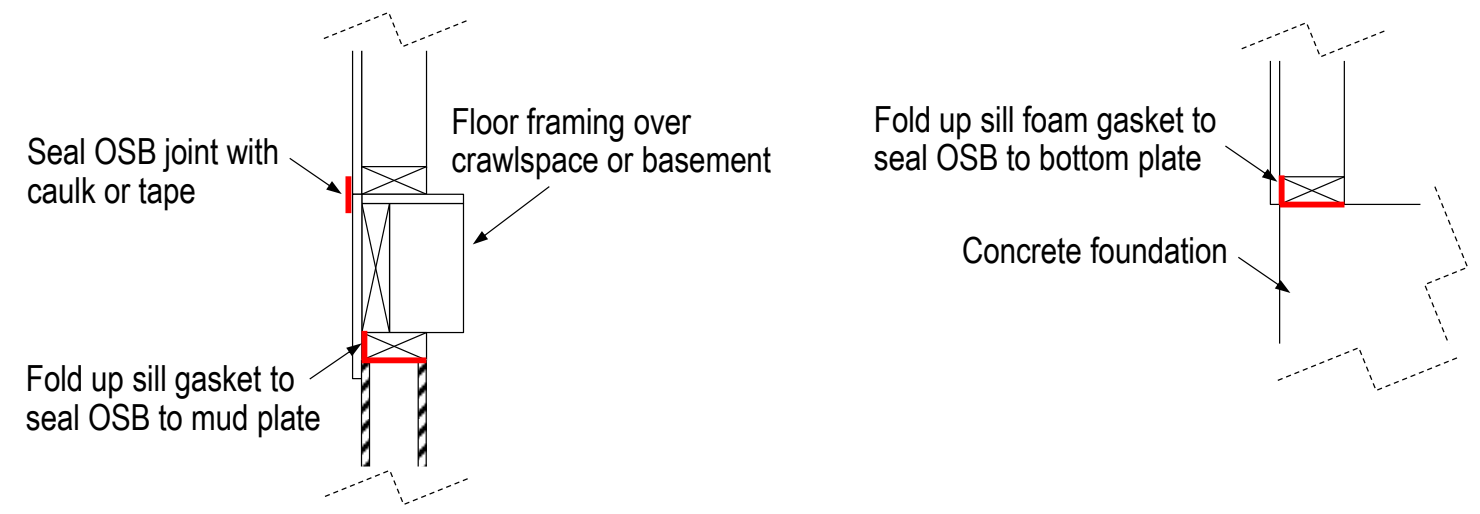

Figure 11. Techniques to seal the wall to foundation joint.

Figure 12 indicates the distribution of airflows at the wall to roof joint. The test wall was framed in such a manner that the airflow at this joint ends up within the wall instead of at the roof attic, which would occur in a house with an unvented attic where the inner side of the blocking members between rafters were sealed. Just as with the wall to foundation joint, the interface between the OSB and the top plates is responsible for most of the inflow at the wall to roof joint. Therefore, techniques to stop the air leakage at this location also involve taping or caulking the OSB joint, or installing a foam gasket between the OSB and the plates as shown in Figure 13. As with the previous example, the gasket should only be used with the following air barrier types: fluid-applied membranes, self-adhered membranes, insulating sheathing, non-insulating sheathing, and spray-applied foam on outer side of exterior sheathing. 

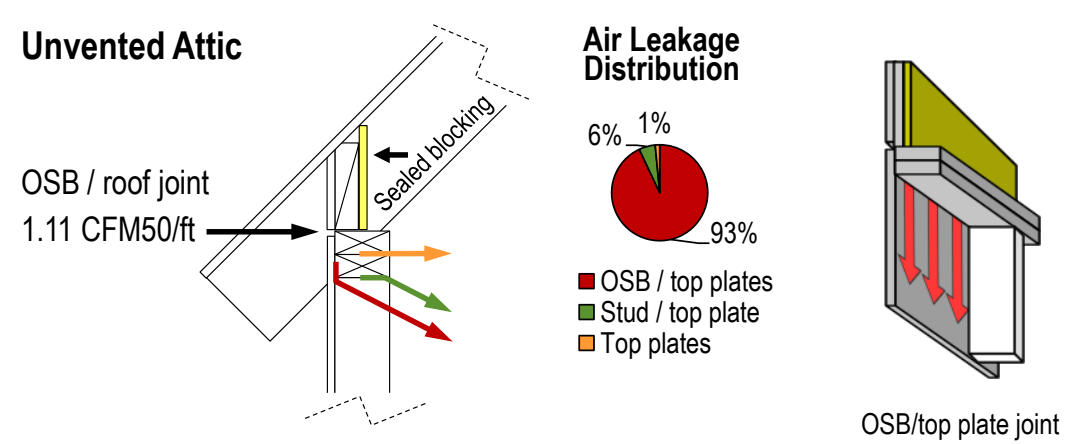

Air Leakage Sites

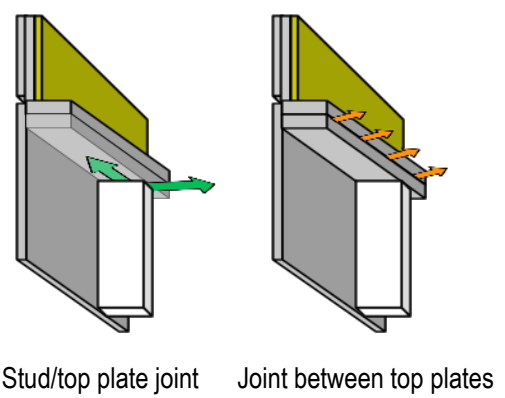

Figure 12. Air distribution at wall to roof joint in a house with an unvented attic.
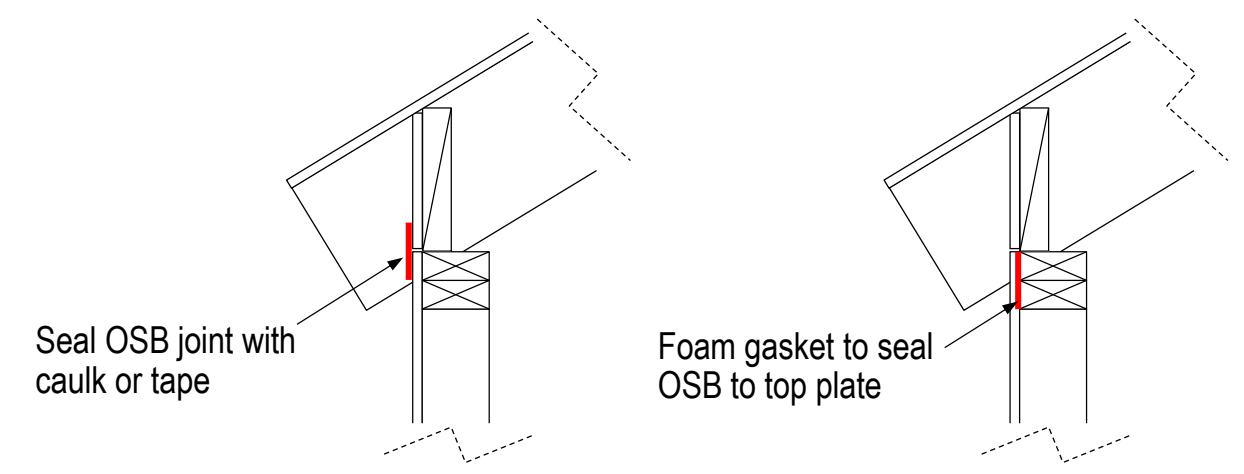

Figure 13. Techniques to eliminate airflow into the exterior walls of a house with an unvented attic due to leakage at the wall to roof joint.

\subsection{Interior Air Barrier}

\subsubsection{Drywall}

Figure 14 shows the test wall with interior drywall as the air barrier and how the perimeter of the penetrations was sealed with an acrylic latex sealant. Table 7 lists the measured air leakage rates before and after gaps around penetrations through the drywall were sealed, as well as flow rates before and after the gypsum board was sealed to the top plate and to the OSB subfloor. Results indicate that unsealed penetrations can yield air leakage rates ranging from 13 to 25 CFM50. Additionally, after we sealed the perimeter of electrical boxes to the wallboard, we estimated that the airflow through the unsealed wire holes in a single circular box was around 4.2 CFM50. Leakage rate through each sealed penetrations was less than 0.03 CFM50. Flow rates at the top and bottom of the drywall were 0.3 and 1.8 CFM50, respectively; differences were likely due to how tightly the drywall was screwed to the plates. Although the acrylic latex sealant initially appeared to work well around electrical boxes, Figure 14 illustrates how it separated from some of the boxes after a few months. We did not measure the implications from the aging of the sealant on airflow, and retouched all questionable spots before we began the ASTM E2357 test. Air leakage rates before and after wind conditioning loads per ASTM E2357 remained at 0.03 CFM75/ft ${ }^{2}\left(0.15 \mathrm{~L} /\left(\mathrm{s} \cdot \mathrm{m}^{2}\right)\right.$ at $\left.75 \mathrm{~Pa}\right)$. 

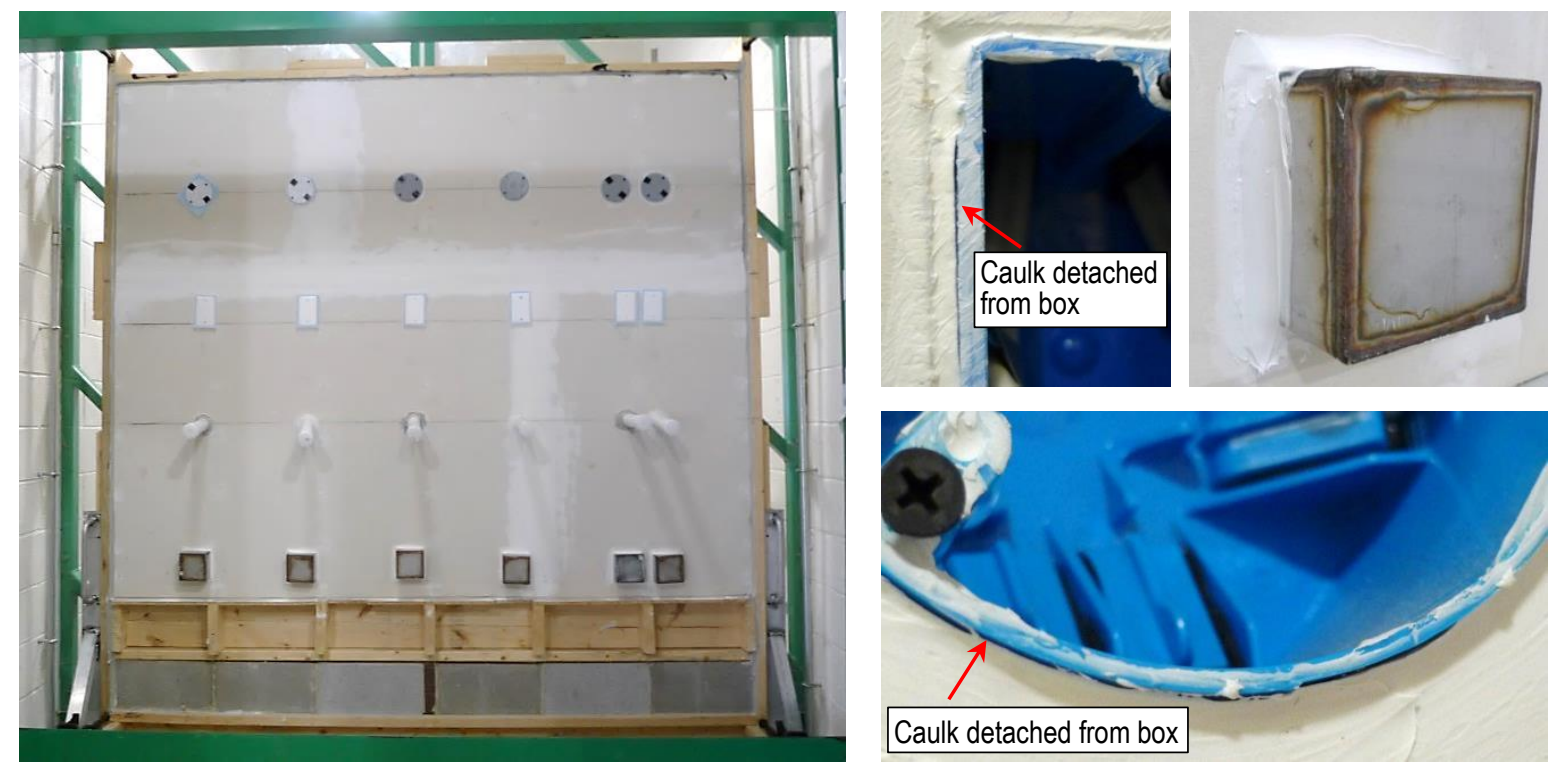

Figure 14. Test wall with interior drywall as the air barrier material.

Note: We temporarily installed cover plates over the electrical boxes, as shown in the picture above, to evaluate how well we sealed the perimeter of the boxes and the wire holes. We removed the plates before conducting the ASTM E2357 test.

Table 7. Air leakage rates through penetrations in a test wall with interior drywall as the air barrier material.

\begin{tabular}{lcc}
\hline \multicolumn{1}{c}{ Air Leakage Site } & $\begin{array}{c}\text { Airflow Rate } \\
\text { (CFM50) }\end{array}$ & $\begin{array}{c}\text { Airflow Rate at } \\
\text { Unsealed Joints } \\
\text { (CFM50/ft) }\end{array}$ \\
\hline $1-1 / 2^{\prime \prime} \phi$ PVC pipe w/ unsealed perimeter & 13 & NA \\
$1-1 / 2^{\prime \prime} \phi$ PVC pipe w/ sealed perimeter & $<0.03^{\mathrm{a}}$ & $\mathrm{NA}$ \\
\hline Rectangular electrical box w/ unsealed perimeter and wire holes & 15 & $\mathrm{NA}$ \\
Rectangular electrical box w/ sealed perimeter and wire holes & $<0.03^{\mathrm{a}}$ & $\mathrm{NA}$ \\
\hline Circular electrical box w/ unsealed perimeter and wire holes & 17 & $\mathrm{NA}$ \\
Circular electrical box w/ sealed perimeter and unsealed wire holes & $4.2^{\mathrm{b}}$ & $\mathrm{NA}$ \\
Circular electrical box w/ sealed perimeter and wire holes & $0.03^{\mathrm{b}}$ & $\mathrm{NA}$ \\
\hline $4 \times 4$ steel duct w/ unsealed perimeter & 25 & $\mathrm{NA}$ \\
$4 \times 4$ steel duct w/ sealed perimeter & $<0.03^{\mathrm{a}}$ & $\mathrm{NA}$ \\
\hline Drywall to top plate joint & $\mathrm{NA}$ & 0.3 \\
\hline Drywall to OSB subfloor joint & $\mathrm{NA}$ & 1.8 \\
\hline
\end{tabular}

Abbreviations: n, sample size; NA, not applicable.

a. The measured increase in air leakage due to the added sealed penetrations was not reported because it was lower than the average extraneous leakage (0.2 CFM50) of all test walls $(n=12)$. Instead, we state that increase in airflow was lower than the average extraneous value divided by the number of penetrations $(n=6)$.

b. Reported flow rate was calculated by dividing the total leakage rate by the number of penetrations $(n=6)$. 


\section{Benefits}

1. Limited increases in first cost due to additional materials given that drywall is the interior cladding.

2. Required materials are easily accessible.

3. Sealing around penetrations can be performed by subcontractors already involved in a typical project (e.g., framers, drywall installers, electricians and plumbers) if they are trained on air barrier systems.

4. Installation is less vulnerable to outdoor environmental conditions during construction because it is applied on the inner side of exterior walls.

5. General details are available on how to achieve continuity in the air barrier system (BSC 2009).

\section{Recommendations and Considerations}

1. General contractor and subcontractors, especially the drywall installers and framers, need to be trained on the airtight drywall approach. There are numerous locations where the drywall needs to be sealed to the framing, and where framing components need to be sealed to each other to achieve a continuous air barrier system in the building.

2. The perimeter of electrical boxes that penetrate the drywall in exterior walls need to be sealed. Foam gaskets between the box and the cover plate will not eliminate the air leakage if the plate is not pressed against the drywall and if the wire holes are left unsealed.

\subsubsection{Mechanically-Fastened Interior Membrane}

Installation of the polyamide membrane as an interior air barrier is illustrated in Figure 15. Here, we followed instructions from a manufacturer with regard to spacing of staples, adequate sealants and tapes, and how to seal penetrations (http://www.certainteed.com/resources/30-28137.pdf). We included in the wall assembly the OSB sheathing with unsealed joints and unfaced fiberglass insulation because these are in place when the interior membrane is installed. We also included the drywall because it is an integral part of this air barrier assembly given that it provides support against infiltration loads.

Before inserting a type of penetration, we removed the drywall so we would be able to seal the penetration directly to the membrane. We then reinstalled the drywall before conducting a leakage test. Per the manufacturer's instructions, we initially only taped the face of the penetrations to the membrane. However, it was difficult to avoid air gaps under the tape, as illustrated on the right picture in Figure 16, partly because we could not roll the tape given that there was no support behind the membrane. Consequently, we applied silicone sealant over the tape to eliminate airflow paths at tape joints as shown in Figure 16.

Air leakage rates through the sealed penetrations are reported in Table 8. These ranged from $<0.03$ to 2.4 CFM50. Flow rates decreased in a rectangular box from 2.4 to 1.3 CFM50, and in a circular box from 1.9 to 0.5 CFM50, after the wire holes were caulked. After installing all the penetrations, we subjected the wall to the conditioning loads described in ASTM E2357. These loads do not appear to have affected the air barrier assembly given that the air leakage rate remained at $0.14 \mathrm{CFM} 75 / \mathrm{ft}^{2}\left(0.69 \mathrm{~L} /\left(\mathrm{s} \cdot \mathrm{m}^{2}\right)\right.$ at $\left.75 \mathrm{~Pa}\right)$ before and after it was stressed with 
prescribed wind loads. Nevertheless, these measurements exceed the leakage requisite for an air barrier assembly by a factor of 3.4.
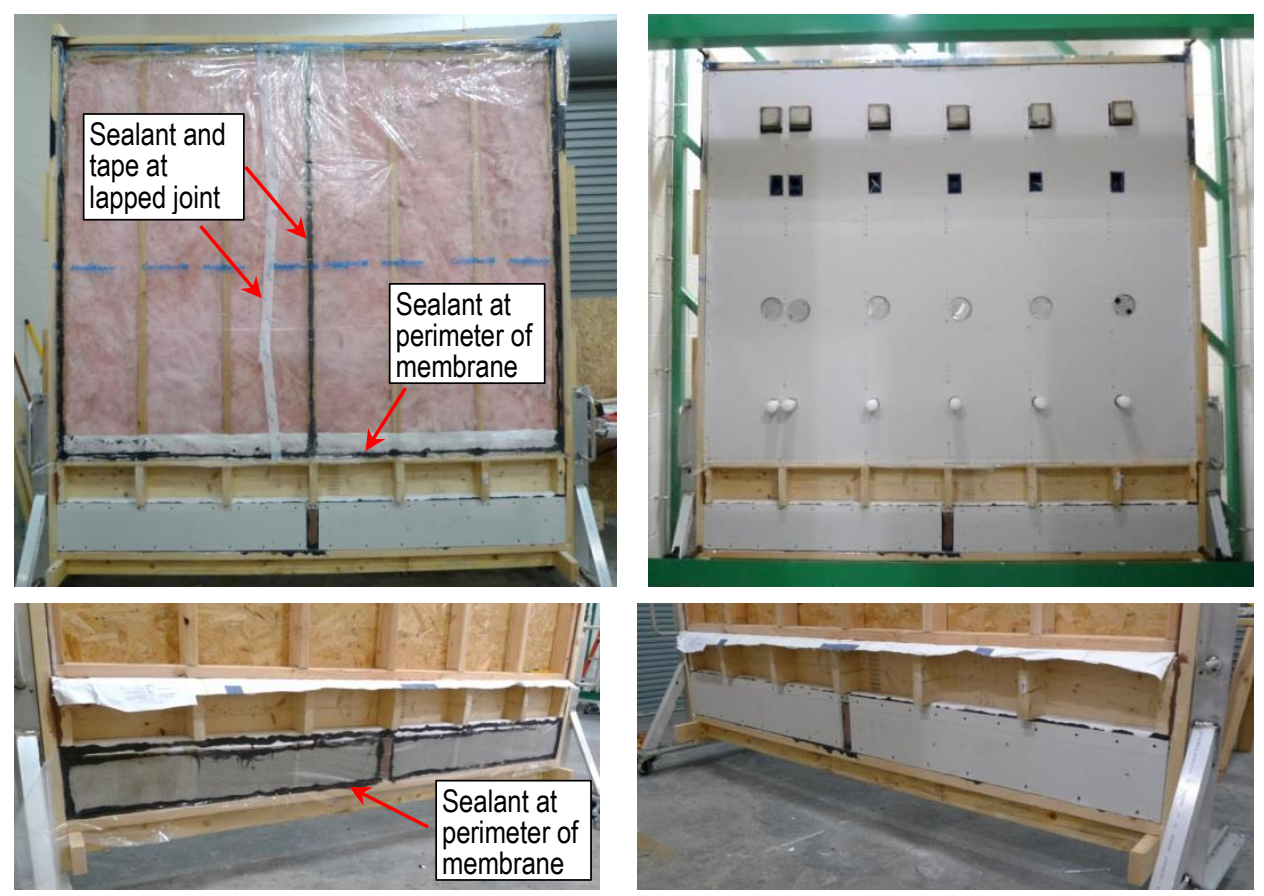

Figure 15. Test wall with polyamide membrane as the air barrier material.

Note: We temporarily installed cover plates over the electrical boxes, as shown in the picture above, to evaluate how well we sealed the perimeter of the boxes and the wire holes. We removed the plates before conducting the ASTM E2357 test.
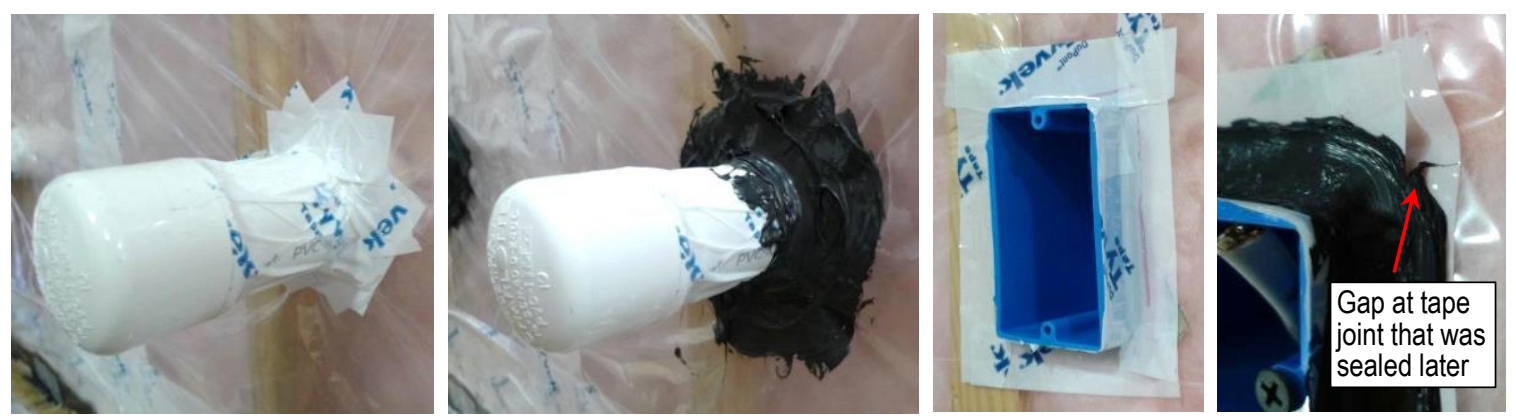

Figure 16. Penetrations through membrane sealed with tape and sealant. 
Table 8. Air leakage rates through penetrations in a test wall with polyamide membrane as the air barrier material.

\begin{tabular}{lc}
\hline \multicolumn{1}{c}{ Air Leakage Site } & Airflow Rate (CFM50) \\
\hline $1-1 / 2 " \phi$ PVC pipe w/ sealed perimeter & $0.3^{\mathrm{a}}$ \\
\hline Rectangular electrical box w/ sealed perimeter and unsealed wire holes & $2.4^{\mathrm{a}}$ \\
Rectangular electrical box w/ sealed perimeter and wire holes & $1.3^{\mathrm{a}}$ \\
\hline Circular electrical box w/ sealed perimeter and unsealed wire holes & $1.9^{\mathrm{a}}$ \\
Circular electrical box w/ sealed perimeter and wire holes & $0.5^{\mathrm{a}}$ \\
\hline $4 \times 4$ steel duct w/ sealed perimeter & $<0.03^{\mathrm{b}}$ \\
\hline
\end{tabular}

Abbreviations: $n$, sample size.

a. Reported flow rate was calculated by dividing the total leakage rate by the number of penetrations $(n=6)$.

b. The measured increase in air leakage due to the added sealed penetrations was not reported because it was lower than the average extraneous leakage (0.2 CFM50) of all test walls $(n=12)$. Instead, we state that increase in airflow was lower than the average extraneous value divided by the number of penetrations $(n=6)$.

\section{Benefits}

1. Relatively easy availability of required materials.

2. Membrane can be installed by the framing or insulation crew if they are trained on air barrier systems.

3. Installation is less vulnerable to outdoor environmental conditions during construction because it is applied on the inner side of exterior walls.

4. Membrane serves as a water vapor retarder; therefore, it can reduce the transport of water vapor from the living area into the wall cavity. A hygrothermal analysis is recommended to determine if the location of the membrane in the wall system is appropriate for the climate zone where it will be used.

5. The vapor permeance of certain membranes, known as "smart" membranes, significantly changes with variations in relative humidity, which allows the membrane to "breath" when moisture levels are high.

6. Details are available on how to use mechanically-fastened interior membranes in attic floors and crawlspace ceilings in order to provide continuity in the air barrier system.

\section{Recommendations and Considerations}

1. The membrane has to be sealed to the face of penetrations with tape, and sealant needs to be applied over the tape to eliminate airflow paths at tape joints. Sealant is needed because contractor tape is typically too rigid and does not easily follow the contour of penetrations with curved perimeter. Also, the tape can't be rolled to eliminate air gaps because there is no support behind the membrane.

2. Penetrations through the membrane that are installed after the drywall is up can't be seal to the membrane. Sealing these penetrations to the drywall does not maintain continuity in the air barrier system because the air barrier material is the membrane and not the drywall.

3. Thin membranes may be susceptible to wrapping around screws during the installation of the drywall. This condition can cause the membrane to be dislodged from some areas behind the drywall without being noticed by the installer, thus compromising the integrity of the air barrier. 
4. Double walls in the building envelope allow for the membrane to be installed between the wall cavities, and for the interior cavity to accommodate electrical boxes and plumbing without penetrating the membrane.

\subsection{Mechanically-Fastened Membrane}

In residential construction, mechanically-fastened membranes are typically attached with either $5 / 8$ " long staples that have 1" plastic caps or with \#4 nails that include 1" plastic caps. We selected the latter to fasten the non-woven, spun bonded polyolefin membrane to the studs. Figure 17 shows how the plastic caps bent under exfiltration loads, and in some of these an airflow path was created between the cap and the nail. Therefore, we reinstalled the membrane using 2" diameter caps that were more rigid than the 1" caps per manufacturers' instructions for commercial construction (http://www.dupont.com/content/dam/assets/products-andservices/construction-materials/assets/77251_lr.pdf, http://www.trustgreenguard.com/ProductFiles/PRODUCT-DOWNLOADS/InstallationGuides/CommercialInstallGuide.pdf). We also screwed the larger caps in place per the manufacturer's guidelines.
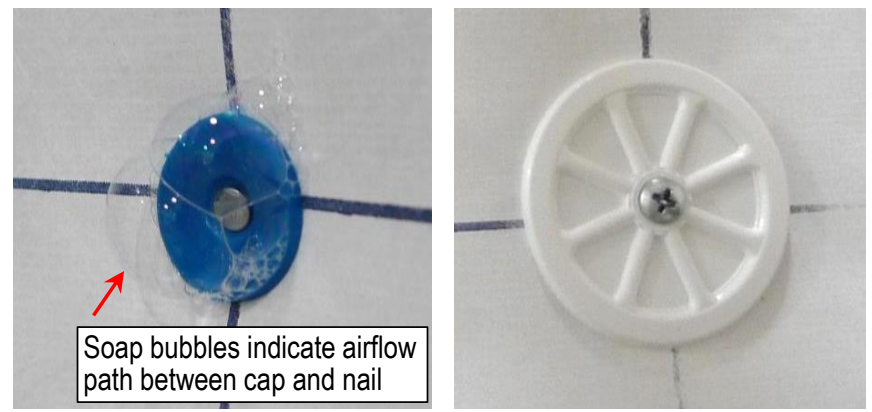

Figure 17. Air leakage through fasteners was avoided by replacing the typically used 1" caps (left) with stiffer 2" caps and screws (right).

We encountered a difficulty at the wall to foundation interface while conducting the ASTM E2357 test. Here, we taped the membrane to the foundation after we sprayed the CMU blocks with high-strength primer/adhesive as recommended by the membrane manufacturer. As shown in Figures 18 and 19, the tape detached from the CMU during the conditioning part of the ASTM test. Figure 19 also depicts the sawdust that fell to the bottom of the wall when we cut holes in the OSB to install penetrations, and that ended up between the flashing and the CMU as the tape failed. Therefore, re-rolling of the tape would have been of minimal use because the sawdust would have prevented proper adhesion. 

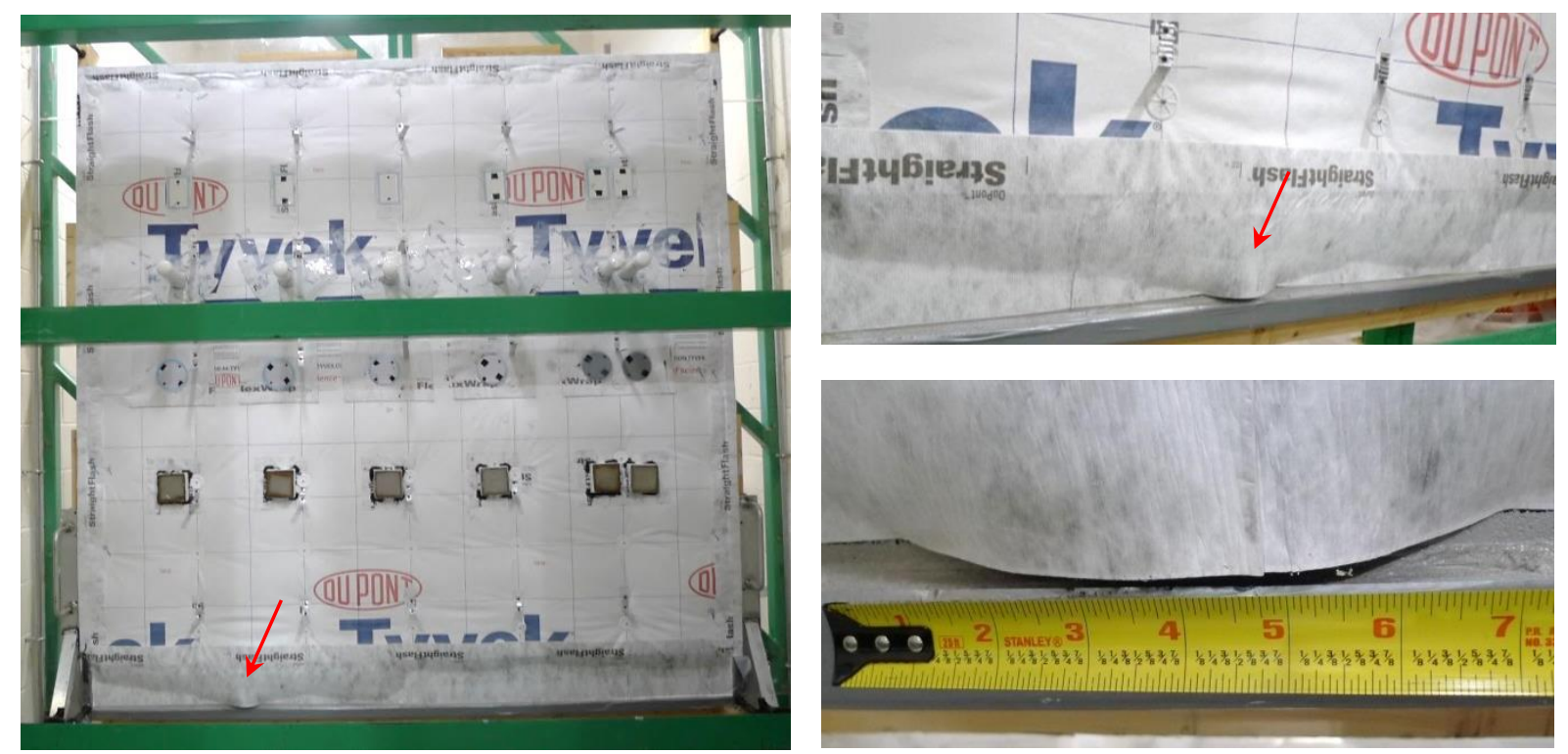

Figure 18. Flashing tape detached from the left side of the CMU during the ASTM E2357 test. Note: We installed cover plates over the electrical boxes, as shown in the picture above, because the flashing tape we used to seal the boxes to the membrane either detached or tore during the ASTM E2357 exfiltration loads. The plates allowed us to conduct the test.
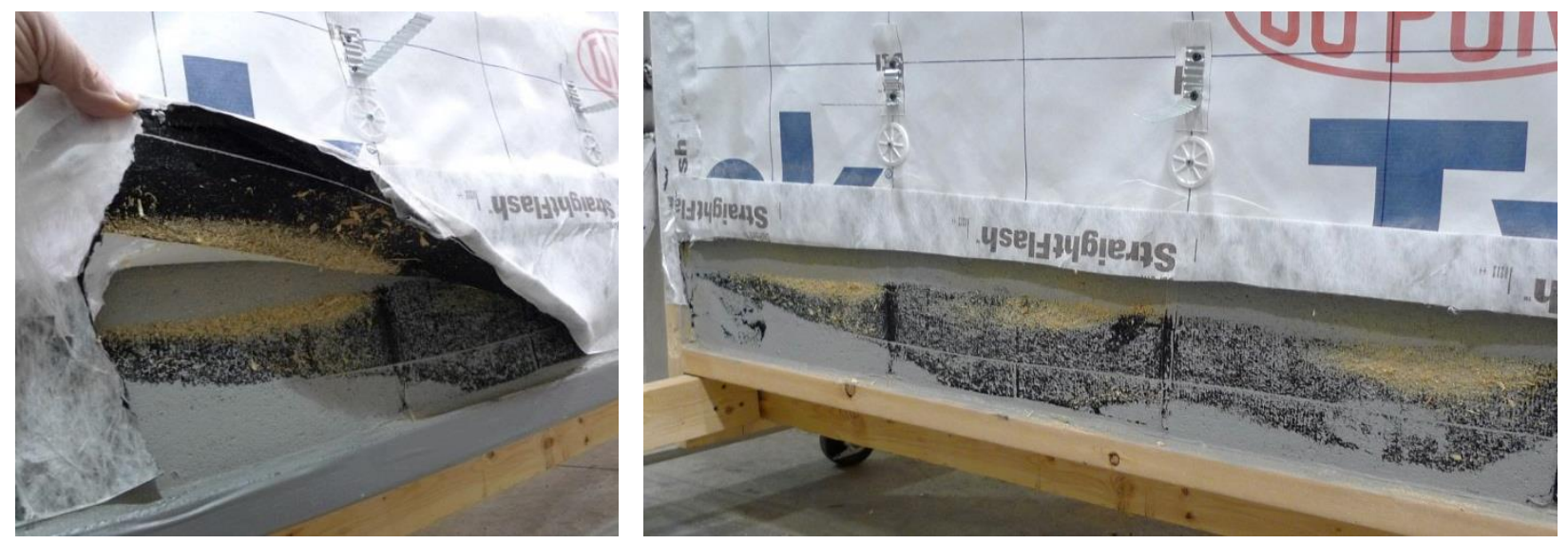

Figure 19. Failure of the flashing tape adhesive.

Figure 20 illustrates how we repaired the air barrier assembly at the CMU area. The steps we followed are: cut and removed the old flashing tape, cleaned the surface of the CMU, sprayed the CMU with high-strength adhesive, applied and rolled new flashing tape, and installed a row of fasteners at the mud plate to reduce the wind force on the tape.

Table 9 summarizes the air leakage rates at sealed penetrations. This table does not include results at electrical boxes because we incorrectly sealed them to the membrane, and therefore had to cover them with blank plates in order to be able to continue with the test. Air leakage rates before and after wind conditioning loads were about $0.015 \mathrm{CFM} 75 / \mathrm{ft}^{2}\left(0.07 \mathrm{~L} /\left(\mathrm{s} \cdot \mathrm{m}^{2}\right)\right.$ at $\left.75 \mathrm{~Pa}\right)$. 

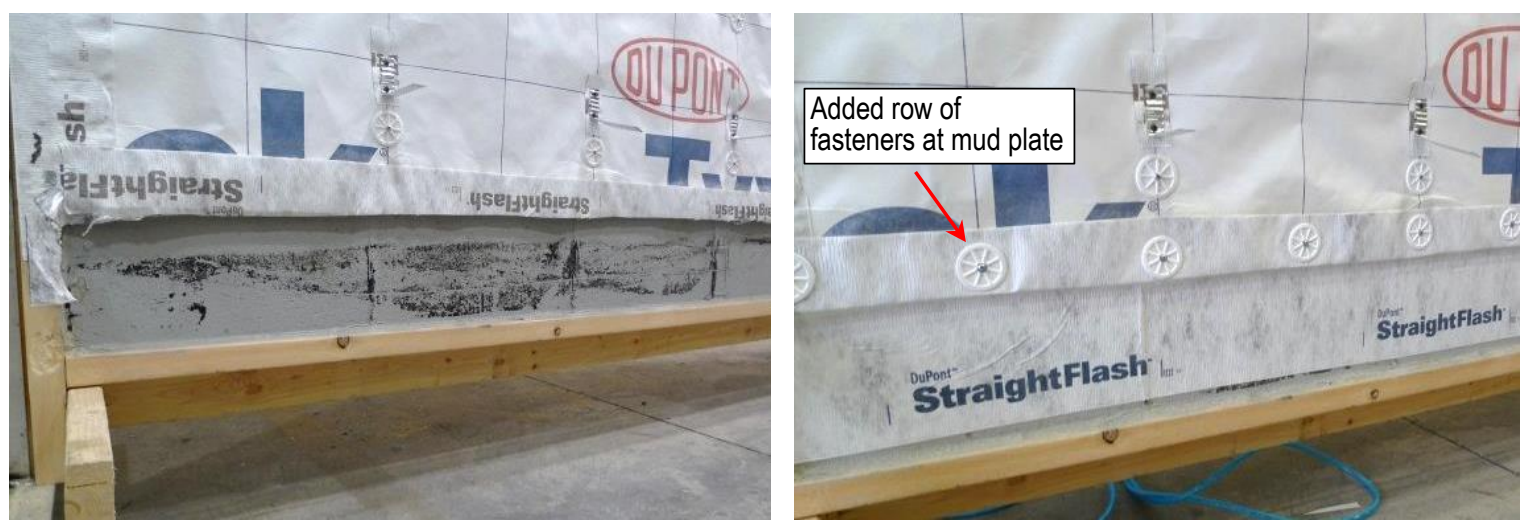

Figure 20. Fixed flashing tape connecting membrane to CMU block.

Table 9. Air leakage rates through penetrations in a test wall with non-woven, spun bonded polyolefin membrane as the air barrier material.

\begin{tabular}{lc}
\hline \multicolumn{1}{c}{ Air Leakage Site } & Airflow Rate (CFM50) \\
\hline $1-1 / 2^{\prime \prime} \phi$ PVC pipe w/ sealed perimeter & $0.07^{\mathrm{a}}$ \\
\hline $4 \times 4$ steel duct w/ sealed perimeter & $<0.03^{\mathrm{b}}$ \\
\hline Corrugated brick tie & $<0.008^{\mathrm{b}}$ \\
\hline
\end{tabular}

Abbreviations: $\mathrm{n}$, sample size.

a. Reported flow rate was calculated by dividing the total leakage rate by the number of penetrations $(n=6)$.

b. The measured increase in air leakage due to the added sealed penetrations was not reported because it was lower than the average extraneous leakage ( 0.2 CFM50) of all test walls $(n=12)$. Instead, we state that increase in airflow was lower than the average extraneous value divided by the number of penetrations (steel ducts: $n=6$; corrugated brick ties: $n=25$ ).

\section{Benefits}

1. Relatively easy availability of required materials.

2. Membrane can be installed by framers if they are trained on air barrier systems.

3. Membrane can serve as a drainage plane and a water-resistive barrier.

\section{Recommendations and Considerations}

1. Installation guidelines for mechanically-fastened membranes to serve as the main air barrier material in residential buildings are needed. Most of the available guidelines for residential construction do not address ASTM E2357 requirements. Guidelines for mechanicallyfastened membranes that comply with ASTM E2357 pertain primarily to commercial buildings.

2. Typical installation practices for mechanically-fastened membranes in residential construction utilize staples or nails with 1" caps. Fasteners with larger ( 2" diameter) and stiffer caps are needed in order for some mechanically-fastened membranes to comply with air barrier assembly requirements. Consult with the membrane manufacturer for adequate installation guidelines.

3. Vertical furring strips could be used instead of the large caps, but this should be confirmed with the membrane manufacturer. 
4. Most guidelines for mechanically-fastened membranes primarily focus on its installation to walls. Residential details do not appear to be readily available on how to achieve continuity at the wall to roof joint.

5. Contractor tape is too rigid to seal around some penetrations and does not easily follow the contour of penetrations with curved perimeters. A flexible tape is more appropriate for this application.

6. Tapes need to be rolled after installation for better adhesion to substrates.

7. Concrete foundations have to be cleaned and primed with high-strength primer/adhesive in order for tapes to adequately adhere to the concrete.

8. A row of fasteners may be needed at the bottom edge of the membrane where it meets the bottom plate or the mud plate. Consult with the membrane manufacturer for adequate installation guidelines.

9. Penetrations through the membrane that are installed after the cladding is up can't be seal to the membrane. Sealing these penetrations to the OSB from the inner side of the wall cavity does not maintain continuity in the air barrier system because the air barrier material is the membrane and not the OSB.

\subsection{Sealant with Backup Structure}

For the sealant with backup structure air barrier type, we used OSB as the air barrier material and sealed the wood joints with a latex foam sealant as illustrated in Figure 21. At the gaps around the steel ducts we also used the latex sealant; in all other penetrations we sprayed canned foam as indicated in Figure 22. The sealant partly separated from the OSB, steel and sawn lumber at a few locations (Figure 23) two months after it was applied. It is possible that the equipment used to install the sealant was not working properly, which could have produced an off-ratio mixture. We retouched the sealant before continuing with the tests.
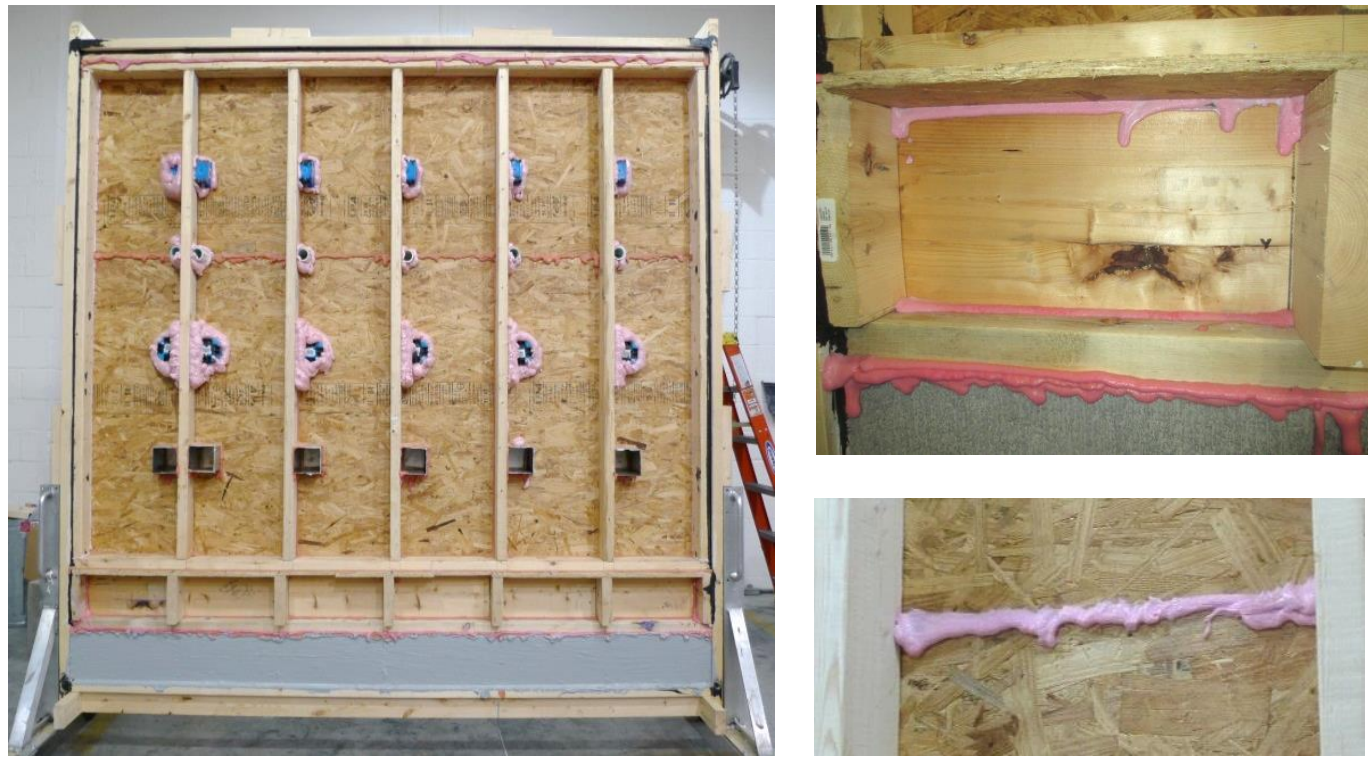

Figure 21. Test wall with OSB as the air barrier material and latex foam sealant at OSB joints. 

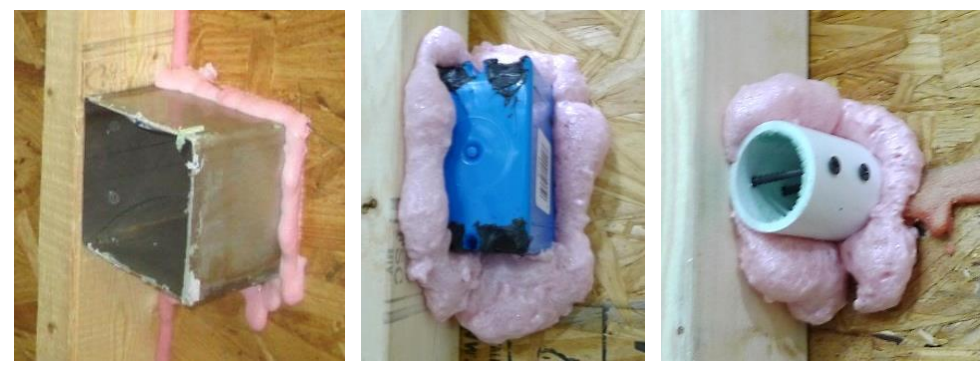

Figure 22. Penetrations through OSB sealed with latex foam sealant or canned foam.
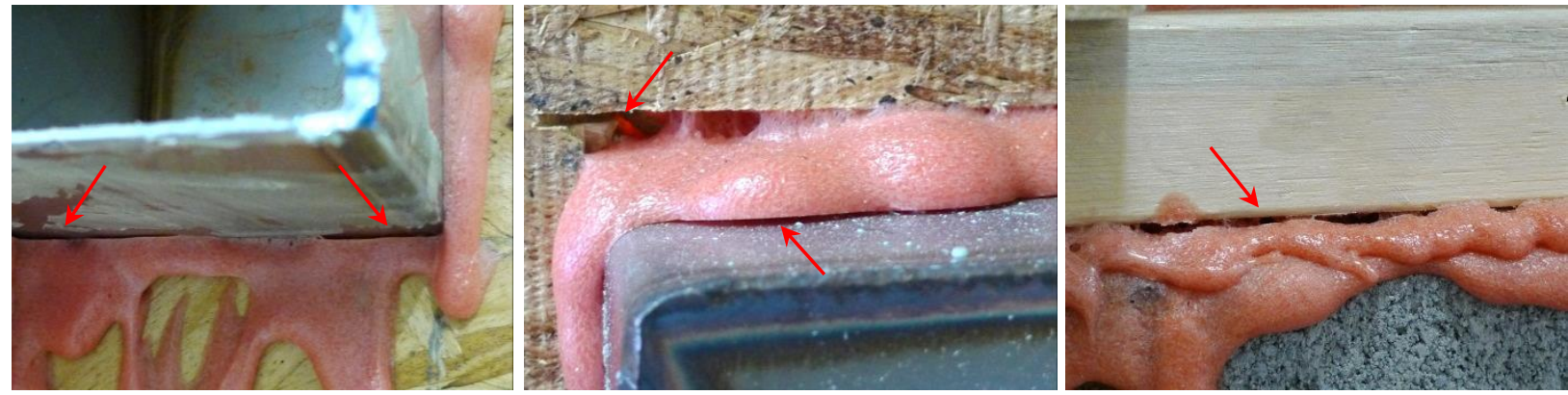

Figure 23. Locations where the latex foam sealant detached from substrates after two months probably because of equipment malfunction.

Table 10 indicates that leakage rates through sealed penetrations were similar to what we obtained from other test walls, with measurements not surpassing 0.06 to 0.11 CFM50. Airflow rates before and after wind pressures per ASTM E2357 increased slightly from $0.10 \mathrm{CFM} 75 / \mathrm{ft}^{2}$ $\left(0.49 \mathrm{~L} /\left(\mathrm{s} \cdot \mathrm{m}^{2}\right)\right.$ at $\left.75 \mathrm{~Pa}\right)$ to $0.11 \mathrm{CFM} 75 / \mathrm{ft}^{2}\left(0.56 \mathrm{~L} /\left(\mathrm{s} \cdot \mathrm{m}^{2}\right)\right.$ at $\left.75 \mathrm{~Pa}\right)$. The final air leakage rate exceeds the air barrier assembly requirement by a factor of 2.8. These results may have been influenced by equipment malfunction as was noted earlier. Also, this air barrier assembly is heavily dependent on the air permeance of the OSB. Langmans et al. (2010) evaluated 0.71"thick OSB samples from various Western European manufacturers. Their findings indicate that very few of the samples met the air barrier material requirement of $0.004 \mathrm{CFM} 75 / \mathrm{ft}^{2}(0.02$ $\left.\mathrm{L} /\left(\mathrm{s} \cdot \mathrm{m}^{2}\right)\right)$ at $\left.75 \mathrm{~Pa}\right)$. Additionally, Langmans and colleagues observed a large variability in the air permeance of the materials they examined from different manufacturers, as well as from the same manufacturer; measurements ranged from $<0.004$ to $0.04 \mathrm{CFM} 75 / \mathrm{ft}^{2}(<0.02$ to 0.2 $\left.\mathrm{L} /\left(\mathrm{s} \cdot \mathrm{m}^{2}\right)\right)$ at $\left.75 \mathrm{~Pa}\right)$. It would be beneficial to conduct a similar study with OSB samples fabricated in North America. 
Table 10. Air leakage rates through penetrations in a test wall OSB as the air barrier material and a latex foam as the main air barrier accessory.

\begin{tabular}{lc}
\hline \multicolumn{1}{c}{ Air Leakage Site } & Airflow Rate (CFM50) \\
\hline $1-1 / 2^{\prime \prime} \phi$ PVC pipe w/ sealed perimeter & $0.06^{\mathrm{a}}$ \\
\hline Rectangular electrical box w/ sealed perimeter and wire holes & $0.08^{\mathrm{a}}$ \\
\hline Circular electrical box w/ sealed perimeter and wire holes & $<0.03^{\mathrm{b}}$ \\
\hline $4 \times 4$ steel duct w/ sealed perimeter & $0.11^{\mathrm{a}}$ \\
\hline Corrugated brick tie & $<0.08^{\mathrm{b}}$ \\
\hline
\end{tabular}

Abbreviations: $n$, sample size.

a. Reported flow rate was calculated by dividing the total leakage rate by the number of penetrations $(n=6)$.

b. The measured increase in air leakage due to the added sealed penetrations was not reported because it was lower than the average extraneous leakage (0.2 CFM50) of all test walls $(n=12)$. Instead, we state that increase in airflow was lower than the average extraneous value divided by the number of penetrations (electrical boxes: $n=6$; corrugated brick ties: $n=25$ ).

\section{Benefits}

1. Installation is less vulnerable to outdoor environmental conditions during construction because it is applied on the inner side of exterior sheathings.

2. General details are available on how to achieve continuity in the air barrier system.

\section{Recommendations and Considerations}

1. This air barrier type relies on the air permeance of the OSB; therefore, the quality of the OSB can compromise the airtightness of the house. 


\subsection{Non-Insulating Sheathing}

We utilized an OSB with an integrated water-resistive overlay as the non-insulating sheathing. As shown in Figure 24, OSB joints were sealed with tape. Moreover, gaps around penetrations were first sealed with tape on the outer side of the OSB, and canned foam was sprayed afterwards from the inner side of the sheathing. Although this method is somewhat redundant, it provides for a more robust seal because the tape directs the foam expansion to fill the gap between the penetration and the OSB instead of beyond the exterior face of the sheathing. Additionally, the tape protects the foam from water. Nevertheless, builders usually install only tape or foam.
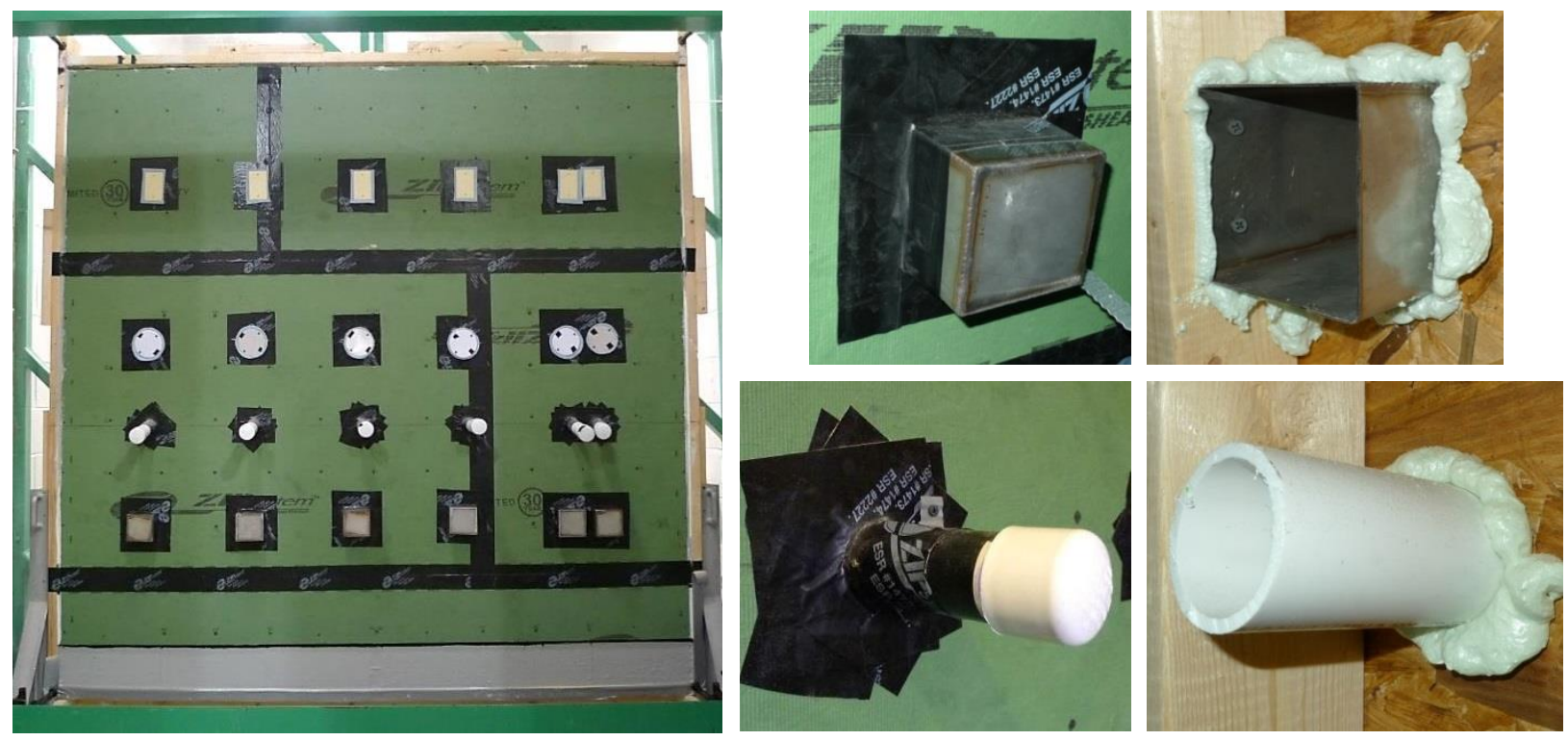

Figure 24. Test wall with OSB with an integrated water-resistive overlay as the air barrier material. Note: We temporarily installed cover plates over the electrical boxes, as shown in the picture above, to evaluate how well we sealed the perimeter of the boxes and the wire holes. We removed the plates before conducting the ASTM E2357 test.

Table 11 lists the measured airflows, which clearly illustrate the reduction in air leakage before and after penetrations were sealed. Leakage rates through unsealed penetrations ranged from 14 to 26 CFM50; after these were sealed, the maximum airflow through a penetration was 0.14 CFM50. Wind pressure loads did not affect the air leakage of the air barrier system; airflow remained at $0.026 \mathrm{CFM} 75 / \mathrm{ft}^{2}\left(0.13 \mathrm{~L} /\left(\mathrm{s} \cdot \mathrm{m}^{2}\right)\right.$ at $\left.75 \mathrm{~Pa}\right)$ before and after the wall was subjected to the wind conditioning loads. 
Table 11. Air leakage rates through penetrations in a test wall with OSB with an integrated waterresistive overlay as the air barrier material.

\begin{tabular}{lc}
\multicolumn{1}{c}{ Air Leakage Site } & Airflow Rate (CFM50) \\
\hline $1-1 / 2^{\prime \prime} \phi$ PVC pipe w/ unsealed perimeter & 14 \\
$1-1 / 2^{\prime \prime} \phi$ PVC pipe w/ sealed perimeter & $<0.03^{\mathrm{a}}$ \\
\hline Rectangular electrical box w/ unsealed perimeter and wire holes & 26 \\
Rectangular electrical box w/ sealed perimeter and unsealed wire holes & $5.55^{\mathrm{b}}$ \\
Rectangular electrical box w/ sealed perimeter and wire holes & $0.14^{\mathrm{b}}$ \\
\hline Circular electrical box w/ unsealed perimeter and wire holes & $>$ Flow meter range $^{\mathrm{c}}$ \\
Circular electrical box w/ sealed perimeter and unsealed wire holes & $4.62^{\mathrm{b}}$ \\
Circular electrical box w/ sealed perimeter and wire holes & $0.06^{\mathrm{b}}$ \\
\hline $4 \times 4$ steel duct w/ unsealed perimeter & $23^{\mathrm{c}}$ \\
$4 \times 4$ steel duct w/ sealed perimeter & $<0.03^{\mathrm{a}}$ \\
\hline Corrugated brick tie & $<0.008^{\mathrm{a}}$ \\
\hline
\end{tabular}

Abbreviations: n, sample size; NA, not applicable; NM, not measured.

a. The measured increase in air leakage due to the added sealed penetrations was not reported because it was lower than the average extraneous leakage $(0.2$ CFM50) of all test walls $(n=12)$. Instead, we state that increase in airflow was lower than the average extraneous value divided by the number of penetrations (pipes: $n=6$; electrical boxes: $n=6$; corrugated brick ties: $\mathrm{n}=25$ ).

b. Reported flow rate was calculated by dividing the total leakage rate by the number of penetrations $(n=6)$.

c. Total airflow through the six penetrations was higher than the flow meter capacity of $30 \mathrm{cfm}$.

\section{Benefits}

1. Sheathings that include the adequate overlay can also serve as a drainage plane.

2. Sheathings can be installed by framers following typical wood-framing practices.

3. If the OSB has an integrated overlay that is installed under factory-controlled conditions and this overlay serves as a water-resistive barrier, this sheathing has the potential to reduce problems encountered in the field with regard to the installation of water-resistive barriers. Additionally, this overlay could lessen the variability in the air permeance of OSB sheathings that was observed by Langmans et al. (2010).

\section{Recommendations and Considerations}

1. Foundation needs to be free of dirt in order for the tapes that are used to seal the sheathing to the foundation to work properly.

2. Guidelines are needed to complete the air barrier system in a house: air barrier components required at the roof, foundation, wall to roof joint, and wall to crawlspace ceiling joint.

3. Electrical boxes with flanges throughout its entire perimeter allow for faster and better connections between the box and the air barrier material. 


\subsection{Insulating Sheathing}

We used 2"-thick XPS foam board as the air barrier material in a test wall. In order for it to function in an assembly, we followed instructions from a manufacturer (http://insulation.owenscorning.ca/docs/CABS/en_installationmanual.pdf ), which specify that XPS butt joints are sealed with tape, and a foam gasket is installed between the foam board and wood at the perimeter of each XPS board as illustrated in Figure 25. We differed from the instructions in that we used boards with square edges instead of shiplap edges because the latter was not available in the Cleveland area. Another deviation was that we initially purchased boards with scores because this is what was readily available. The scores are partial-depth cuts on each side of the board that make it easier for installers to break the foam. Figure 26 depicts the result from the airflow path created by the combination of a taped butt joint and a score. As shown in Figure 27, we rebuilt the wall with solid XPS boards. Here, we used curved-caps that flattened as fasteners exerted pressure on them, which helped seal the area around the fasteners. Lastly, we sealed penetrations with canned foam and tape.
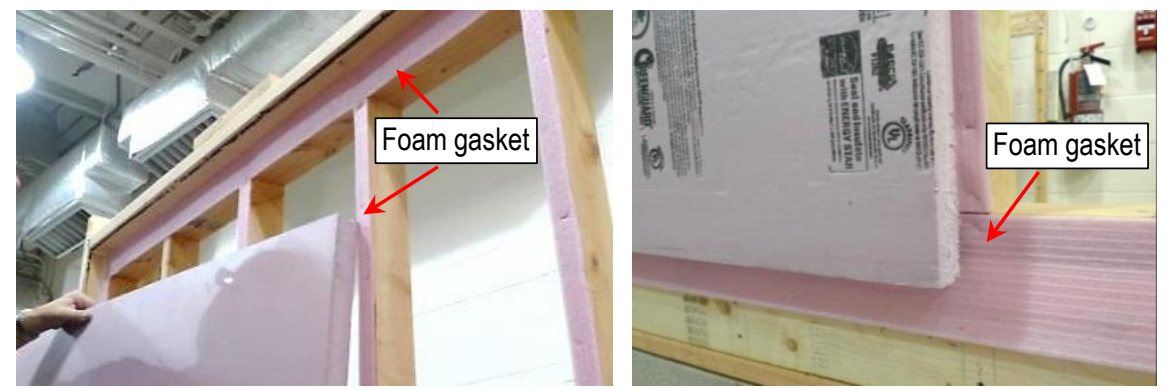

Figure 25. Gasket installed between the foam board and wood at the perimeter of each XPS board.

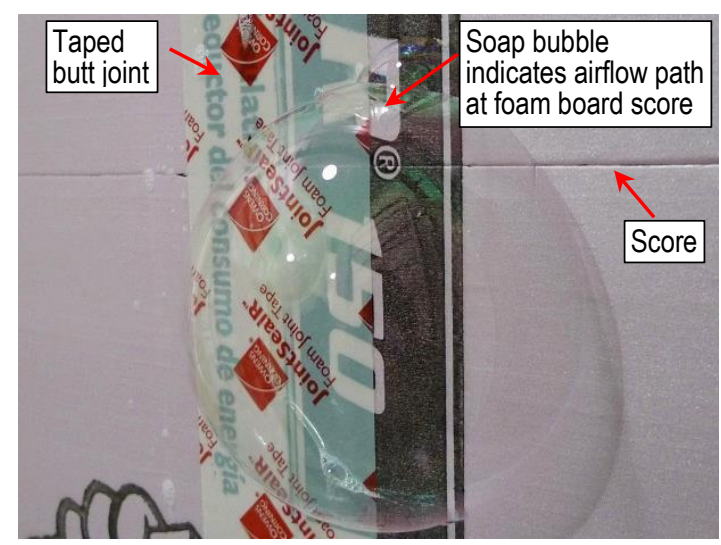

Figure 26. Air bypassed the tape at the butt joint through the score in the foam board. 

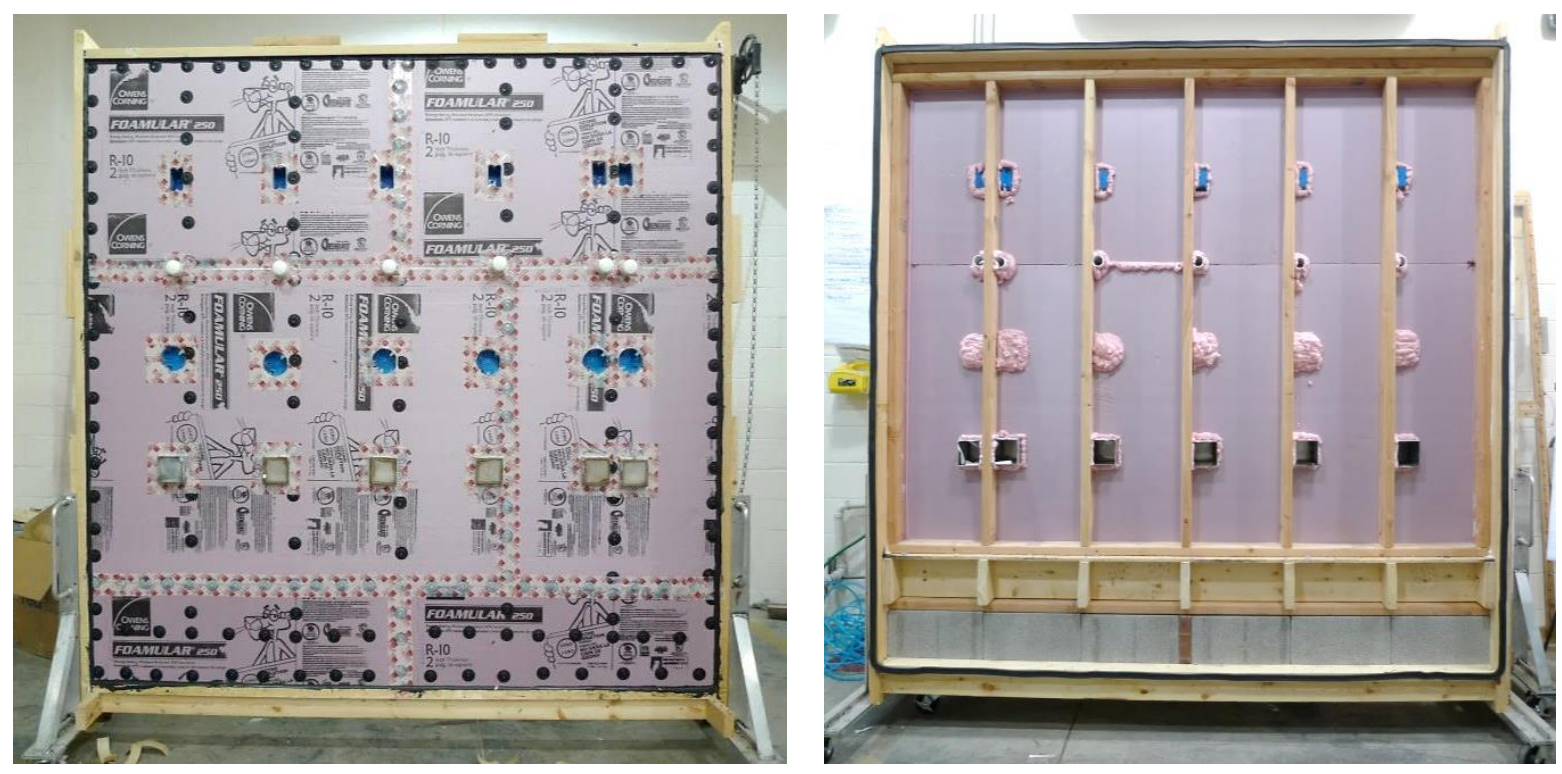

Figure 27. Test wall with 2" XPS foam board as the air barrier material.

Table 12 summarizes the air leakage rates we measured through the sealed penetrations. All flow rates were lower than 0.03 CFM50, which is comparable or lower than other measurements we observed throughout this study. The air leakage rates before and after the wind conditioning loads did not change and stayed at $0.004 \mathrm{CFM} 75 / \mathrm{ft}^{2}\left(0.02 \mathrm{~L} /\left(\mathrm{s} \cdot \mathrm{m}^{2}\right)\right.$ at $\left.75 \mathrm{~Pa}\right)$.

Table 12. Air leakage rates through penetrations in a test wall with 2" XPS foam board as the air barrier material.

\begin{tabular}{lc}
\hline \multicolumn{1}{c}{ Air Leakage Site } & Airflow Rate (CFM50) \\
\hline $1-1 / 2^{\prime \prime} \phi$ PVC pipe w/ sealed perimeter & $<0.03^{\mathrm{a}}$ \\
\hline Rectangular electrical box w/ sealed perimeter and wire holes & $<0.03^{\mathrm{a}}$ \\
\hline Circular electrical box w/ sealed perimeter and wire holes & $<0.03^{\mathrm{a}}$ \\
\hline $4 \times 4$ steel duct w/ sealed perimeter & $<0.03^{\mathrm{a}}$ \\
\hline Corrugated brick tie & $<0.03^{\mathrm{a}}$ \\
\hline
\end{tabular}

Abbreviations: $\mathrm{n}$, sample size.

a. The measured increase in air leakage due to the added sealed penetrations was not reported because it was lower than the average extraneous leakage (0.2 CFM50) of all test walls $(n=12)$. Instead, we state that increase in airflow was lower than the average extraneous value divided by the number of penetrations (pipes: $n=6$; electrical boxes: $n=6$; corrugated brick ties: $n=25$ ).

\section{Benefits}

1. Provides thermal insulation.

2. Insulating sheathing can serve as a drainage plane and a water vapor retarder.

3. Insulating sheathing reduces thermal bridging when installed on the outer side of the wall cavity.

4. General details are available on how to achieve continuity in the air barrier system. 


\section{Recommendations and Considerations}

1. Insulating sheathing manufacturers need to specify the spacing of the capped fasteners based on the thickness of the foam board. The instructions that we followed specified fasteners to be spaced 6" on center along the edges of the board, and 8 " apart in the field of the board in order for the sheathing to act as the air barrier material in the assembly. This spacing should increase as the foam boards get thicker. No distinction is made based on the thickness of the insulating sheathing.

2. Specify solid rigid foam boards when using it as the air barrier material. Scores in boards in conjunction with taped joints between sheathings create airflow paths.

\subsection{Self-Adhered Membrane}

Figure 28 illustrates the test wall where an asphalt-based, self-adhered membrane composed of 36 mil rubber asphalt on a 4 mil polyethylene film was used as the air barrier material. We first installed a type of penetration, and sealed them by applying primer on the OSB, letting the primer cure for at least one hour, installing membrane cutouts around the penetration, rolling the membrane, and adding mastic at the edges of the membrane cutouts. In order to evaluate the effect that mastic has on air leakage, we measured the airflow rate before and after we applied the mastic as shown in Figure 29. Results indicate that flow rates per steel duct decreased from 0.34 to 0.1 CFM50, and leakage rates per PVC pipe were reduced from 0.22 to 0.09 CFM50 due to the mastic. Note that applying mastic to the edges of membrane cutouts is more important when penetrations are installed after the membrane sheets are in place, that is, when the detailing around penetrations occurs after the OSB has been covered with the self-adhered membrane. If the opposite sequence occurs (i.e., the penetrations are added before the membrane sheets), mastic is primarily required at the non-factory edges of membrane sheets.

Table 13 summarizes the collected airflow measurements through the sealed penetrations. After sealing all the penetrations, we applied primer and waited for it to cure, and installed and rolled membrane sheets; Figure 28 shows the end product. Air leakage rates before and after the ASTM E2357 conditioning loads remained at about $0.014 \mathrm{CFM} 75 / \mathrm{ft}^{2}\left(0.07 \mathrm{~L} /\left(\mathrm{s} \cdot \mathrm{m}^{2}\right)\right.$ at $\left.75 \mathrm{~Pa}\right)$. 

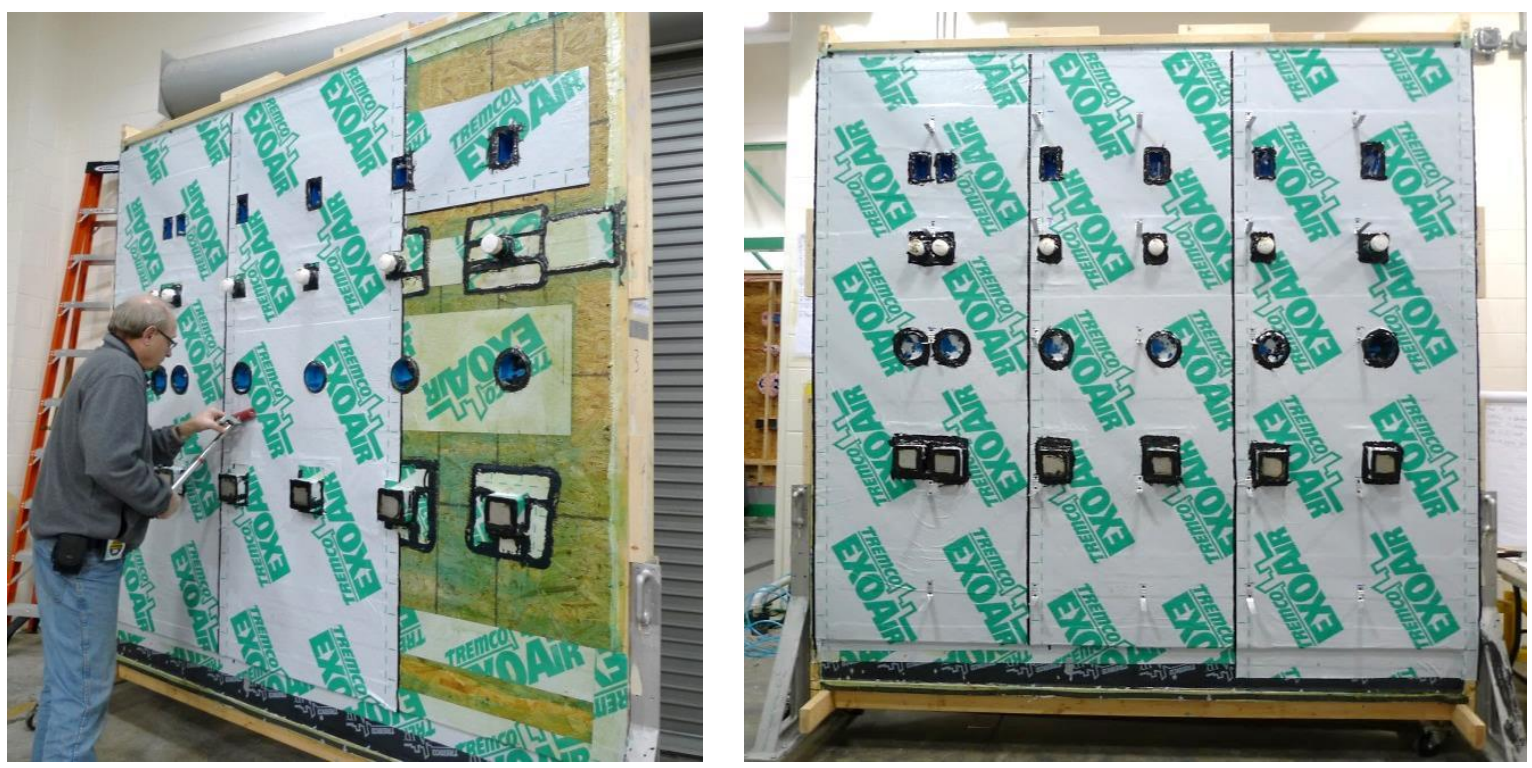

Figure 28. Test wall with asphalt-based, self-adhered membrane as the air barrier material.
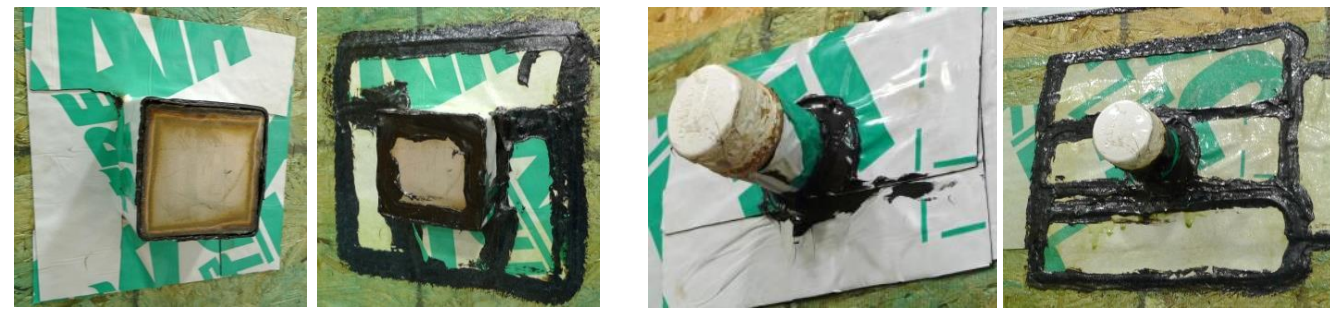

Figure 29. Sealing of steel ducts and PVC pipes was evaluated by measuring air leakage before and after mastic was applied to the perimeter of the membrane.

Table 13. Air leakage rates through penetrations in a test wall with asphalt-based, self-adhered membrane as the air barrier material.

\begin{tabular}{lc}
\hline \multicolumn{1}{c}{ Air Leakage Site } & Airflow Rate (CFM50) \\
\hline $1-1 / 2^{\prime \prime} \phi$ PVC pipe w/ sealed perimeter (membrane but no mastic) & $0.22^{\mathrm{a}}$ \\
$1-1 / 2^{\prime \prime} \phi$ PVC pipe w/ sealed perimeter (membrane and mastic) & $0.09^{\mathrm{a}}$ \\
\hline Rectangular electrical box w/ sealed perimeter and unsealed wire holes & $3.9^{\mathrm{a}}$ \\
Rectangular electrical box w/ sealed perimeter and wire holes & $0.08^{\mathrm{a}}$ \\
\hline Circular electrical box w/ sealed perimeter and unsealed wire holes & $4.1^{\mathrm{a}}$ \\
Circular electrical box w/ sealed perimeter and wire holes & $<0.03^{\mathrm{b}}$ \\
\hline $4 \times 4$ steel duct w/ sealed perimeter (membrane but no mastic) & $0.34^{\mathrm{a}}$ \\
$4 \times 4$ steel duct w/ sealed perimeter (membrane and mastic) & $0.1^{\mathrm{a}}$ \\
\hline Corrugated brick tie & $<0.008^{\mathrm{b}}$ \\
\hline
\end{tabular}

Abbreviations: $\mathrm{n}$, sample size.

a. Reported flow rate was calculated by dividing the total leakage rate by the number of penetrations $(\mathrm{n}=6)$.

b. The measured increase in air leakage due to the added sealed penetrations was not reported because it was lower than the average extraneous leakage (0.2 CFM50) of all test walls $(n=12)$. Instead, we state that increase in airflow was lower than the average extraneous value divided by the number of penetrations (pipes: $n=6$; electrical boxes: $n=6$; corrugated brick ties: $n=25$ ). 


\section{Benefits}

1. A self-adhered membrane allows for the air barrier material to have a uniform thickness.

2. The self-adhered membrane can serve as a drainage plane.

\section{Recommendations and Considerations}

1. Manufacturer's produce self-adhered membranes for various environmental conditions. Consult with the manufacturer for the appropriate membrane.

2. Self-adhered membranes are available with different levels of water vapor permeance. It is important that the designer or specification writer of the project selects the adequate material based on a hygrothermal analysis.

3. Some self-adhered membranes require that the substrates be primed before the membrane is installed. These membranes rely heavily on proper installation and curing of the primer. Blisters may form behind the membrane if the primer does not cure for an adequate amount of time.

4. Solvent-based primers are flammable and require that the general contractor schedule the various trades appropriately to avoid potential fires.

5. Water-based primers can re-emulsify due to vapor diffusion or condensation behind membranes with very low water vapor permeance. This can result in delamination of the membrane from the substrate. Follow installation guidelines to avoid this problem.

6. Some self-adhered membranes require that their non-factory edges be sealed with mastic; these edges are common around penetrations. Consult with the membrane manufacturer for special requirements at non-factory edges.

7. Guidelines are needed to complete the air barrier system in a house: air barrier components required at the roof, foundation, wall to roof joint, and wall to crawlspace ceiling joint.

\subsection{Fluid-Applied Membrane}

We used a water vapor permeable (12 perms), fluid-applied membrane as the air barrier material over the OSB sheathing and the CMU block. As indicated in Figure 30, canned foam was utilized to seal gaps between the OSB and penetrations, and foam that expanded beyond the outer face of the OSB was trimmed after it cured. Subsequently, we used a roller to apply the membrane and obtain a minimum thickness of 70 wet mils. Small gaps, such as saw cuts in the OSB where the foam was not able to penetrate (top right image in Figure 30), were later sealed by the fluid-applied membrane. Measured flow rates through sealed penetrations are described in Table 14; values are similar to those we observed in other walls and are less than 0.18 CFM50 after the wires holes in electrical boxes were sealed. 

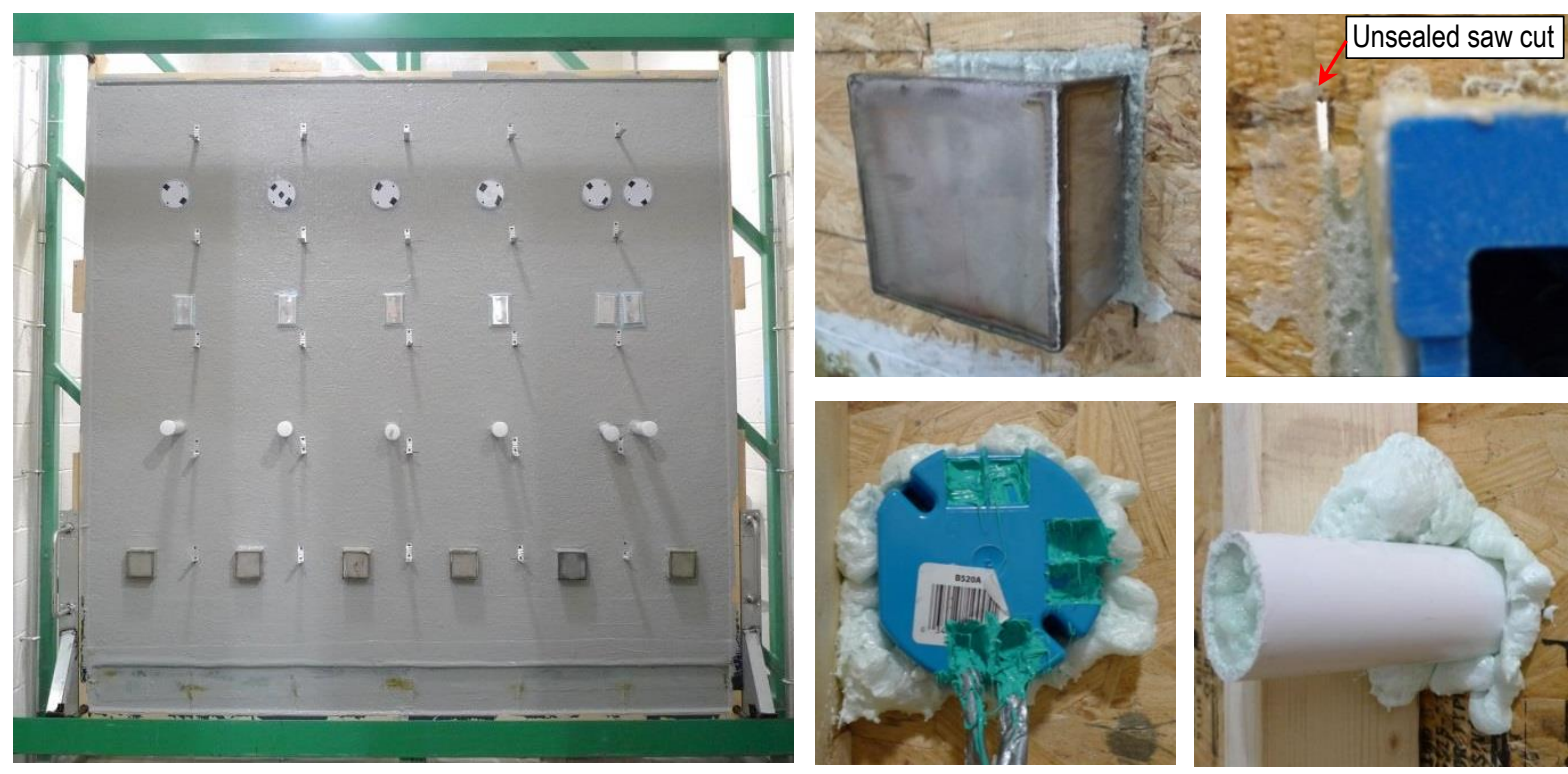

Figure 30. Test wall with fluid-applied membrane as the air barrier material.

Note: We temporarily installed cover plates over the electrical boxes, as shown in the picture above, to evaluate how well we sealed the perimeter of the boxes and the wire holes. We removed the plates before conducting the ASTM E2357 test.

Table 14. Air leakage rates through penetrations in a test wall with fluid-applied membrane as the air barrier material.

\begin{tabular}{lc}
\hline \multicolumn{1}{c}{ Air Leakage Site } & Airflow Rate (CFM50) \\
\hline $1-1 / 2 "$ PVC pipe w/ unsealed perimeter & 17 \\
$1-1 / 2{ }^{\prime \prime} \phi$ PVC pipe w/ sealed perimeter & $0.07^{\mathrm{a}, \mathrm{b}}$ \\
\hline Rectangular electrical box w/ unsealed perimeter and wire holes & $>$ Flow meter range ${ }^{\mathrm{c}}$ \\
Rectangular electrical box w/ sealed perimeter and wire holes & $0.13^{\mathrm{a}, \mathrm{b}}$ \\
\hline Circular electrical box w/ unsealed wire holes & $>$ Flow meter range \\
Circular electrical box w/ sealed perimeter and unsealed wire holes & $3.89^{\mathrm{a}, \mathrm{b}}$ \\
Circular electrical box w/ sealed perimeter and wire holes & $0.18^{\mathrm{a}, \mathrm{b}}$ \\
\hline $4 \times 4$ steel duct w/ unsealed perimeter & $>$ Flow meter range ${ }^{\mathrm{c}}$ \\
$4 \times 4$ steel duct w/ sealed perimeter & $<0.03^{\mathrm{d}}$ \\
\hline Corrugated brick tie & $<0.008^{\mathrm{d}}$ \\
\hline
\end{tabular}

Abbreviations: $n$, sample size.

a. Reported flow rate was calculated by dividing the total leakage rate by the number of penetrations $(n=6)$.

b. Sealing at this stage only included canned foam and not the fluid-applied membrane.

c. Total airflow through the six penetrations was higher than the flow meter capacity of $30 \mathrm{cfm}$.

d. The measured increase in air leakage due to the added sealed penetrations was not reported because it was lower than the average extraneous leakage $(0.2$ CFM50) of all test walls $(n=12)$. Instead, we state that increase in airflow was lower than the average extraneous value divided by the number of penetrations (pipes: $n=6$; steel ducts: $n=6$; corrugated brick ties: $\mathrm{n}=25)$.

\section{Benefits}

1. Fast installation if applied with a sprayer.

2. Membrane can serve as the drainage plane. 


\section{Recommendations and Considerations}

1. If the membrane is sprayed, overspray can occur and surfaces close to the work area could be affected. To reduce these potential problems, fluid-applied membranes can also be installed with a roller or brush.

2. Fluid-applied membranes are available with different levels of water vapor permeance. It is important that the designer or specification writer of the project selects the adequate material based on a hygrothermal analysis.

3. Installers need to be adequately trained in order to avoid common problems such as nonuniform thicknesses and thin coatings.

4. Guidelines are needed to complete the air barrier system in a house: air barrier components required at the roof, foundation, wall to roof joint, and wall to crawlspace ceiling joint.

\subsection{Spray-Applied Foam}

The enclosed area shown in Figure 31 was built to contain fumes and overspray that occur during foam spraying. Air pollutants were directly exhausted outdoors by locating the built-up area next to a roll-up door and placing a fan at this door. Four tests were conducted to compare the air leakage through walls with the following installations: 1) foam was properly installed to serve as the reference wall, 2) foam was sprayed over damp wood members and CMU blocks, 3) foam was installed in a wall where the penetrations had been sprayed with a release agent, and 4) the foam mixture was resin-rich. One-inch thick, medium-density, closed-cell polyurethane foam was used in all of these cases. Due to lack of time, we only subjected the wall with good foam installation to the wind pressure loads described in ASTM E2357. However, we conducted ASTM E283 in all walls to obtain their leakage rates at different pressure differentials.
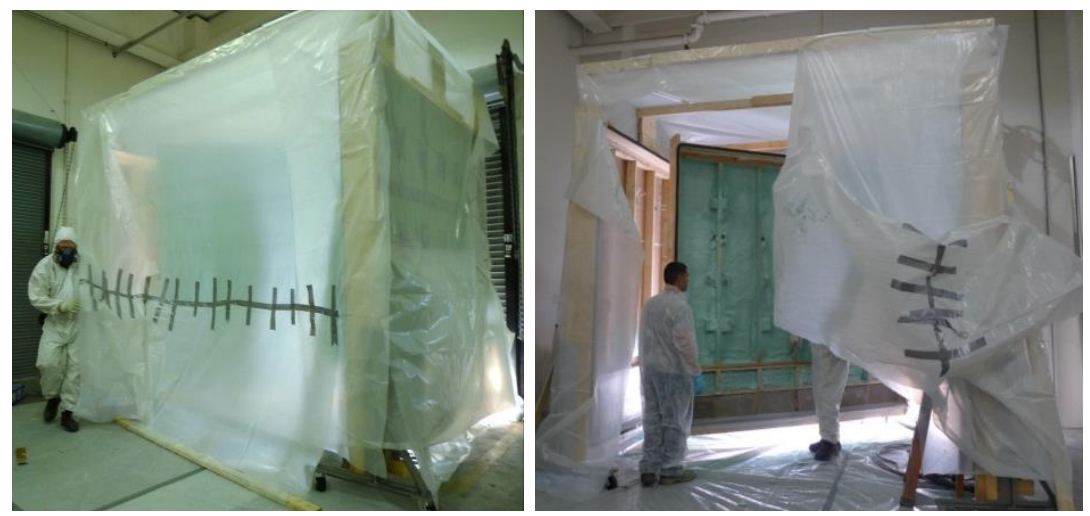

Figure 31. Enclosed and ventilated area built to contain emissions during spray foam installation.

\subsubsection{Properly Followed Installation Guidelines}

Figure 32 shows the finished wall where foam was sprayed in the wall cavity, between the rim joists, and over the CMU. The average foam thickness from 12 samples was 1.3", and the average foam density from three samples that were gathered from the wall cavity was $2.5 \mathrm{lb} / \mathrm{ft}^{3}$. In order to maintain continuity in the air barrier assembly, the wall to foundation and the wall to roof joints were caulked. Results from ASTM E283 before and after the wind pressure conditioning loads remained around $0.003 \mathrm{CFM} 75 / \mathrm{ft}^{2}\left(0.01 \mathrm{~L} /\left(\mathrm{s} \cdot \mathrm{m}^{2}\right)\right.$ at $\left.75 \mathrm{~Pa}\right)$. Note that this 
measurement would have been much larger if only the foam had been applied. Per Table 6, we measured leakage rates at the wall to foundation and the wall to roof joints to be $0.24 \mathrm{CFM} 75 / \mathrm{ft}^{2}$ $\left(1.21 \mathrm{~L} /\left(\mathrm{s} \cdot \mathrm{m}^{2}\right)\right.$ at $\left.75 \mathrm{~Pa}\right)$ and $0.18 \mathrm{CFM} 75 / \mathrm{ft}^{2}\left(0.92 \mathrm{~L} /\left(\mathrm{s} \cdot \mathrm{m}^{2}\right)\right.$ at $\left.75 \mathrm{~Pa}\right)$, respectively. If either one of these joints had not been sealed, the air barrier assembly requisite of $0.04 \mathrm{CFM} 75 / \mathrm{ft}^{2}$ would not have been met. As illustrated in Figure 33, leakage spots occurred at locations where gaps were too narrow for foam to penetrate.
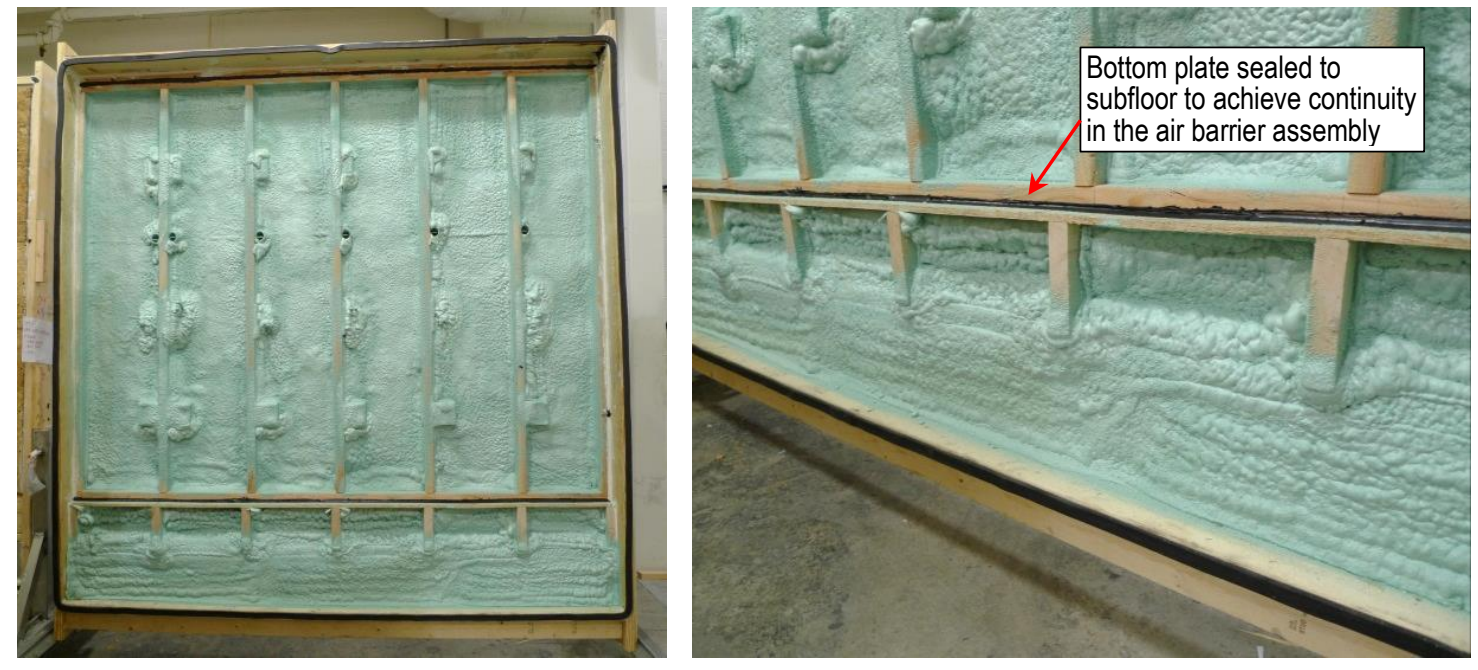

Figure 32. Test wall with 1" closed-cell foam as the air barrier material.

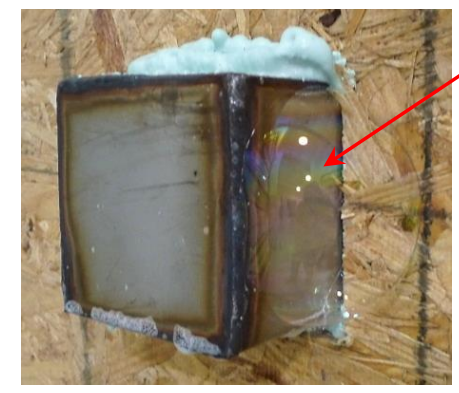

Soap bubble indicates airflow path at the duct to stud joint where the gap was too narrow for the foam to penetrate

Figure 33. Leakage site between OSB and steel duct where gap was too narrow for the foam to penetrate.

We conducted adhesion tests in this wall following ASTM D4541 Standard Test Method for Pull-Off Strength of Coatings Using Portable Adhesion Testers. We collected six foam samples from the wall cavity and between floor joists, and obtained an average result of 27 psi.

Similarly, we gathered three samples from the CMU with an average pressure of 57 psi. The Air Barrier Association of America recommends a minimum pull adhesion pressure of 16 psi for medium-density, closed-cell, sprayed polyurethane foam.

\subsubsection{Damp Substrates}

The wood and CMU in the test wall were sprayed with water before the closed-cell foam was installed on them. The water was quickly absorbed by these substrates so their surfaces were damp; however, droplets likely remained over some of the steel ducts, electrical boxes and PVC pipes. Afterwards, the wall cavity, the cavity between the floor joists, and the interior CMU surface were sprayed with foam. Furthermore, the wall to foundation and wall to roof joints 
were sealed. Although we sprayed the entire wall with water, we only observed one large foam blister as shown in Figures 34 and 35, where the foam lost adhesion to the OSB. Small foam blisters may have occurred, but these were not easily noticed. Results from the ASTM E283 indicate that the air leakage rate of the wall was $0.005 \mathrm{CFM} 75 / \mathrm{ft}^{2}\left(0.03 \mathrm{~L} /\left(\mathrm{s} \cdot \mathrm{m}^{2}\right)\right.$ at $\left.75 \mathrm{~Pa}\right)$, which is approximately twice the flow rate we measured through the reference foam wall.

We also evaluated how well the foam adhered to the damp OSB and CMU. ASTM D4541 data from four foam samples indicated an average pressure force of $17 \mathrm{psi}$ at the wall cavity, which is $60 \%$ of the measurement we gathered from the reference wall. The three samples we collected at the CMU yielded an average pressure force of $20 \mathrm{psi}$, which is $40 \%$ of the pressure we obtained from the reference wall. These values suggest that moisture reduced the adhesion of the foam to the OSB and CMU, but this did not appear to influence air leakage because the continuity of the foam was not affected. However, it should be noted that this test was conducted in a somewhat controlled environment that was not as dependent on fluctuations of outdoor conditions as in a regular job site.
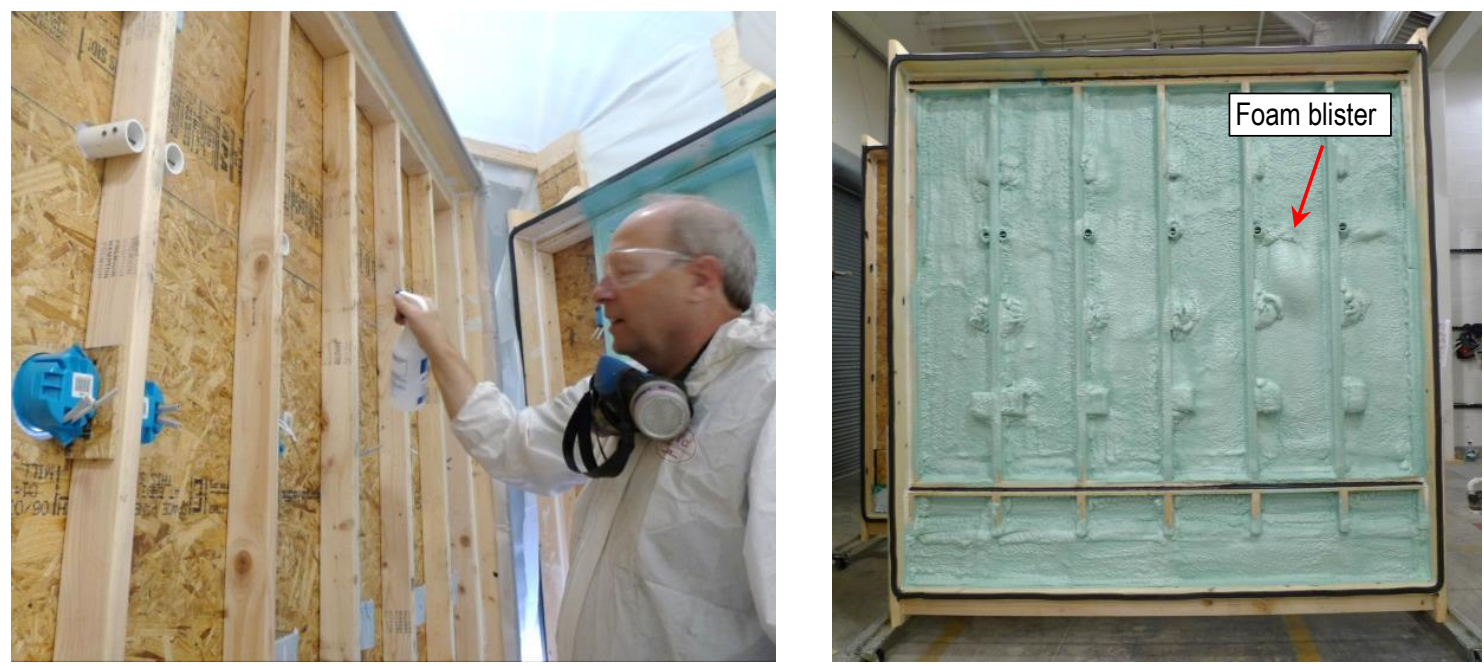

Figure 34. Test wall where 1" closed-cell foam was applied over damp surfaces.
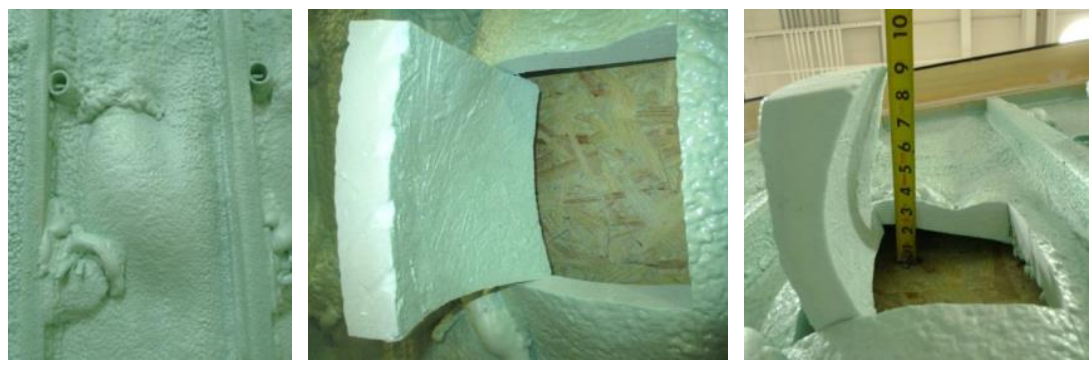

Figure 35. Blister due to loss of adhesion of the sprayed

\subsubsection{Release Agent on Penetrations}

We sprayed silicone on the electrical boxes (Figure 36), steel ducts, and PVC pipes to simulate conditions at the construction site where a substrate may have a film of oil on it. Afterwards, the wall cavity, rim joist cavity, and CMU were covered with 1" foam. The measured air leakage 
rate through the wall was $0.009 \mathrm{CFM} 75 / \mathrm{ft}^{2}\left(0.05 \mathrm{~L} /\left(\mathrm{s} \cdot \mathrm{m}^{2}\right)\right.$ at $\left.75 \mathrm{~Pa}\right)$, which is about three times higher than the flow rate we obtained from the reference foam wall, but still well below the 0.04 CFM $75 / \mathrm{ft}^{2}\left(0.2 \mathrm{~L} /\left(\mathrm{s} \cdot \mathrm{m}^{2}\right)\right.$ at $\left.75 \mathrm{~Pa}\right)$ for an air barrier assembly. After the air leakage test we examined the adhesion of the foam to the penetrations. Figure 37 illustrates how we were able to cleanly remove the foam from some of the penetrations. Findings suggest that although the silicone was effective in lessening foam adhesion, airflow through gaps around penetrations was limited by the expansion of the foam within these gaps.

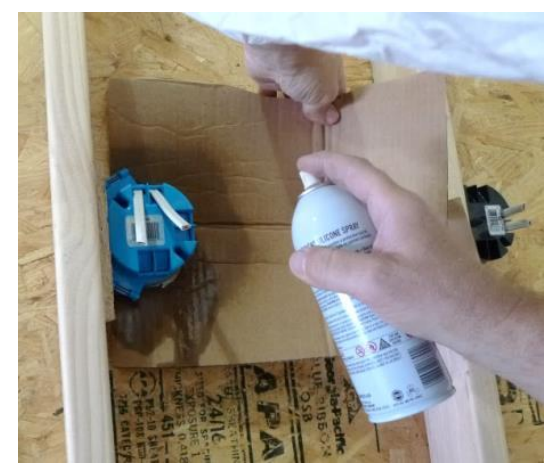

Figure 36. Penetrations sprayed with silicone to simulate on oil film that would compromise the adhesion of the foam to surfaces.
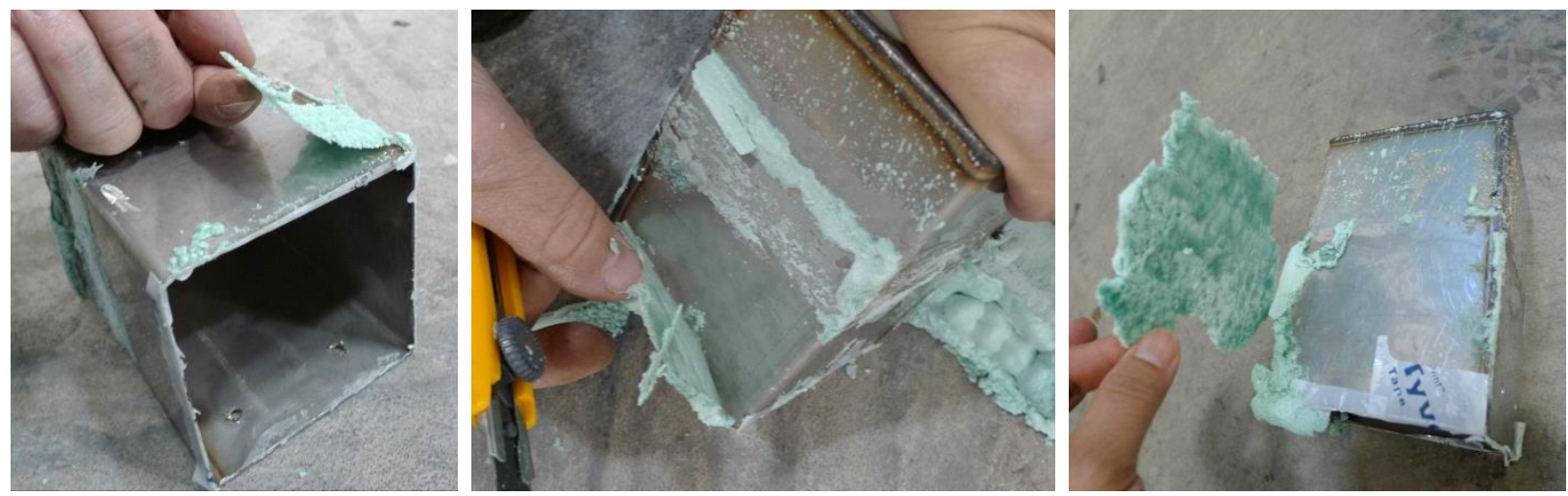

Figure 37 . Foam easily detached from ducts that were sprayed with silicone. 


\subsubsection{Resin-Rich Mixture}

In the last spray foam wall we used a resin-rich mixture. Figure 38 shows one location where the resin was leaching out of the foam, while most of the other sites in the wall had the more common soft and spongy characteristics of a resin-rich foam. The air leakage rate through the wall was $0.013 \mathrm{CFM} 75 / \mathrm{ft}^{2}\left(0.07 \mathrm{~L} /\left(\mathrm{s} \cdot \mathrm{m}^{2}\right)\right.$ at $\left.75 \mathrm{~Pa}\right)$, which is 4.6 times higher than the airflow through the reference foam wall. Nevertheless, this wall still complied with the $0.04 \mathrm{CFM} 75 / \mathrm{ft}^{2}$ $\left(0.2 \mathrm{~L} /\left(\mathrm{s} \cdot \mathrm{m}^{2}\right)\right.$ at $\left.75 \mathrm{~Pa}\right)$ requirement for an air barrier assembly. Table 15 summarizes the results from the four tested walls.
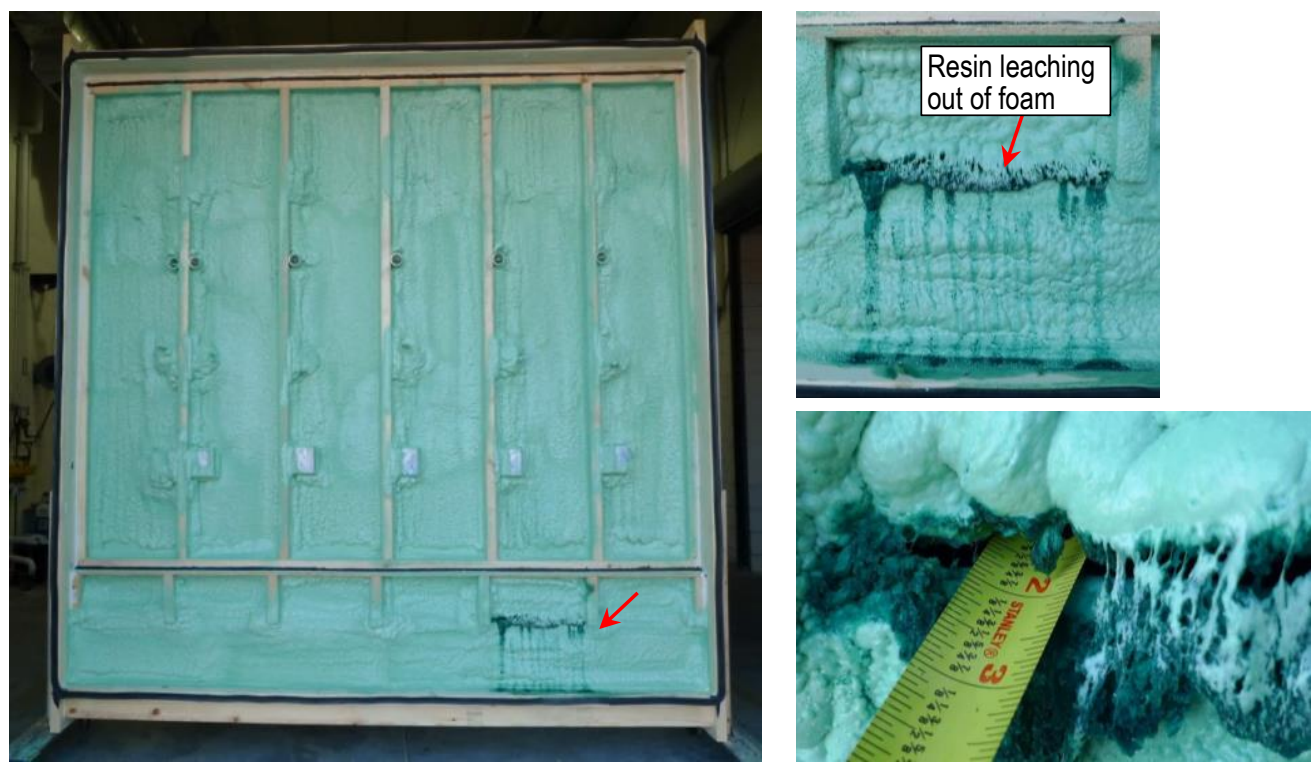

Figure 38. Test wall where a resin-rich foam mixture was utilized.

Table 15. Air leakage rates through walls sprayed with 1" closed-cell foam under different conditions.

\begin{tabular}{lcc}
\hline \multicolumn{1}{c}{ Wall Description } & $\begin{array}{c}\text { Air Leakage a } \\
\left.\text { (CFM75/ft2 } \mathbf{L} /\left(\mathbf{s} \cdot \mathbf{m}^{2}\right)\right) \\
\Delta \mathrm{P}=1.57 \mathbf{~ p s f}=\mathbf{7 5} \mathbf{~ P a}\end{array}$ & $\begin{array}{c}\text { Air Leakage Increase } \\
\text { factor w/ Respect to the } \\
\text { Reference Wall }\end{array}$ \\
\hline Foam applied following installation guidelines (reference) & $0.003,0.01$ & 1 \\
\hline Foam sprayed on damp surfaces & $0.005,0.03$ & 1.9 \\
\hline Foam applied on wall where penetrations were sprayed w/ silicone & $0.009,0.05$ & 3.2 \\
\hline Foam utilized was resin-rich & $0.013,0.07$ & 4.6 \\
\hline
\end{tabular}

a. Air leakage rates include sealing of the wall to foundation and wall to roof joints.

\section{Benefits}

1. Sprayed foam increases thermal insulation.

2. Closed-cell sprayed foam can act as a vapor retarder.

3. Sprayed foam reduces thermal bridging if applied to the outer side of the exterior sheathing.

4. Relatively fast installation. 


\section{Recommendations and Considerations}

1. Air contaminants are emitted during and after installation. Refer to the Ventilation Guidance for Spray Polyurethane Foam Application (http://www.epa.gov/dfe/pubs/projects/spf/ventilation-guidance.html) and the Guidance on Best Practices for the Installation of Spray Polyurethane Foam (http://polyurethane.americanchemistry.com/Spray-Foam-Coalition/Guidance-on-BestPractices-for-the-Installation-of-Spray-Polyurethane-Foam.pdf) for ventilation recommendations. Also, follow the spray polyurethane foam (SPF) manufacturer's guidance for re-occupancy by other trades and by the building occupant. Consult with the foam manufacturer for more information.

2. The spray polyurethane foam should meet CAN/ULC S705.1. These materials have been tested to meet safe volatile organic compound (VOC) emission rates, flammability and flame spread requirements, and dimensional stability characteristics. Although CAN/ULC S705.1 is a Canadian standard, the Air Barrier Association of America is currently utilizing it in its quality assurance program of SPF applications.

3. Installation should be in compliance with the CAN/ULC S705.2, which requires proper density testing and adhesion for the installed system. Although CAN/ULC S705.2 is a Canadian standard, the Air Barrier Association of America is currently utilizing it in its quality assurance program of SPF applications. Alternate acceptance criteria are described in the AC377, which was issued by the International Code Council Evaluation Service (ICCES).

4. Guidelines are needed for areas where foam can't be sprayed and that need to be sealed in order to achieve continuity in the air barrier system. Examples of these areas include the bottom plate to flooring interface, and the wall to roof joint.

5. The designer of the air barrier system needs to know the difference between open cell and closed cell foams, including the limitations and capabilities of these materials.

6. More resilient formulations are needed that are not as susceptible to mixing ratios, moisture on substrates, and substrate temperatures.

\subsection{Summary}

\subsubsection{Penetrations}

Table 16 summarizes the leakage data we collected from unsealed and sealed penetrations. These values indicate that not sealing one of the penetrations we studied can lead to airflows ranging from 15 to 24 CFM50. All the techniques we examined to seal gaps around penetrations (i.e., sealants, tapes and caned foams) appear to have been effective: on average, the leakage rate at these locations decreased to about 0.15 CFM50. Figures 39 and 40 illustrate the steps we followed to successfully seal pipes and ducts with an asphalt-based, self-adhered membrane. The same steps could be followed when using tape; however, mastic or sealant may not be required at the edges of the tape depending on the manufacturer's instructions. Other general findings include that airflows through the wire holes in electrical boxes constituted about $20 \%$ of the total leakage through the box. Table 16 does not include corrugated brick ties because these had minimal effect on air leakage. Nevertheless, these results will vary depending on the type of brick tie used. Table 16 also indicates higher airflows through sealed penetrations in the test wall with a mechanically-fastened interior membrane. This occurred mainly because the lack of a support behind the membrane made it difficult to properly install tape over it. 
It should be noted that the present work did not evaluate two major penetrations in air barrier systems: windows and doors. Their contribution to air leakage is likely to be higher than that of the penetrations we examined because windows and doors have longer perimeters, and gaps between them and adjacent materials can be in the order of $1 / 2$ " wide.

Table 16. Summary of air leakage rates through unsealed and sealed penetrations.

\begin{tabular}{|c|c|c|c|c|c|}
\hline \multirow{2}{*}{ Air Leakage Site } & \multirow{2}{*}{$\mathbf{n}$} & \multicolumn{4}{|c|}{ Airflow Rate (CFM50) } \\
\hline & & Avg & Min & Max & SD \\
\hline $1-1 / 2 " \phi$ PVC pipe w/ unsealed perimeter & 3 & 15 & 13 & 17 & 2 \\
\hline $1-1 / 2 " \phi$ PVC pipe w/ sealed perimeter & 54 & 0.09 & 0.03 a & 0.35 & 0.11 \\
\hline Rectangular electrical box w/ unsealed perimeter and wire holes & 2 & 21 & 15 & 26 & 8 \\
\hline Rectangular electrical box w/ sealed perimeter and unsealed wire holes & 18 & 3.9 & 2.4 & 5.6 & 1.6 \\
\hline Rectangular electrical box w/ sealed perimeter and wire holes & 48 & 0.24 & 0.03 a & 1.3 & 0.44 \\
\hline Circular electrical box w/ unsealed perimeter and wire holes & 1 & 17 & - & - & - \\
\hline Circular electrical box w/ sealed perimeter and unsealed wire holes & 30 & 3.7 & 1.9 & 4.6 & 1.1 \\
\hline Circular electrical box w/ sealed perimeter and wire holes & 42 & 0.12 & 0.03 a & 0.48 & 0.17 \\
\hline $4 \times 4$ steel duct $w /$ unsealed perimeter & 2 & 24 & 23 & 25 & 1 \\
\hline $4 \times 4$ steel duct w/ sealed perimeter & 48 & 0.05 & $0.03^{a}$ & 0.11 & 0.04 \\
\hline
\end{tabular}

Abbreviations: avg, average; max, maximum; min, minimum; n, sample size; SD, standard deviation.

a. Used the average extraneous air leakage from the 12 test walls ( 0.2 CFM50), and divided it by the number of penetrations ( $\mathrm{n}$ $=6)$.

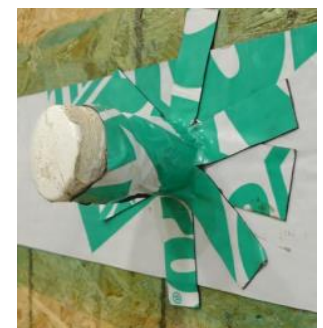

Step 1: install "hula skirt" around pipe to bridge gap between OSB and pipe

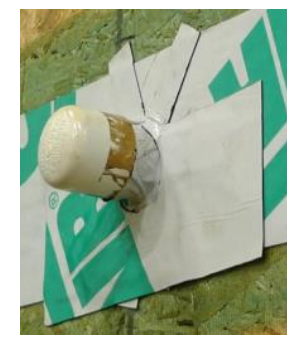

Step 2: apply membrane cutout under pipe to reinforce "hula skirt"

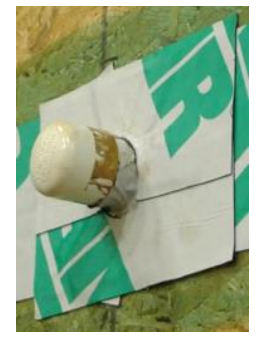

Step 3: apply membrane cutout above pipe to reinforce "hula skirt"

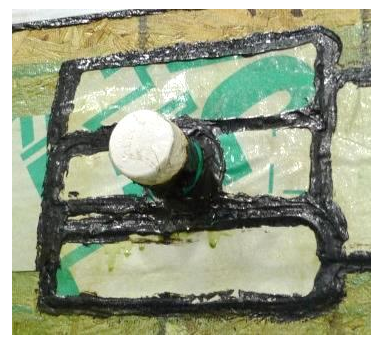

Step 4: seal membrane edges with mastic

Figure 39. Steps to seal the perimeter of a pipe with a self-adhered membrane or tape.

Note: horizontal membrane piece shown in the background was initially installed to seal an OSB joint. 

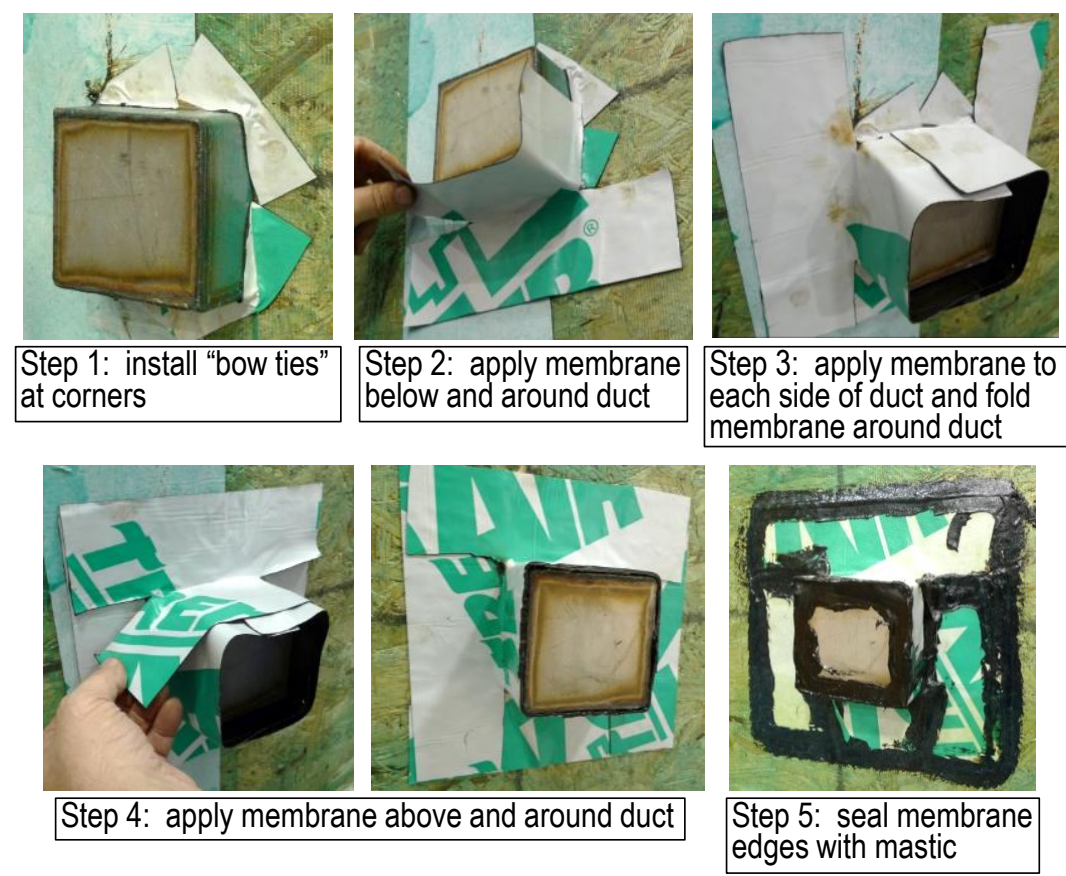

Figure 40. Steps to seal the perimeter of a duct with a self-adhered membrane or tape.

In order to put the measurements in Table 16 into context, we estimated their contribution to the 2012 IECC airtightness requirement of 3 ACH50 in DOE zones 3 to 8. Results from the following example are primarily intended to give guidance on the potential effects from various air leakage paths. This procedure is not meant to be used to estimate the actual air leakage of a house because it does not include the effect of building materials in the wall assembly that may help decrease airflows, such as the drywall. In this example we used a single-story house with a $2,000 \mathrm{ft}^{2}$ square footprint that sits on a slab-on-grade. The building has 8 ' -0 " walls, and an unvented attic under a gable roof with a 3:12 slope. The total volume of the house is therefore $16,125 \mathrm{ft}^{3}$, which leads to a maximum allowable airflow rate of 806 CFM50 per IECC 2012. We also assumed that the air barrier system was on the outer side of the exterior sheathing and above the ceiling drywall. In addition to the values in Table 16, we incorporated into our calculations the leakage rates at the wall to foundation and wall to roof joints shown in Table 6 because it is common for these to be left unsealed by builders unfamiliar with air barrier systems. Further assumptions are listed in Table 17, and results are described in Table 17 and Figure 41.

Although conservative as previously explained, findings indicate that the combination of the unsealed wall to foundation and wall to roof joints can contribute to about $50 \%$ of the leakage allowed by the IECC, while the miscellaneous unsealed penetrations we considered can account for an additional 30\%. These estimates indicate that the combined contribution from these leakage sites (638 CFM50 or $80 \%$ of the IECC requirement) can be significant. Nonetheless, we describe in the previous sections general techniques that, on average, can reduce the combined leakage rate to less than 50 CFM50. 
Table 17. Air leakage rates used in airtightness example.

\begin{tabular}{|c|c|c|c|c|c|c|}
\hline \multirow[b]{2}{*}{ Unsealed Air Leakage Sites } & \multicolumn{2}{|c|}{ Unsealed Joints } & \multicolumn{2}{|c|}{ Unsealed Penetrations } & \multirow{2}{*}{$\begin{array}{l}\text { Airflow Rate } \\
\text { (CFM50) }\end{array}$} & \multirow[b]{2}{*}{$\%$ of $3 \mathrm{ACH} 50$} \\
\hline & Length (ft) & $\begin{array}{l}\text { Airflow Rate } \\
\text { (CFM50/ft) }\end{array}$ & Quantity & $\begin{array}{l}\text { Airflow Rate } \\
\text { (CFM50/unit) }\end{array}$ & & \\
\hline Wall / CMU joint & 179 & 1.1 & - & - & 199 & 25 \\
\hline Wall / roof joint & 179 & 1.1 & - & - & 199 & 25 \\
\hline Circular electrical box (walls) & - & - & 6 & 17 & 102 & 13 \\
\hline Rectangular electrical box & - & - & 4 & 21 & 84 & 10 \\
\hline 1-1/2" $\phi$ PVC pipe & - & - & 2 & 15 & 30 & 4 \\
\hline $4 \times 4$ steel duct & - & - & 1 & 24 & 24 & 3 \\
\hline Total & & & & & 638 & 80 \\
\hline
\end{tabular}
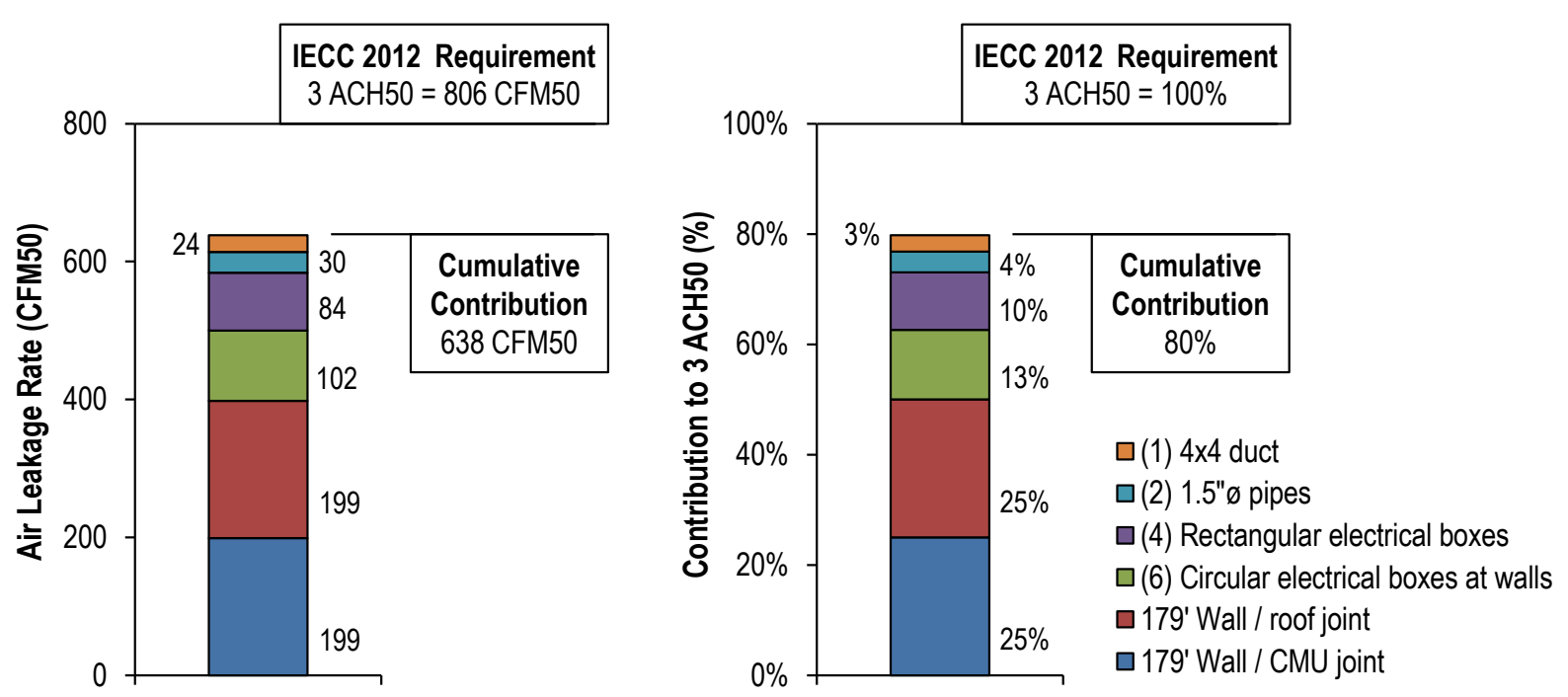

Figure 41. Cumulative contribution of unsealed joints and penetrations to total air leakage in a 2,000 $\mathrm{ft}^{2}$ single-story house.

\subsubsection{Air Barrier Assemblies}

Table 18 lists the air leakage rates from the test walls before and after they were subjected to the wind pressure loads specified in ASTM E2357. In general, the air barrier assemblies did not appear to have been affected by the conditioning loads given that before and after airflow rates did not show much of a difference. Two of the walls did not meet the air barrier assembly requirement of $0.04 \mathrm{CFM} 75 / \mathrm{ft}^{2}\left(0.2 \mathrm{~L} /\left(\mathrm{s} \cdot \mathrm{m}^{2}\right)\right.$ at $\left.75 \mathrm{~Pa}\right)$; the air barrier materials in these walls were 1) a mechanically-fastened interior membrane and 2) OSB sheathings with latex foam sealant at joints. In the case of the wall with the mechanically-fastened interior membrane, the high rates were primarily due to leakages at gaps around penetrations that we were not able to seal thoroughly as discussed in Section 3.2.2. In the test wall with OSB sheathings with latex sealant at joints, Section 3.4 suggests that equipment malfunction could have affected the mixing ratio of the components in the sealant during installation. Additionally, it is possible that the OSB that we utilized did not meet the requirements of an air barrier material. 
Table 18. Summary of air leakage rates before and after wind conditioning loads per ASTM E2357.

\begin{tabular}{|c|c|c|c|c|c|}
\hline \multirow{3}{*}{ Air Barrier Type } & \multicolumn{3}{|c|}{ Test Wall Components } & \multirow{2}{*}{\multicolumn{2}{|c|}{$\begin{array}{c}\text { Air Leakage } \\
\left(\mathrm{CFM} 75 / \mathrm{ft}^{2}, \mathrm{~L} /\left(\mathrm{s} \cdot \mathrm{m}^{2}\right)\right) \\
\Delta \mathrm{P}=0.3 \text { in w.c., } 75 \mathrm{~Pa}\end{array}$}} \\
\hline & \multicolumn{2}{|c|}{ Wood Frame } & \multirow{2}{*}{$\begin{array}{c}\text { CMU } \\
\begin{array}{c}\text { Air Barrier } \\
\text { Material }\end{array}\end{array}$} & & \\
\hline & Air Barrier Material & $\begin{array}{c}\text { Air Barrier } \\
\text { Accessories }^{b}\end{array}$ & & $\begin{array}{c}\text { Before } \\
\text { Conditioning }\end{array}$ & $\begin{array}{c}\text { After } \\
\text { Conditioning }\end{array}$ \\
\hline Interior air barrier & $1 / 2 "$ drywall sheathing & Sealant & $\begin{array}{l}\text { Fluid-applied } \\
\text { membrane }\end{array}$ & $0.03,0.15$ & $0.03,0.15$ \\
\hline Interior air barrier & $\begin{array}{l}\text { Polyamide } \\
\text { membrane }^{c}\end{array}$ & $\begin{array}{l}\text { Tape, sealant, } \\
\text { interior drywall }\end{array}$ & $\begin{array}{c}\text { Fluid-applied } \\
\text { membrane }\end{array}$ & $0.14,0.69$ & $0.13,0.68$ \\
\hline $\begin{array}{l}\text { Mechanically-fastened } \\
\text { membrane }\end{array}$ & $\begin{array}{l}\text { Non-woven, spun } \\
\text { bonded polyolefin } \\
\text { membrane }\end{array}$ & $\begin{array}{l}\text { Screws with 2" caps, } \\
\text { tape, sealant }\end{array}$ & $\begin{array}{l}\text { Fluid-applied } \\
\text { membrane }\end{array}$ & $0.015,0.07$ a & $0.011,0.05^{a}$ \\
\hline $\begin{array}{l}\text { Sealant w/ backup } \\
\text { structure }\end{array}$ & 7/16" OSB sheathing & Latex sealant & $\begin{array}{l}\text { Fluid-applied } \\
\text { membrane }\end{array}$ & $0.1,0.49$ & $0.11,0.56$ \\
\hline $\begin{array}{l}\text { Non-insulating } \\
\text { sheathing }\end{array}$ & 7/16" OSB sheathing & Tape, canned foam & $\begin{array}{l}\text { Fluid-applied } \\
\text { membrane }\end{array}$ & $0.026,0.13$ & $0.025,0.13$ \\
\hline Insulating sheathing & $\begin{array}{l}\text { 2" XPS rigid foam } \\
\text { sheathingd }\end{array}$ & $\begin{array}{l}\text { Screws with 2" caps, } \\
\text { tape, canned foam }\end{array}$ & $\begin{array}{l}\text { 2" XPS rigid } \\
\text { foam }\end{array}$ & $0.004,0.02$ & $0.003,0.02$ \\
\hline $\begin{array}{l}\text { Self-adhered } \\
\text { membrane }\end{array}$ & $\begin{array}{l}40 \text { mil asphalt-based } \\
\text { membrane }\end{array}$ & Primer, mastic & $\begin{array}{l}\text { Self-adhered } \\
\text { membrane }\end{array}$ & $0.014,0.07$ & $0.012,0.06$ \\
\hline $\begin{array}{l}\text { Fluid-applied } \\
\text { membrane }\end{array}$ & $\begin{array}{l}70 \text { mil rolled fluid- } \\
\text { applied membrane }\end{array}$ & $\begin{array}{l}\text { Sealant, transition } \\
\text { membrane }\end{array}$ & $\begin{array}{l}\text { Fluid-applied } \\
\text { membrane }\end{array}$ & $0.005,0.02$ & $0.006,0.03$ \\
\hline Spray-applied foam & 1" closed-cell foam & Sealant & $\begin{array}{l}\text { 1" Closed-cell } \\
\text { foam }\end{array}$ & $0.003,0.01$ & $0.004,0.02$ \\
\hline
\end{tabular}

\subsubsection{General Recommendations and Considerations}

Below are general recommendations for designers, specification writers and builders to consider. These suggestions apply to all the air barrier types.

1. Designers and specification writers should verify that the air barrier materials and assemblies being considered for the project have been tested per ASTM E2178 and ASTM E2357, respectively, and that results meet the maximum air leakage requirements of 0.004 CFM75/ft ${ }^{2}\left(0.02 \mathrm{~L} /\left(\mathrm{s} \cdot \mathrm{m}^{2}\right)\right.$ at $\left.75 \mathrm{~Pa}\right)$ for an air barrier material, and $0.04 \mathrm{CFM} 75 / \mathrm{ft}^{2}(0.2$ $\mathrm{L} /\left(\mathrm{s} \cdot \mathrm{m}^{2}\right)$ at $\left.75 \mathrm{~Pa}\right)$ for an air barrier assembly. Also, designers and specification writers need to verify that the manufacturers of the air barrier materials provide adequate installation instructions and details to maintain continuity in the air barrier system.

2. Designers and builders should verify with the air barrier manufacturer if their product requires a certified installer.

3. Designers and builders should review installation instructions issued by the air barrier material manufacturer. Tapes and sealants are not necessarily compatible with all materials. 
4. The water vapor permeance of the air barrier material needs to be considered to avoid moisture problems during or after construction. Hygrothermal analyses of the wall and roof assemblies are recommended to avoid these problems.

5. Based on the air barrier type, the builder needs to determine if it is preferable to detail most of the penetrations through the OSB before or after the air barrier material is installed. Although most air barrier materials can follow either sequence, it is likely that one of them reduces labor and improves workmanship. Consult with the air barrier manufacturer for guidance.

6. An ASTM E779 whole-building air leakage test (i.e., blower door test) should be conducted after the installation of the air barrier system to ensure compliance with the building code and owner's request. If the air barrier material is installed on the outer side of the stud cavity, it is preferable to conduct this test after the air barrier system is in place, and before the cavity insulation and drywall are installed. This will make it easier to find and fix leakage spots, but will require extra coordination by the general contractor.

7. The general contractor needs to be educated on the various air barrier types and manufacturer's instructions to ensure proper installation and sequencing. It is very likely that various subcontractors (e.g., framers, drywall installers, electricians and plumbers) will be collaborating on the installation of the air barrier system and on maintaining its integrity during construction. Therefore, the general contractor should coordinate all of these trades accordingly.

8. Wire holes in electrical boxes need to be sealed with caulk or low expansion canned foam from the exterior side of the box because local electrical codes do not allow combustible materials within the box. Therefore, the wire holes have to be sealed before the cavity insulation and drywall are installed. Alternatively, electrical boxes that have been designed to facilitate sealing of wire holes could be utilized as a few models are available in the market.

9. Electrical boxes with flanges throughout its entire perimeter may allow for faster and better connections between the box and the air barrier material.

\section{Conclusion}

We assessed air barrier assemblies that incorporated the eight air barrier types commonly installed in the US. Most of the air barrier materials we evaluated complied with the maximum leakage requirement for air barrier assemblies. Airflow rates through all of the test walls were not affected by the wind conditioning loads specified in ASTM E2357 that are supposed to simulate an accelerated aging test; this demonstrates the robustness of the air barrier assemblies we tested under various pressure loads. Findings suggest that wall to foundation and wall to roof joints can be major contributors to air leakage, although these are typically left unsealed by builders who are unfamiliar with air barrier systems. Results also indicate that the aggregate contribution from the assessed unsealed penetrations (i.e., electrical boxes, PVC pipes and steel ducts) can have considerable detrimental effects on the airtightness of homes. However, these 
can be effectively sealed with most of the readily available materials such as tapes, canned foam and sealants.

Based on the experience we gathered while installing the different air barrier materials, we provide recommendations on how to improve some of the available air barrier types in order to more easily achieve a continuous assembly and system. Furthermore, we also supply designers and contractors with general information that could facilitate their selection of the appropriate air barrier type for their building. This information should help promote the use and enhance the effectiveness of air barrier technologies, which will in turn improve the airtightness of homes.

\section{Acknowledgements}

This work was supported by the Assistant Secretary for Energy Efficiency and Renewable Energy, Office of the Building Technology Program, U.S. Department of Energy, under Contract No. DE- AC05-00OR22725. Support was also provided by the Air Barrier Association of America (ABAA). Special thanks to Tim Mattox and Tremco for allowing ORNL and ABAA to use the company's Sustainable Building Solutions Test Facility. 


\section{References}

ASTM International. 2009. ASTM D4541. Standard Test Method for Pull-Off Strength of Coatings Using Portable Adhesion Testers. Pennsylvania: American Society for Testing and Materials International.

ASTM International. 2004. ASTM E283. Standard Test Method for Rate of Air Leakage through Exterior Windows, Curtain Walls, and Doors under Specific Pressure Differentials Across the Specimen. Pennsylvania: American Society for Testing and Materials International.

ASTM International. 2010. ASTM E779. Standard Test Method for Determining Air Leakage Rate by Fan Pressurization. Pennsylvania: American Society for Testing and Materials International.

ASTM International. 2011. ASTM E2357. Standard Test Method for Determining Air Leakage of Air Barrier Assemblies. Pennsylvania: American Society for Testing and Materials International.

Building Science Corporation. 2009. Info-401: Air Barriers - Airtight Drywall Approach.

CAN/ULC Standards. 2001. CAN/ULC-S705.1-01. Standard for Thermal Insulation - Medium Density Closed Cell Spray Applied Rigid Polyurethane Foam - Material Specification. Underwriters Laboratories of Canada.

CAN/ULC Standards. 2005. CAN/ULC-S705.2-05. Standard for Thermal Insulation - Medium Density Closed Cell Spray Applied Rigid Polyurethane Foam - Application. Underwriters Laboratories of Canada.

Chan WR, Joh J, Sherman MH. 2013. Analysis of Air Leakage Measurements in US Houses. Energy and Buildings 66:616-625.

Colliver DG, Murphy WE, Sun W. 1994. Development of a Building Component Air Leakage Data Base. ASHRAE Transactions 100(1):292-305.

Dickerhoff DJ, Grimsrud DT, Lipschutz RD. 1982. Component Leakage Testing in Residential Buildings. Lawrence Berkeley National Laboratory. LBNL 14735.

EERE. 2011. Building energy data book. Washington, DC. Office of Energy Efficiency and Renewable Energy.

ICC-ES. 2013. AC377 Spray-applied foam plastic insulation. International Code Council Evaluation Service.

IECC. 2012. 2012 International Energy Conservation Code. Country Club Hill, IL: International Code Council. 
Langmans J, Klein R, Roels S. 2010. Air permeability requirements for air barrier materials in passive houses - Comparison of the air permeability of eight commercial brands of OSB. $5^{\text {th }}$ International Symposium on Building and Ductwork Air-tightness. Copenhagen, Denmark.

Murray DM, Burmaster DE. 1995. Residential Air Exchange Rates in the United States:

Empirical and Estimated Parametric Distributions by Season and Climatic Region. Risk Analysis 15(4):459-465.

Sherman MH, Matson NE. 2002. Air Tightness of New US Houses: A Preliminary Report. Lawrence Berkeley National Laboratory. LBNL 16644. 